\title{
KGEMM:
}

\section{A Macroeconometric Model for Saudi Arabia}

Fakhri J. Hasanov, Frederick L. Joutz, Jeyhun I. Mikayilov, Muhammad Javid 


\section{About KAPSARC}

The King Abdullah Petroleum Studies and Research Center (KAPSARC) is a non-profit global institution dedicated to independent research into energy economics, policy, technology and the environment across all types of energy. KAPSARC's mandate is to advance the understanding of energy challenges and opportunities facing the world today and tomorrow, through unbiased, independent, and high-caliber research for the benefit of society. KAPSARC is located in Riyadh, Saudi Arabia.

This publication is also available in Arabic.

\section{Legal Notice}

(C) Copyright 2020 King Abdullah Petroleum Studies and Research Center ("KAPSARC"). This Document (and any information, data or materials contained therein) (the "Document") shall not be used without the proper attribution to KAPSARC. The Document shall not be reproduced, in whole or in part, without the written permission of KAPSARC. KAPSARC makes no warranty, representation or undertaking whether expressed or implied, nor does it assume any legal liability, whether direct or indirect, or responsibility for the accuracy, completeness, or usefulness of any information that is contained in the Document. Nothing in the Document constitutes or shall be implied to constitute advice, recommendation or option. The views and opinions expressed in this publication are those of the authors and do not necessarily reflect the official views or position of KAPSARC. 


\section{Key Points}

The KAPSARC Global Energy Macroeconometric Model (KGEMM), is a policy analysis tool for examining the impacts of domestic policy measures and global economic and energy shocks on the Kingdom of Saudi Arabia.

The model captures New Keynesian demand side features 'anchored' to medium-run equilibrium and long-run aggregate supply. There are eight blocks (real sector, fiscal, monetary, external sector, price, labor and wages, energy, population and age cohorts) that interact with each other to represent the Kingdom's macroeconomy and energy linkages.

KGEMM can be used to analyze the current status and future paths of macroeconomic and energy indicators. It can also be used to evaluate the effects of different policy options on the Kingdom's economy.

KGEMM is a time series macroeconometric model that integrates data properties with relevant theory. There is empirical coherence: the relationships are interpretable in an economic framework.

It has flexibility and simultaneity in evaluating multiple research/policy questions.

It can be easily customized for different research/policy questions.

The energy (oil, natural gas, and electricity) sector is not exogenous domestically, because it is interlinked with the non-oil activity.

KGEMM has been validated using different validation tests, such as the theoretical consistency of the estimated relations, post-estimation tests, the statistical significance of the estimated coefficients, and in-sample and out-of-sample performance.

In-sample and out-of-sample simulations show that KGEMM has robust predictive and policy analysis capabilities.

KGEMM has been used extensively since December 2015 in multi-stakeholder projects to evaluate the macroeconomic effects of the Kingdom's domestic energy price and fiscal reforms, the key initiatives in Saudi Vision 2030's Fiscal Balance Program. 
$\mathrm{T}$ The objective of the research presented in this paper is to conduct a detailed survey of the existing macroeconomic models for Saudi Arabia and to introduce the KAPSARC Global Energy Macroeconometric Model (KGEMM). The paper also considers the strengths and weaknesses of the earlier models. KGEMM is a policy analysis tool for examining the impacts of Saudi Arabia's internal decisions, and global economic and energy shocks on the country's macroeconomic-energy environment.

Macroeconometric models inform policymakers about the dynamic relationships among economic indicators, how economies have performed in the past, and how their current and future behaviors might differ. Models are simplifications of actual economies that provide analytical and empirical frameworks concentrating on important aspects of an economy.

Macroeconometric models can explain, project and evaluate economic processes. They can be especially useful in helping policymakers to evaluate the impact of alternative policy choices. In this regard, macroeconometric models provide analytical and evidence-based foundations for policy decisions, contributing to the increased likelihood of successful policies.

A macroeconometric model for Saudi Arabia is particularly important for the country's policymakers. The Kingdom faces numerous economic, demographic, and social challenges as it diversifies its economy away from its dependence on oil exports toward a greater role for the non-oil private sector and a more efficient public sector with enhanced services. The Kingdom's economy is sensitive to international energy market dynamics. The future of the country's economy is based on a transformation process, outlined in the Kingdom's strategic roadmap, Saudi Vision 2030 (SV2030). SV2030 involves important initiatives such as an energy price reform to induce the rational use of the Kingdom's energy resources, fiscal reforms for more effective government spending and increasing non-oil revenues. The energy (price) subsidies affecting all sectors of the economy are already being reduced. While Saudi Arabia's fiscal policy and economy will certainly continue to depend on oil exports and revenues during the transition, the outlook for global consumption and prices suggests global energy markets will see slower oil consumption growth and lower prices.

Labor market reforms are also necessary to absorb the current and coming large demographic bulge of young male and female Saudis entering the labor force. Expatriate labor's role in the workforce will change. Moreover, reforming the Kingdom's investment environment and legislation should attract more foreign direct investment. Such reform would imply changes to the country's monetary policy and financial markets. Quantifying the possible effects of oil market changes and understanding the domestic impact of Saudi Arabia's economic transition require well-designed models.

Policymakers need to know how the country's fiscal stance might be affected by low oil prices and energy price reforms. Macroeconometric models could highlight how the economy, including sectors of the economy, could be restructured and how economic indicators could be changed to help achieve SV2030 targets.

No publicly available energy-macroeconometric models are able to address the points above. The KGEMM research project is an attempt to resolve this gap and provide insights into energy-economy and policy options for the Kingdom's decisionmakers. KGEMM has contributed to policy advice 
for decision-makers in three areas since December 2015: 1) energy price reform, 2) fiscal policy reform, and 3 ) the route to achieving the SV2030 targets.

The model has eight blocks (real sector, fiscal, monetary, external sector, price, labor and wages, energy, population and age cohorts) that interact with each other to represent the Kingdom's macroeconomy and energy linkages.

KGEMM can address two broad sets of policies and areas of research: relationships within the Saudi Arabian macroeconomic-energy environment, including between fiscal, monetary, labor market, prices and domestic energy factors, and the effect of the rest of the world, particularly global energy markets, on its domestic economy.

The following characteristics of KGEMM show how it contributes to the existing macroeconomic models of Saudi Arabia:

This is one of the very few macroeconometric models that incorporates an input-output framework into its structure.

It combines cutting-edge econometric methods, a well-established theoretical foundation, empirical coherence, and stylized facts of the Kingdom's economy.

It has the flexibility to evaluate multiple research/ policy questions simultaneously.

It is easy to customize for different research/ policy questions.

The oil sector is not treated purely exogenously as it is linked with the non-oil sector.

Aggregate demand is disaggregated into economic sectors using an input-output framework.
Aggregate supply is the sum of the sectoral productions derived from the production function framework.

A detailed energy block representing 14 energy demand relationships by energy type and customers.

A user-friendly interface and an open-box environment.

It also contributes to the existing body of macroeconomic modeling for natural resource-rich open economies.

KGEMM can be used to analyze the current status and project the future paths of macroeconomic and energy indicators. It can also be used to evaluate the effects of different policy options (e.g., SV2030 initiatives and targets) and energy market dynamics. It can lead to more effective cooperation between modelers/researchers of different government agencies as it represents different aspects of the economy, including monetary, fiscal, labor market, real sector, external, and energyrelated factors.

KGEMM has been validated using different validation tests, such as statistical significance and theoretical consistency of the estimated parameters, post-estimation tests for the residuals of the estimated equations, in-sample performance for the approximation of historical data, and out-ofsample performance for policy analysis.

We run the model for an in-sample forecast to approximate the historical time path of the endogenous variables as well as to produce an out-of-sample simulation to assess the impact of the domestic energy price reform on Saudi Arabia's key macroeconomic indicators. In-sample and out-of-sample simulations show that KGEMM has 
robust predictive and policy analysis capabilities. Indeed, KGEMM has been used extensively in multistakeholder projects to assess the macroeconomic effects of the Kingdom's domestic energy price and fiscal reforms, the key initiatives in SV2030's Fiscal Balance Program since December 2015. 


\section{Literature Review}

T

The history of macroeconometric modelbuilding is comprehensively documented in Fair (1984, 1994), Botkin et al. (1991), Hendry and Mizon (2000), Favero (2001), Pagan (2003a, 2003b), Bårdsen et al. (2004, 2005). Valadkhani (2004), Hendry and Muellbauer (2018) inter alia.

This section reviews only general equilibrium macroeconomic models that have been built for the Saudi Arabian economy. In other words, we do not review either partial equilibrium models built for Saudi Arabia or general equilibrium models built for other resource-rich economies. The former are not in line with our research objectives, and the latter have been reviewed mainly by Hasanov and Joutz (2013), among others. We also review models that are publicly available or available to us. ${ }^{1}$ Table 1 documents these models.

Table 1. Macroeconomic models for Saudi Arabia.

\begin{tabular}{|c|c|c|c|c|c|}
\hline Name & Period & Type & Strengths & Weaknesses & Note \\
\hline $\begin{array}{l}\text { Ezzati } \\
(1976)\end{array}$ & $\begin{array}{l}1963- \\
1972\end{array}$ & $\begin{array}{l}\text { Combined } \\
\text { dynamic } \\
\text { intertemporal, } \\
\text { multi-sectoral, } \\
\text { empirical linear } \\
\text { programing } \\
\text { model and } \\
\text { macroeconometric } \\
\text { model }\end{array}$ & $\begin{array}{l}\text { Combination of } \\
\text { optimization with } \\
\text { MEM. }\end{array}$ & $\begin{array}{l}\text { - Insufficient theoretical underpinning } \\
\text { (e.g., private investment and } \\
\text { consumption equations contain only } \\
\text { income; export and import equations } \\
\text { ignore relative prices or real exchange } \\
\text { rates; production function ignores labor. } \\
\text { - The model does not capture labor and } \\
\text { monetary markets (we could not find a } \\
\text { consumer price inflation (CPI) or gross } \\
\text { domestic product (GDP) deflator and } \\
\text { exchange rate in the model). }\end{array}$ & $\begin{array}{l}\text { Designed to } \\
\text { analyze the impact } \\
\text { of oil price and } \\
\text { production on } \\
\text { macroeconomic } \\
\text { indicators in OPEC } \\
\text { member countries } \\
\text { including Saudi } \\
\text { Arabia. }\end{array}$ \\
\hline $\begin{array}{l}\text { Looney } \\
\text { (1986) }\end{array}$ & $\begin{array}{l}1980- \\
1985\end{array}$ & $\begin{array}{l}\text { Optimal Control } \\
\text { Macroeconomic } \\
\text { Model }\end{array}$ & $\begin{array}{l}\text { Macroeconomic } \\
\text { model within the } \\
\text { framework of optimal } \\
\text { control can distinguish } \\
\text { the most efficient } \\
\text { growth path to the end } \\
\text { target. }\end{array}$ & $\begin{array}{l}\text { - Stochastic properties (unit root } \\
\text { and cointegration) of the time series } \\
\text { variables used in the econometric } \\
\text { estimations were ignored. Therefore, } \\
\text { one can argue that the study might } \\
\text { suffer from spurious regression issues. } \\
\text { Addressing these issues is particularly } \\
\text { important for this study, as it is } \\
\text { designed for policy analysis. }\end{array}$ & $\begin{array}{l}\text { The Optimal } \\
\text { Control } \\
\text { Macroeconomic } \\
\text { Model has been } \\
\text { used to examine } \\
\text { the Saudi Arabia's } \\
\text { third Five Year } \\
\text { Development Plan } \\
\text { (1980-1985) for } \\
\text { goal feasibility and } \\
\text { trade-offs among } \\
\text { the plan's major } \\
\text { goals. }\end{array}$ \\
\hline
\end{tabular}

(1) Of course, we are unable to review the models that are not publicly available, including those built and used by government agencies, international institutions, academia and research centers, and private companies. 


\begin{tabular}{|c|c|c|c|c|c|}
\hline Name & Period & Type & Strengths & Weaknesses & Note \\
\hline $\begin{array}{l}\text { Looney } \\
\text { (1988) }\end{array}$ & $\begin{array}{l}1986- \\
1992\end{array}$ & $\begin{array}{l}\text { Optimal Control } \\
\text { Macroeconomic } \\
\text { Model }\end{array}$ & $\begin{array}{l}\text { A macroeconomic } \\
\text { model within the } \\
\text { framework of optimal } \\
\text { control can distinguish } \\
\text { the most efficient } \\
\text { growth path to the end } \\
\text { target. }\end{array}$ & $\begin{array}{l}\text { - The stochastic properties (unit root } \\
\text { and cointegration) of the time series } \\
\text { variables used in the econometric } \\
\text { estimations were ignored. Therefore, } \\
\text { one can argue that the study might } \\
\text { suffer from spurious regression issues. } \\
\text { Addressing these issues is particularly } \\
\text { important for this study as it is } \\
\text { designed for policy analysis. } \\
\text { - It would be informative for readers } \\
\text { if the study reports post-estimation } \\
\text { test results so that they can see } \\
\text { the adequacy of the estimated } \\
\text { relationships. }\end{array}$ & $\begin{array}{l}\text { This model has } \\
\text { been developed } \\
\text { to examine the } \\
\text { socioeconomic } \\
\text { planning dilemmas } \\
\text { confronting Saudi } \\
\text { Arabian policy } \\
\text { during an era of } \\
\text { falling oil revenue. }\end{array}$ \\
\hline
\end{tabular}

- Global coverage.

$\begin{array}{lll}\text { OEGEM } & 1980- & \begin{array}{l}\text { Combination of } \\ (2018)\end{array} \\ 2017 & \text { MEM and IOM }\end{array}$

- Large database with historical and projected values.

- Insufficient theoretical foundation.

- In most cases, quarterly data is converted from annual data.

\section{- Combination of MEM and IOM.}

- Accounts for the stylized facts of Saudi Arabia.
- Not enough attention paid to the Saudi MEM module as OEGEM has very wide global coverage*.
Commercial model available on a subscription basis.

${ }^{*}$ OEGEM has 80 countries and 13 regional blocks. Saudi MEM is just one country module.

- The model does not capture the monetary aspects of the economy.

- Combination of MEM and IOM.

- Accounts for the stylized facts of Saudi Arabia.

\section{- Employs ECM specifications in the model.}

- The empirical analysis does not consider the integration and cointegration properties of the data used. So, the risk of spurious results and consequently misleading recommendations exists.

- There are some assumptions which are hard to believe can hold in reality in Saudi Arabia. E.g., export categories are treated as exogenous; coefficients in the linear expenditure system are not estimated but calibrated using studies of other countries; the real oil price is included in the private consumption equation along with disposable income, which may cause double accounting of the oil effect; neither consumption nor investment equations include interest rates.
Developed by the Research Department, Statistics Norway for the Kingdom of Saudi Arabia's

Ministry of Economy and Planning. Its main purpose is to assist in the Kingdom's fiveyear development plans by analyzing fiscal and monetary policies and shocks from the oil sector and abroad. 


\section{Cappelen}

and

Magnussen

(1996)
1989

\section{CGE model}

- Well-established theoretical foundation combined with the stylized facts of Saudi Arabia.

\section{- Very disaggregate representation of the Kingdom's economy.}

- The modelling of production sectors and capital stock data are based on weak data foundations and strong assumptions.

- Some rough assumptions of the labor market (e.g., wage rate and foreign workers are exogenous).

- The governmental sector is aggregated in the model; there is no breakdown of government consumption.

- The model does not capture monetary, labor and energy aspects of the economy.

- It does not have an explicit price block (Johansen and Magnussen 1996).

- The model's equations do not consider the integration and cointegration properties of the data used. So, the risk of spurious results and, consequently, misleading recommendations exist.

\section{Bjerkholt} (1993)

NR

MEM
- Important linkages are ignored. For example, changes in government consumption and private consumption do not affect GDP.

- Lack of theoretical foundation. For example, non-oil GDP is only the function of its own lag and non-oil investment; Some sectors' production capacities are modeled as only the function of the time trend.
Designed for the preparation of fiveyear development plans, especially to explore the outcome of investment programs.
Designed as a planning model for the fifth Development Plan of the Ministry of Economy and Planning

- The model does not account for simultaneity. 


\begin{tabular}{|c|c|c|c|}
\hline Name & Period & Type & Strengths \\
\hline $\begin{array}{l}\text { Bjerkholt } \\
\text { (1993) }\end{array}$ & NR & AGE & $\begin{array}{l}\text { Very disaggregate } \\
\text { representation } \\
\text { of the economy } \\
\text { (model contains } 36 \\
\text { production sectors, } \\
14 \text { household types, } 5 \\
\text { labor skill categories, } \\
31 \text { consumption } \\
\text { groups). }\end{array}$ \\
\hline
\end{tabular}

Given the level of granularity, it was very difficult to handle, maintain, update and upgrade the model due to

(a) the technical capacity of the Ministry of Economy and Planning employees, and (b) periodic surveys had to be conducted to obtain the required data, which was not resource and cost effective.

- The model does not capture monetary, labor and energy aspects of the economy.

- The model's equations do not consider the integration and cointegration properties of the data used. So, the risk of spurious results and, consequently, misleading recommendations exists.

Very disaggregate representation of the economy (model contains 36 production sectors, 14 household types, 5 labor skill categories, and 31 consumption groups).

$\begin{array}{llll}\begin{array}{l}\text { Bjerkholt } \\ \text { (1993) }\end{array} 1969- & \text { MEM } & \begin{array}{l}\text { (model contains } 36 \\ \text { production sectors, } \\ \end{array} \\ & & 14 \text { household types, } \\ & \text { labor skill categories, } \\ & \text { and } 31 \text { consumption } \\ & \text { groups) } .\end{array}$

- Important linkages are ignored. For example, spillover from the oil sector to the non-oil sector is only through oil revenues, not via intermediate consumption and investment.

- The exogeneity assumptions are overly set. For example, non-oil export and oil refining are exogenous.

- Very weak theoretical foundation. E.g., government consumption is a residual of GDP identity; production capacity depends only on investment; private consumption is a function of income only; the deflator is only dependent on wages.

- The model does not account for simultaneity and fine-tunings.
Coopers \&

Lybrand built the model for the Ministry of Economy and

Planning.
Designed as a planning model for the sixth Development Plan of the Ministry of Economy and Planning by the Research Department of Statistics, Norway.

The project was financed by the United Nations' Department of Economic and Social Development as part of a technical cooperation project to strengthen the planning capabilities of the Kingdom of Saudi Arabia's Ministry of Economy and Planning. 


\begin{tabular}{|c|c|c|c|c|c|}
\hline Name & Period & Type & Strengths & Weaknesses & Note \\
\hline
\end{tabular}

- The model does not capture labor market aspects of the economy.

- The energy sector is represented mainly by crude oil.

Well-established

De Santis (2003) 1990

Static multisector CGE model

theoretical foundation combined with the stylized facts of Saudi Arabia.
- Exogeneity assumptions are overly set. For example, investments and the current account deficit are exogenous.

- There are a few assumptions, which are hard to believe can hold in reality in Saudi Arabia. E.g., the sources of private income are wages and returns on capital; the budget balance is always in equilibrium.

- This is a theoretical model and not simulated using data for Saudi Arabia.

Well-established

$\begin{aligned} & \text { Alam } \\ & (2007)\end{aligned} \quad$ NA $\quad$ GE model

theoretical foundatio

combined with the stylized facts of an oildependent economy.
- The model has very limited coverage as it includes only tradable and nontradable goods, reserves, and prices of non-tradable goods.
This is a

theoretical model designed to investigate the impact of oil revenue financed government expenditure on the indicators included in the model. 


\begin{tabular}{|c|c|c|c|}
\hline Name & Period & Type & Strengths \\
\hline $\begin{array}{l}\text { Bayoumi et } \\
\text { al. (2004) }\end{array}$ & 2004 & $\begin{array}{l}\text { IMF-Global } \\
\text { Economy Model }\end{array}$ & $\begin{array}{l}\text { The model is } \\
\text { based on explicit } \\
\text { microeconomic } \\
\text { foundations; changing } \\
\text { one of the deep } \\
\text { parameters in the } \\
\text { model can affect } \\
\text { a wide range of } \\
\text { relationships. }\end{array}$ \\
\hline
\end{tabular}

Weaknesses

Note

Calibrating GEM is time-consuming because the concepts in the model often do not match the existing data.

Moving to a model with a tight theoretical structure also imposes limitations, at least in the short term.
GEM is a largescale version of a micro-based open economy model. It primarily focuses on creating a unifying framework for the analysis of international interactions.

\author{
- This is a very specific (oil-focused) \\ model*.
}

\title{
Average
}

$\begin{array}{lll}\text { Nakov } & \text { of } & \\ \text { and Nuno } & \text { January } & \\ \text { (2013) } & \text { 1973- } & \\ & \text { April } & \\ & 2009\end{array}$

Theoretically well-established
- There are a few assumptions, which are hard to believe can hold in reality. E.g., there is no labor and wage in production function and profit maximization of oil exporters, respectively; the oil-exporters maximize their profits only through oil production.
${ }^{*}$ It is built to investigate the impacts of oil production options, taxes and subsidies mainly on oil importers' welfare and oil-exporters' oil production and oil revenues.

- This is a very specific (renewablefocused) model ${ }^{\star}$. Hence, it covers only three sectors, i.e., a representative household, firms producing energy and aggregate non-energy products, and a restricted government.
Blazquez et 1995- al. (2017)
DSGE model
Theoretically well-established
- Again, since this is a very specific model, it has some restrictive assumptions. E.g., government revenues are only from energy sales; government expenditures only comprise investment and transfers to households; natural gas is utilized only in electricity generation.

* Designed to investigate the effects of renewables penetration and a reduction in energy subsidies on some macroeconomic indicators in Saudi Arabia. 


\begin{tabular}{|c|c|c|c|c|c|}
\hline Name & Period & Type & Strengths & Weaknesses & Note \\
\hline $\begin{array}{l}\text { Gonand et } \\
\text { al. (2019) }\end{array}$ & $\begin{array}{l}1980- \\
2016\end{array}$ & GE model & $\begin{array}{l}\text { The OLG model takes } \\
\text { a finite lifetime into } \\
\text { account and offers } \\
\text { a more realistic } \\
\text { approach to the } \\
\text { study of long-run } \\
\text { effects. The OLG } \\
\text { model deals with the } \\
\text { life cycle behavior of } \\
\text { human capital, and } \\
\text { the implication of the } \\
\text { allocation of resources } \\
\text { across generations. }\end{array}$ & $\begin{array}{l}\text { Economic interaction takes place } \\
\text { between agents belonging to many } \\
\text { different age groups. }\end{array}$ & $\begin{array}{l}\text { The authors } \\
\text { developed an } \\
\text { energy sector } \\
\text { augmented } \\
\text { dynamic } \\
\text { macroeconomic } \\
\text { model with } \\
\text { overlapping } \\
\text { generations for } \\
\text { Saudi Arabia. } \\
\text { This is a bespoke } \\
\text { model for Saudi } \\
\text { Arabia that builds } \\
\text { on and develops } \\
\text { the overlapping } \\
\text { generation (OLG) } \\
\text { model of Gonand } \\
\text { and Jouvet (2015) } \\
\text { by including the } \\
\text { characteristics } \\
\text { of the Saudi } \\
\text { economy. }\end{array}$ \\
\hline
\end{tabular}

\section{KGEMM}

(the model presented in this paper)
1980- Combination of 2017 MEM and IOM

\section{- Well-established theoretical foundation coupled with the empirical coherence, stylized facts of the Saudi economy and cutting-edge econometric methods.}

\section{- Flexible and} simultaneous evaluation of different research/ policy-related questions.

\footnotetext{
- Customizable model to address different research/policy questions.
}

\footnotetext{
- User-friendly interface and openbox environment.
}

- Heavily data intensive. - Longer data time spans give more
accurate results.

- Data updates and/or revision issues require a reconsideration of all the built relationships.
The model has been built and is currently in use at KAPSARC. 


\section{Literature Review}

\begin{tabular}{cl} 
Name Period $\quad$ Type $\quad$ Strengths \\
\hline $\begin{array}{l}\text { - Disaggregated sectoral demand using } \\
\text { an input-output framework and sectoral } \\
\text { productions from the production functions. }\end{array}$ \\
$\begin{array}{l}\text { - Detailed energy block representing } 14 \text { energy } \\
\text { demand relationships by energy type and } \\
\text { customer. }\end{array}$
\end{tabular}

Notes: $M E M=$ macroeconometric model; $I O M=$ input output model; $N R=$ not reported; $N A=$ not applicable; $E C M=e r r o r$ correction model; $\mathrm{CPI}=$ consumer price index; GDP=gross domestic product; OEGEM=Oxford Economics' Global Economic Model; GE= general equilibrium; AGE=applied general equilibrium; KEM-SA=KAPSARC Energy Model for Saudi Arabia. Calibrated models include computable general equilibrium (CGE), dynamic stochastic general equilibrium (DSGE), and hybrid, among others.

As the strengths and weaknesses of each model are documented in Table 1, we do not discuss them again in the paper. However, it is worth mentioning that their strengths and weaknesses are also determined by the type that they belong to among other factors. In general, calibrated models such as computable general equilibrium (CGE) and dynamic stochastic general equilibrium (DSGE) models have the main strengths of being strongly consistent with textbook economic theory, useful for long-term projections and analyzing the effects of changes in policy variables. Their main weaknesses include, but are not limited to, the following: using micro-foundations strictly as theoretical foundations and not allowing data 'to speak freely'; they do not incorporate information about behavioral economics and information economics; they are calibrated to capture only equilibrium positions with no information about disequilibrium, and they do not provide information about the errors that they make in their representations and simulations (e.g., see Romer [2016]; Stiglitz [2018]; Blanchard [2018]; Hendry and Muellbauer [2018]; Wren-Lewis [2018]; Fair [2019], Colander et al. [2008], Colander [2006], Hara et al. [2009], Pagan [2003a] inter alia). The main strengths of the hybrid types of macroeconometric models (MEMs) over the other types of macroeconomic models are that they have theoretical coherence (like CGE and DSGE models and unlike VAR models).
They represent long-run equilibrium relationships and possess empirical coherence, i.e., they allow the data 'to speak freely' (unlike CGE and DSGE models and like VAR models) to represent shortrun dynamics. In other words, they bring together "theory-driven" and "data-driven" approaches (Hendry 2018). They can represent the behavioral aspects of economic relationships based on the statistical time series properties of national data. Policy projections and simulations capture short-run deviations and speeds of adjustment to equilibrium relations. Other advantages of MEMs are that they can be modified/customized to accommodate different policy questions, and various simulations can be done in one model simultaneously, making them easier to use for policy analyses. Their main weaknesses are related to being data-dependent. For detailed strengths and weaknesses of different kinds of models, interested readers can refer to the abovelisted references as well as Ackerman (2002), Pagan (2003b), Hoover, Johansen, and Juselius (2008), Herbst et al. (2012), Arora (2013), Hurtado (2014), and Oxford Economics (2018).

Conceptually, KGEMM is a hybrid model, i.e., it incorporates economic theory with empirical evidence. This is performed through statistical testing, not by imposing theory on the model. Practically, it attempts to adjust for econometric weaknesses in earlier models built for Saudi Arabia. 


\section{Theoretical Framework and Stylized Facts}

$n$ a very broad sense, KGEMM is a demandside short-to-medium-term macroeconometric model augmented with several supply-side elements. The third version of KGEMM, presented in this paper, has more supply-side augmentation compared to earlier versions.

The demand-side relationships are mainly represented using Keynesian and new-Keynesian schools of thought. The relationships between the variables modeled in most blocks use Keynesian and/or new-Keynesian approaches as theoretical foundations. Hence, we do not discuss which blocks of the model use these theoretical foundations, as their application ranges from modeling demand for consumption in the real block to modeling demand for exports and imports in the external block.

Supply-side representations in the model are mainly in the real and price blocks. Modeling the supplyside of the economic activities uses the production function framework from new-classical theory. Supply- and demand-side determinants have also been considered in modeling the consumer price index for the consumer basket subgroups.

KGEMM also uses an input-output framework in the real block modeling, which combines demand- and supply sides.

The model brings together demand-side factors such as consumption, investment, exports and imports, and supply-side factors such as prices, wages, employment, capital stock and production.

As mentioned earlier, one of the characteristics of KGEMM is that it takes into consideration stylized facts of the Saudi Arabian economy in modeling relationships in the macroeconomic and energy environments. The stylized facts originate from a number of characteristics of Saudi Arabia, some of which are listed below:

Saudi Arabia is an oil-based economy. In 2007-2016, oil constituted on average $46 \%$ of the total economy, $85 \%$ of budget revenues and $80 \%$ of total exports.

Saudi Arabia, like other Gulf Cooperation Council countries, has a substantial foreign labor force. Foreign nationals, particularly from East and Southeast Asian countries, account for $40 \%$ of its total population and more than $80 \%$ of the country's private sector employment.

Policy-makers do not consider taxes as main sources of fiscal revenue and thus they do not use taxes as key policy variables in economic adjustments.

The country is the custodian of the two holiest cities of the Islamic world, Makkah Al-Mukarramah and Al-Madinah Al-Munawwarah. As such, there is great potential for religious tourism to be one of the main sources of the country's fiscal revenues. 


\section{KGEMM Methodology}

$\mathrm{T}$ his section briefly describes the methodology KGEMM uses. KGEMM is a hybrid model, i.e., it brings together theoretical and empirical coherences at some degree. Put differently, KGEMM nests "theory-driven" and "data-driven" approaches as suggested by Hendry (2018), among others. For this purpose, it uses an equilibrium correction modeling (ECM) framework, in which the long-run relationships follow economic theories and the short-run relationships are data driven (see Pagan 2003a and 2003b inter alia). Hara et al. (2009) and Yoshida (1990), among others, note that ECM-based MEMs provide realistic projections for both the short- and long-run, as their equilibrium correction mechanisms help stabilize long-term projections and capture short-term fluctuations more than other models.

KGEMM's methodology for estimating the behavioral equations is based on three pillars: cointegration and ECM, the general-to-specific modeling strategy (Gets) with Autometrics and an encompassing test (Figure 1). These elements of the methodology will be described later in this section.
The econometric methods are employed to estimate behavioral equations, which represent behavioral aspects of the macroeconomic-energy environment of Saudi Arabia, and also test the existence of relationships. The following is the 'road map' that we use in our empirical estimations and testing.

Because we use time series data, the first step is to check the stochastic properties of this data using unit-root tests. For the unit-root analysis, we use Augmented Dickey-Fuller (ADF) (Dickey and Fuller 1981), Phillips-Perron (PP) (Phillips and Perron 1988), and Kwiatkowski et al. (KPSS 1992) tests. We also use unit root tests with structural breaks where it seems reasonable to do so based on the nature of the data. We employ the ADF with structural breaks (ADFBP hereafter) developed by Perron (1989), Perron and Vogelsang (1992a), Perron and Vogelsang (1992b), and Vogelsang and Perron (1998). We do not describe these tests here as they are widely used in the literature. Readers interested in these tests can refer to the above-given references as well as Enders (2015), Perron (2006), Zivot and Andrews (1992), and Banerjee et al. (1992).

Figure 1. KGEMM's econometric methodology.

\section{General to specific modeling approach + Autometrics}

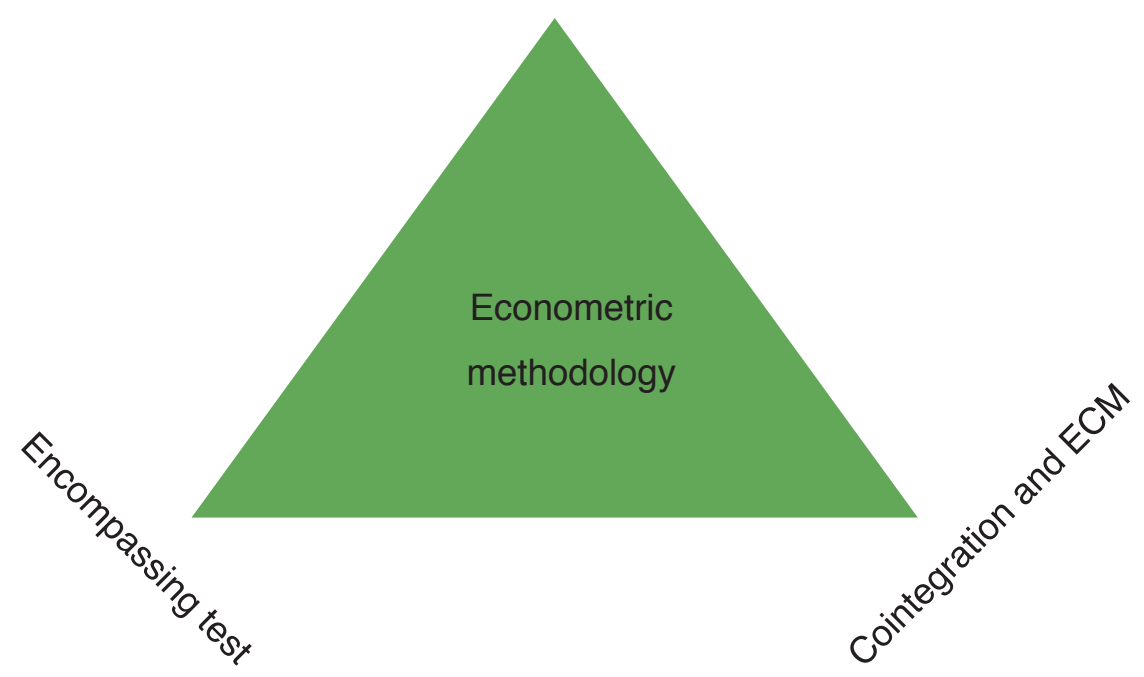


If the series is non-stationary, we perform cointegration tests to check whether the variables under consideration are cointegrated. For this purpose, we use Johansen's (1988) trace and maximum eigenvalue tests, the Pesaran's bounds test (Pesaran and Shin 1999, Pesaran et al. 2001), the Engle-Granger (1987) test, Phillips-Ouliaris test (Phillips and Ouliaris 1990), and Park's (1990) variable addition test (VAT, 1990). If more than two variables are involved in the analyses, which is mostly the case, then we first apply Johansen's cointegration test since it is the only test that can reveal the number of cointegrating relationships, while the other tests assume only one or no cointegrating relationship. We also use Hansen's (2000) cointegration test, which considers the break in the cointegration relationship. If there is a need to include level shift or trend break dummies in the Johansen cointegration test procedure, then we conduct our analysis in OxMetrics, as this program automatically calculates critical values that account for dummy variables.

If cointegration exists between the variables, then we estimate numerical parameters such as longrun coefficients or elasticities and the speed of adjustment of the relationship. To estimate the long-run relationship among the variables, we employ vector error correction (VEC) (Johansen 1988; Johansen and Juselius 1990), autoregressive distributed lags (ADL), fully modified ordinary least squares (FMOLS) (Phillips and Hansen 1990), dynamic ordinary least squares (DOLS) (Saikkonen 1992; Stock and Watson 1993) and canonical cointegration regression (CCR) (Park 1992) methods. After the estimation, we apply postestimation tests, such as residuals diagnostics, parameter stability, among others, where possible.

In the last part of the chain, we employ an ECM to conduct a short-run analysis. We utilize the Gets and Autometrics tools, following the London School of Economics, or the Hendry, modeling approach. Gets first includes contemporaneous and lagged values of all the relevant variables, based on the related economic theory, to the general specification, a general unrestricted model (GUM). Then it chooses the final specification based on a range of econometric tests for diagnostics, stability and misspecification. Further details of the Gets can be found in Davidson et al. (1978), Hendry et al. (1984), Ericsson et al. (1990), de Brouwer and Ericsson (1995) and Campos et al., 2005, among others.

We usually perform Gets using Autometrics in the OxMetrics package (Doornik 2009; Doornik and Hendry 2018). Autometrics is a cutting-edge method of modern econometrics. It performs Gets automatically to select a final specification from a GUM using the tests indicated above. One of the advantages of Autometrics is that it can also account for structural breaks and other extraordinary changes observed in data using the impulse indicator saturation technique. Another key advantage of Autometrics is that it addresses the time invariance of the estimated coefficients. Strong and super exogeneity properties of variables remained in the final ECM specification.

The short-run growth equation is estimated if there is no cointegrating relationship between the variables under consideration. The procedure is the same as in the ECM analysis, but the equilibrium correction term (ECT) is absent as the variables are not cointegrated. Gets with Autometrics is also applied to growth equations.

We use encompassing tests to compare, choose and combine different estimated specification for analysis and forecasting purposes. Encompassing tests compare the predictive ability of alternative specifications and select the best one. Details of 
the test can be found in Mizon (1984), Mizon and Richard (1986), Harvey, Leybourne and Newbold (1998), Harvey and Newbold (2000), Ericsson (1992, 1993), Bontemps and Mizon (2008) and Clements and Hendry (2008).

We use different validation tests to validate the estimated behavioral equations and the entire model as a whole (including testing the in-sample and out-of-sample forecasting quality). These include testing the statistical significance and theoretical consistency of the estimated parameters, post-estimation tests for the residuals of the estimated equations, as well as of the entire model, in-sample performance tests to approximate the historical data, and out-of-sample performance tests for policy analysis. Detailed discussions of these methods can be found in Fair (1984), Klein et al. (1999), Fair (2004), Bårdsen and Nymoen (2008),
Clements and Hendry (2011), Hendry and Mizon (2014), Beenstock et al. (1986), Calzolari and Corsi (1977) and Fair (2004).

The model has been built in the EViews software package, as it provides a number of advanced features for building and simulating MEMs compared to other programs. Different stages of the empirical estimations and testing are conducted in EViews and OxMetrics, which includes Autometrics. The final specifications of the equations are then transferred to EViews to include in the model.

Interested readers can refer to Appendix A for a detailed discussion of KGEMM's methodology and philosophy, including the use of Gets and Autometrics. Appendix A also addresses the Lucas critique using invariance and super exogeneity tests. 


\section{Database}

0 ne of the heaviest resource-consuming components of KGEMM, as with all MEMs, is the necessary collection, updating and maintenance of data. In econometric modeling, data is one of the key elements in determining the statistical properties of relationships. In this regard, data availability plays an important role in establishing linkages between the variables in time series-based MEMs. As discussed in the literature review, MEMs are heavily data-intensive, and obtaining comprehensive results is conditional upon the accuracy and time span of the data. MEMs are also data-dependent, with data updates and/ or revisions resulting in a reconsideration of all the established relationships.

The third version of KGEMM has 588 annual timeseries variables. Three hundred and ten of them are endogenous, represented by behavioral equations and identities. The endogenous variables are those on which we are interested in examining the impacts of domestic policy variables, as well as variables from the rest of the world. The other 278 variables are exogenous in KGEMM. Many of the exogenous variables are rest of the world variables, which provide a comprehensive picture of the global economic and energy ties of Saudi Arabia, ${ }^{2}$ and dummy variables that capture permanent and transitory changes in the relationships that cannot be explained by the data. Policy-related variables are also exogenous in KGEMM.
The data are collected from various domestic and external sources. Most of the domestic data comes from the General Authority of Statistics (GaStat), formerly the Central Department of Statistics (CDSI) and the Saudi Arabian Monetary Agency (SAMA). These two sources provide information on a crucial portion of the country's data. Some domestic data are collected from the Ministry of Economy and Planning (MEP), the Ministry of Finance (MoF), the former Ministry of Energy, Industry and Mineral Resources (MEIM), and Saudi Aramco. External data mainly comes from the databases of Oxford Economics, the World Bank, the United Nations, the International Monetary Fund and the International Energy Agency. The KGEMM database includes aggregated and disaggregated sector-level data. The KGEMM database contains data on the real sector, monetary, fiscal, external sector, consumer and producer prices, labor market, energy sector, and population. The database also covers real (usually at 2010 prices), nominal, index and usercalculated variables.

The mnemonics and descriptions of the variables used in the third version of KGEMM are documented in Appendix B.

(2) For example, the identity for the world trade index for refined oil demand variable (WTREF) contains 45 countries' demand for refined oil products (see equation 151). 


\section{Structure of KGEMM}

$t$ is useful to provide a brief overview of the development stages of KGEMM, as these stages

shaped the current structure of the model. As mentioned previously, KGEMM has been developed to properly represent the Saudi Arabian macroeconomic and energy environment. The main motivation for developing it was that there was no available model (including subscription and/ or fee-based) that properly represented the Saudi Arabian economy and could comprehensively inform the policy decision-making process. The model presented in this paper is the third version of KGEMM. The initial version of KGEMM was built in 2014 upon the Saudi Arabian module of the Oxford Economics Global Economic Model (OEGEM) but differed from it considerably. KGEMM enhanced the OEGEM's Saudi Arabian module by addressing its key limitations, including its oversimplified representation of the Saudi economy, which would prevent it from being used to comprehensively inform the policymaking process. ${ }^{3}$ KGEMM differs from the Saudi Arabian module of OEGEM considerably. ${ }^{4}$ The main feature of the second version of KGEMM was the development of a detailed energy block representing 14 energy demand relationships by energy type and customers. The following are additional features of the third version of KGEMM. It has sectoral-level production function relationships and thus sectoral output gaps feeding into sectoral consumer price indices (CPIs). Sectoral employment is linked to sectoral wages alongside other determinants. Sectoral wage relationships are econometrically estimated as a function of the output price, labor productivity and unemployment rate. However, they have not yet been completed at the time of writing. Finally, it has more detailed external sector representations. For example, it links the export of Saudi Arabian refinery oil to 45 individual countries' refinery oil demand, which offers the opportunity to simulate the impact of the global demand for oil on the Saudi economy.

Figure 2, below, illustrates the structure of the third version of KGEMM.

The model has eight blocks that interact with each other to represent the Saudi Arabian energymacroeconomic environment. What follows is a brief block-by-block description of KGEMM's structure.

(3) The details of the oversimplification of the module were documented by the KGEMM team in 2014-2015 and are available on request. The oversimplification mainly resulted from shortcomings such as numerical unification across the sectors, its limitation to non-theoretical underpinning, and the inconsistency between its reported data and estimated parameters. This is understandable from the perspective of Oxford Economics as they serve more than 1,500 international corporations, financia institutions, government organizations, and universities (https://www.oxfordeconomics.com/about-us). The OEGEM Saudi Arabia module is just one out of 80 countries' and 13 regional modules in OEGEM and developing a model/module would require additional time and resources. The KGEMM team at KAPSARC cooperated with Oxford Economics in 2017-2018 and communicated the shortcomings of OEGEM Saudi Arabia module and the newly developed characteristics of KGEMM so that Oxford Economics could take them (shortcomings and newly developed characteristics) into account in their Saudi Arabian module. Oxford Economics acknowledges KAPSARC's cooperation in their releases.

(4) Since the first version of KGEMM has been built on the OEGEM's Saudi Arabia module to overcome limitations of the module, the notations of the variables in these two models are quite similar. The main points that differentiate KGEMM from the OEGEM' Saudi Arabia module are the well-established theoretical foundation and consistency between data and the estimated parameters. Moreover, KGEMM has a detailed energy block, newly developed sectoral and aggregate relationships, and uses cutting edge econometric methods and tools, such as Autometrics. 
Figure 2. KGEMM structure.

KGEMM Aggregate Level Block Scheme

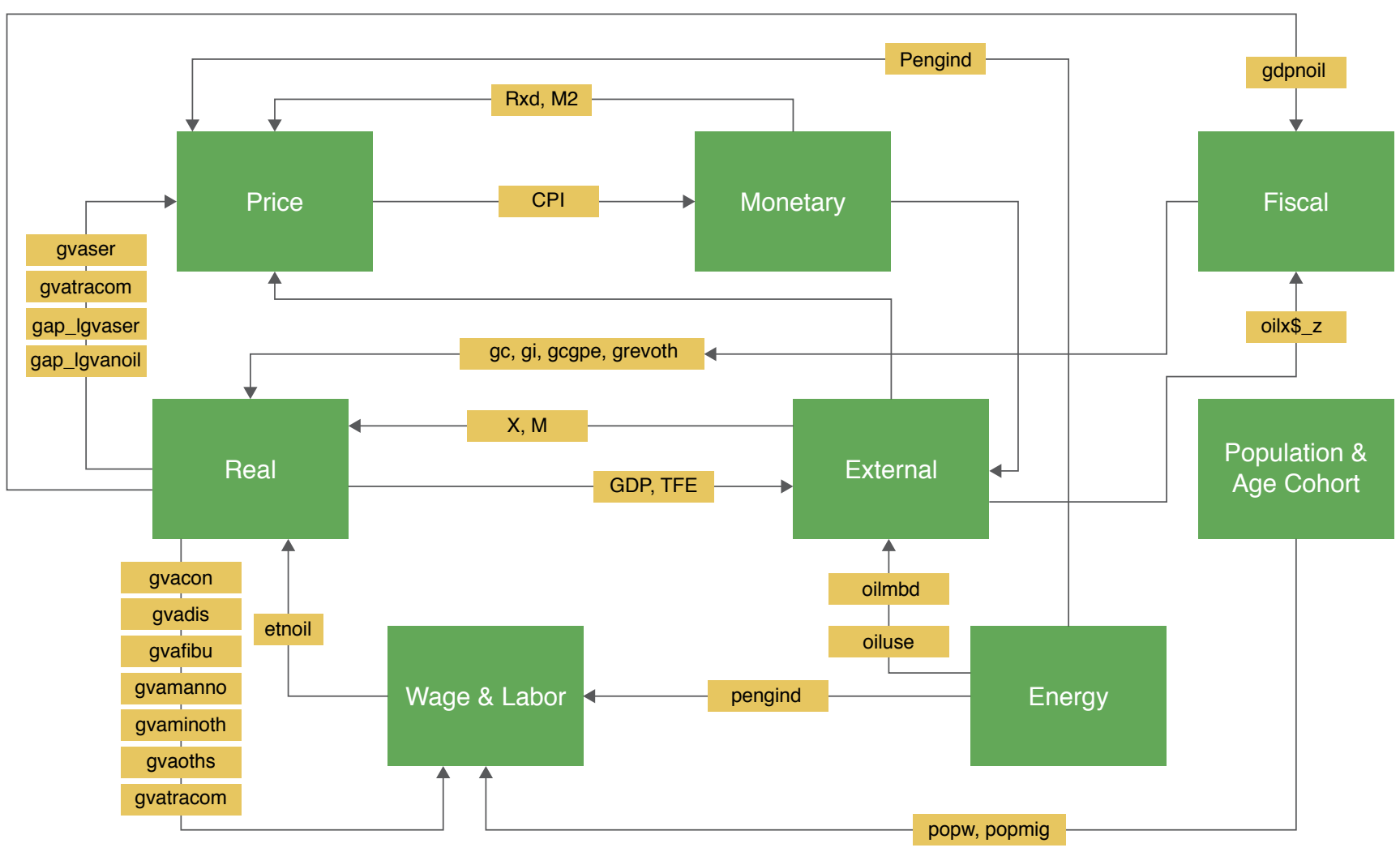

\section{Real block}

This block can be broadly divided into a demandside and supply-side.

\section{Real block: demand-side}

Conventional MEMs, many of them for the Saudi Arabian economy, treat demand on an aggregate level. However, as mentioned earlier, aggregate demand in KGEMM is broken down into sectors of the 14 economic activities of the model. All the final demand components of gross domestic product (GDP), i.e., private consumption, government consumption, investment, exports and imports are disaggregated into the economic activities using the coefficients derived from the input-output table for
Saudi Arabia. The intermediate demand for each of the economic activities is modeled as a function of the demand for all these economic activities, again using coefficients derived from the input-output table. The total demand for a given economic activity is the sum of intermediate demand and final demand.

Private consumption is econometrically estimated as a function of private disposable and interest rate income. Note that the private disposable income data is not available from official agencies and hence has been constructed by the KGEMM team using the System of National Accounts framework (see Hasanov and Olagunju [2019] for further details). 
Investment is the sum of oil and non-oil private and government investments. Non-oil private investment is the sum of foreign and domestic investments. Currently, the KGEMM team works to make non-oil private investment the sum of sectoral domestic and foreign investments.

The other final demand components, i.e., government consumption and net exports, will be discussed in their respective blocks later. These indicators link the real block to the fiscal and external blocks.

The economic activities are econometrically estimated, using the demand-side approach, as functions of total demand for the economic activities and demand for energy in the economic activities. This approach comes from the input-output framework and also includes energy demand. The purpose of including energy demand is to measure the explicit effects of energy demand on economic activities. This makes it possible to use the model to analyze the impact of the domestic energy price reform on economic activities through energy demand. These estimations link the real sector to the energy and price blocks.

\section{Real block: supply-side}

The supply side of the real block mainly contains production functions for the economic activities, which estimate the potential outputs of the activities as functions of mainly capital stocks and employment, alongside technological change proxied by the time trend and other explanatory variables. This is consistent with the theory of production (Cobb and Douglas 1928; Douglas 1976).

The capital stock for a given economic activity has been constructed by the KGEMM team using investment in the activity, the activity-specific depreciation rate and assumed initial capital stock in the perpetual inventory method framework (Collins,
Bosworth, and Rodrik 1996; Nehru and Dhareshwar 1993, Hall and Jones 1999; Caselli 2005; Arezki and Cherif 2010).

The relationships representing employment by economic activity, used in the prediction function estimations, will be discussed in the wage and labor block.

The output gaps of the economic activities have been calculated using the estimated production functions. The gaps feed into the behavioral equations of the CPIs for the different categories, as discussed in the price block.

Demand-side and supply-side breakdowns of the entire economy into economic activities can provide useful information about sectoral compositions and changes in the structure of the economy. This is very important for diversification and local content purposes, key targets of SV2030, as articulated in the National Transformation Program (SV2030 2019b).

Subsection 7.1 provides additional definitional relationships, such as the nominal value added of the economic activities and the aggregation of the economic activities into large sectors, such as the service sector, the industry sector, oil and non-oil sectors, which are the sum of respective economic activities in the real sector.

\section{Fiscal block}

Total government expenditure is the sum of government capital and current expenditure. The former is a function of the one-period lagged capital expenditure, the relative increase in government investment and the remainder of capital expenditure. The government current expenditure is the sum of the government's four current spending components, namely: wages, salaries and 
allowances; administrative expenses; maintenance and operational costs; and transfers to the private sector. Government consumption is the sum of the first three components above as the fourth component is not consumed by the government.

Total government revenue is the sum of the government's oil and other revenues. The former is linked to oil exports from the external block. The government's other revenues are the sum of revenues from energy sales, non-oil revenues, and the remaining part of the other revenues. Energy sales are linked to the economy's total energy consumption coming from the energy block. Nonoil revenues are the sum of the revenues collected from the value added tax (VAT), the expatriate levy, the Umrah and Hajj visa fees, other visa fees, traffic fines, the idle land tax, the luxury good tax and other non-oil sector related fees, tariffs and collections. The remaining part of the other revenues is linked to non-oil sector activity from the real sector and revenues such as government investment returns. The total government revenue in the model has been structured according to the stylized facts of the Saudi Arabian economy. This allows us to model the impacts of oil market changes, which are mostly exogenous, as well as the impacts of internal policy decisions on the energy prices reform, VAT, expatriate fees and other revenue components, the key initiatives of the Fiscal Balance Program of SV2030 (SV2030 2019a), on the Kingdom's economy.

Lastly, the block contains the government's budget balance: the difference between its total revenues and total expenditure. It also contains the government's non-oil budget balance: the difference between the government's non-oil revenues and its total expenditure. The latter is another stylized fact of the economy, and its purpose in the model is to show to what extent non-oil sector revenues can finance government spending. The government can then take measures to increase the efficiency of both its spending and revenue collection, the key targets of the Fiscal Balance Program (FBP) (SV2030 2019a).

Subsection 7.2 details the relationship described above.

\section{Monetary block}

The monetary block of the model is fairly small, mainly because of the nature of monetary policy in Saudi Arabia, another stylized fact of the economy. The exchange rate of the Saudi riyal (SAR) is pegged to the United States dollar (US\$). Hence, Saudi Arabia's interest rate follows the United States Federal Reserve interest rate.

The block contains definitional identities for all monetary aggregates, i.e., cash held outside banks, cash with demand deposits, a broad monetary aggregate, and a broad monetary aggregate with foreign currency deposits.

It also has identities for interest rates, namely the central bank policy rate, short-term (three-month) SAR interbank offered rate, the interest rate on lending, the effective interest rate on external debt and the interest rate on 10-year government bonds.

The block uses the definitional identity for the real effective exchange rate, determined by the ratio of domestic and foreign prices, together with the nominal effective SAR exchange rate against a basket of currencies of its main trading partners. This identity links the monetary block to the external and prices blocks. Real effective exchange rates are considered as a measurement of international competitiveness in many theoretical and empirical studies. In this regard, the model can simulate how changes in domestic and foreign markets can shape Saudi Arabia's international competitiveness, one of the key targets of SV2030. 
Finally, the block contains one behavioral equation for broad money (M2) demand, which estimates it as a function of the interest rate and GDP from the real sector, and domestic prices from the prices block.

Subsection 7.3 provides details of the relationships of the monetary block.

\section{External block}

The external sector in KGEMM is classified into exports, imports and other balance of payment components.

Total exports are the sum of exports of goods and services. The exports of goods are broken down into oil exports and non-oil goods exports as stylized facts of the Saudi economy. The former is the sum of the exports of crude oil and oil refinery products. Crude oil exports are represented by an identity, which links it to domestic oil production less domestic oil use, multiplied by the global price of Arabian light. It is one of the most important relationships in the block, as it links the external block to the real block, the energy block, and to the rest of the world. Thus, one can simulate the model to see how energy price reform could increase crude oil export revenues by lowering domestic oil use and freeing up more crude oil for export. Alternatively, one can look at the impact of oil price dynamics on the international markets, and the impact of OPEC oil production and export quotas on Saudi Arabia's oil export revenues. The behavioral equation for the export of refined oil products includes, alongside other variables, the world trade index for refined oil products. This index combines 45 individual countries' demand for refined oil products. This enables the model to simulate how changes in the demand for refined oil products in a given country influence Saudi Arabia's refinery oil exports. The Kingdom's oil exports feed into the government's oil revenues in the fiscal block.
The non-oil goods exports are estimated as being dependent on the real effective exchange rate, the production levels of the non-oil tradable sector, which is the sum of agriculture, non-oil manufacturing, non-oil mining, and demand from the rest of the world. Put differently, the equation links the external sector to the real sector, and the monetary sector and the rest of the world.

The total exports of services is the sum of the exports of services from the following sources: oil, investment income, other services, transportation, travel, communications, freight and insurance, financial services and government.

Total imports is the sum of the imports of goods and services, broken down into the same categories as total exports. The imports of goods are estimated as a function of domestic demand and the real effective exchange rate. The imports of services are estimated as a function of domestic demand, the nominal effective exchange rate and the import price index. Both equations follow the conventional demand-side approach to import modeling. The price index for the imported goods is determined conventionally as the percentage ratio of the nominal value of the imported goods to that of the real value.

As with other balance of payment components in the model, we have identities for net foreign direct investment and outflows. Outflows are linked to the development of the Saudi economy and the net is the difference between the inflows and outflows. The KGEMM team are estimating the inflows using theoretically predicted explanatory variables such as productivity, macroeconomic stability, openness, and business costs, including the unit labor cost, infrastructure, and institutional development.

Subsection 7.4 details the external sector relationships. 


\section{Domestic prices block}

This block can be divided into three sub-blocks in a broader classification: consumer price indexes (CPIs), GDP deflators or producer price indexes and energy prices.

The model has all 12 consumer basket groups as given by GaStat, estimated using behavioral equations. In forming the specifications for the CPIs, we considered all relevant economic schools of thought on inflation modeling, such as the money market approach, the markup (unit labor cost and energy prices) approach, the purchasing power parity or external sector approach, and the output gap approach. Therefore, estimated long- or short-run equations for CPIs link the block to the rest of the blocks in the model (except population and age cohorts). In addition to the 12 estimated equations, the sub-block contains an identity for overall $\mathrm{CPI}$, which is a weighted average of the 12 CPI components.

GDP deflators, or the producer price indexes subblock, gives the estimated GDP deflator equations by economic activity, considering them as a function of the respective general price (non-oil GDP, oil GDP and GDP deflators) and energy price, among other control variables. The idea is to see how the general price changes affect the price of a given economic activity according to domestic and external factors, including domestic energy prices subject to the country's energy price reform. This setup allows us to simulate the model to investigate the impact of the ongoing energy price reform on the production costs, and thus the competitiveness, of the economic activities. Lastly, the sub-block has an identity for the industrial production index, which links it to the value added in manufacturing.

The energy prices sub-block mainly contains the domestic prices of energy products for energy customers. They are treated exogenously in the model as they are at the core of the energy price reform. The block also contains weighted average prices for some economic activities, if customers use more than one energy product. For example, the aggregate energy price for the utility sector is the weighted average price of natural gas, crude oil, diesel, and heavy fuel oil. The same idea has been applied to the construction of the aggregate prices for transportation, communication, government services, other services, and financial and banking services. Such a weighted average price allows us to simulate the model for both the price and demand effects of different energy products on a given economic activity.

A detailed description of the domestic price block is documented in subsection 7.5.

\section{Labor and wages block}

This block contains behavioral equations for employment in economic activities. These equations estimate the demand for employment in a given economic activity, mainly as a function of the activity's wage and output. The wage equations for the economic activities are econometrically estimated as a function of the output price and labor productivity. However, they have not yet been completed at the time of writing. These employment and wage equations establish links with the real block.

The block also contains definitional identities for non-oil and oil sector employment, the labor force and the unemployment rate. Considering the stylized facts of the Saudi economy, the labor force is linked to working age population groups of Saudis and non-Saudis, with the latter the sum of males and females. This allows one to differentiate the role of each group and the male/female ratio of the labor force and, thus, also in the unemployment figures. 
Lastly, the block contains identities that represent the unit labor costs in each economic activity. The identities use the conventional definition for unit labor cost, i.e., each sector's unit labor cost is the sectorspecific average wage multiplied by the sectorspecific employment over the sector-specific output.

A detailed description of the labor market and wages block is documented in subsection 7.6.

\section{Energy block}

The energy block differentiates KGEMM from other structural macroeconomic models. The block has econometrically estimated 15 behavioral equations for energy demand relationships. There are nine energy products (crude oil, diesel, heavy fuel oil [HFO], natural gas, electricity, liquefied petroleum gas [LPG], kerosene, gasoline, and other oil products) and six customer types (industry, residential, commercial, government, transport, agriculture and forestry). However, not all customers consume all the energy products (e.g., electricity is consumed by all customers except transport, whereas only industry consumes HFO and crude oil). The equations have been estimated using the conventional energy demand framework. In other words, demand for a given energy product is a function of its own price in real terms and customerspecific income. The customer-specific price deflators have been used to calculate energy prices in real terms, as suggested by the energy demand literature. This part of the energy block links it to the prices and real blocks. Recall that energy product consumption feeds into the demand-side estimation of the economic activities in the real block.
The block also classifies energy consumption by the six consumer types in million tonnes of oil equivalent (Mtoe), i.e., in volume terms. Energy consumption is also classified by the same consumer types in million Saudi riyals, i.e., in monetary terms, and this is calculated as a given energy product's consumption in Mtoe, multiplied by its price. Both classifications provide an overview of customers' energy consumption in volume and monetary terms. Both classifications separately sum up to the country's total energy consumption in volume and monetary terms, respectively. Note that total energy consumption in monetary terms feeds into the government's other revenues in the fiscal block.

\section{Population and age cohorts block}

The total population in the block is the sum of the 12 age groups: 0-14, 15-19, 20-24, 25-29, 30-34, 35-39, 40-44, 45-49, 50-54, 55-59, 60-64, 65 and above. Each age group is determined as the sum of males and females. The total Saudi population is the sum of Saudi males and females. The same formula is applied to the non-Saudi population. The working age population is the sum of the age cohorts 15-19 through 60-64, with the years between 20 and 60 broken down into five-year increments. The working age population of Saudis and non-Saudis feeds into the labor force in the wages and labor block. One can simulate the model to assess the impacts of changes in each of the 12 age groups on the economy as a whole, as well as the Saudi and nonSaudi impacts on various relationships.

Details of the block can be found in subsection 7.8 


\section{KGEMM Behavioral Equations and Identities}

Whis section of the paper reports the estimated behavioral equations, i.e., final ECMs and identities for each block. We assign numbers to the behavioral equations and identities below. As mentioned in the methodological section, ECM incorporates long-run equilibrium relationships and short-run dynamics between variables, and the speed of adjustment from the latter to the former. We report long-run relationships right after the associated final ECM specifications, but we do not assign numbers to them. We express longrun relationships in the form of long-run residuals. In other words, they are expressed as equilibrium correction terms and denoted by ECT_I. Here, 'I' stands for a modeled variable. The coefficient of the respective ECT_I is the speed of adjustment (SoA), which indicates how much of the short-run disequilibrium can be corrected back to the long-run equilibrium relationship over one year (recall that we use annual time series observations). To enable readers to further understand the above, let us describe it in terms of gross value added in non-oil manufacturing, (GVAMANNO), i.e., equation (1) below. This description can also be applied to the other variables in the model.

DLOG(GVAMANNO) $=0.03-0.70 *$ ECT_GVAMANNO(-1)+0.59*DLOG(TDMANNO)+0.13*DLOG(DNGA_IND)+0.10*DLOG(DHFO_IND)+ $0.03 *$ DLOG(DCOIL_IND)

ECT_GVAMANNO=LOG(GVAMANNO)-(0.69*LOG(TDMANNO) $+0.25 *$ LOG(DNGA_IND) $+0.39 *$ LOG(DHFO_IND) $+0.07 *$ LOG(DCOIL_IND) +1.64$)$

D is the difference operator, LOG is the natural logarithm operator, ECT_GVAMANNO is the ECT for GVAMANNO. The coefficient of -0.70 is SoA and shows that $70 \%$ of the short-run disequilibrium can be corrected back to the long-run equilibrium relationship during one year.

The first equation, which is the final ECM for GVAMANNO, shows that if the growth rate of total demand for non-oil manufacturing, DLOG(TDMANNO) rises by $1 \%$, then the growth rate of non-oil manufacturing, DLOG(GVAMANNO) will increase by $0.59 \%$. A $1 \%$ increase in the growth rates of natural gas consumption, DLOG(DNGA_IND), heavy fuel oil consumption, DLOG(DHFO_IND), and crude oil consumption, DLOG(DCOIL_IND) result in $0.13 \%, 0.10 \%$ and $0.03 \%$ increases in the growth rate of non-oil manufacturing, DLOG(GVAMANNO), respectively.

The second equation is the expression for ECT_GVAMANNO and shows the long-run residuals of the GVAMANNO equation. The long-run equation can be easily re-expressed from it:

LOG(GVAMANNO) $=0.69 *$ LOG(TDMANNO) $+0.25 *$ LOG(DNGA_IND) $+0.39 *$ LOG(DHFO_IND)+0.07*LOG(DCOIL_IND)+1.64+ECT_GVAMANNO

The long-run equation for GVAMANNO shows that non-oil manufacturing, GVAMANNO increases by $0.69 \%$ if the total demand for it, TDMANNO increases by $1 \%$ in the long-run. A $1 \%$ increase in each of the industrial consumptions of natural gas, DNGA_IND, heavy fuel oil, DHFO_IND and crude oil, DCOIL_IND cause $0.25 \%$, $0.39 \%, 0.07 \%$ increases in non-oil manufacturing, GVAMANNO respectively in the long-run.

To save space, we do not report other estimation and test statistics, such as unit root and cointegration test results, the statistical significance of the estimated parameters, post-estimation test results for residuals. They are available from the authors on request.

There are two main types of identities across the blocks: System of National Accounting identities (e.g., total demand is the sum of private and government consumption, investments, and net exports) and definitional identities (e.g., nominal value added is obtained by multiplying real value added and the respective price deflator). 


\section{Real block (demand-side and supply-side) Behavioral equations, ECMs for sectoral gross value added. Demand-side}

DLOG $($ GVAMANNO $)=0.03-0.70 *$ ECT_GVAMANNO(-1) $+0.59 *$ DLOG(TDMANNO) $+0.13 *$ DLOG(DNGA_IND) $+0.10 *$ DLOG(DHFO_IND) $+0.03 *$ DLOG(DCOIL_IND) ECT_GVAMANNO $=$ LOG $(G V A M A N N O)-\left(0.69 *\right.$ LOG $($ TDMANNO $)+0.25 * L O G\left(D N G A \_I N D\right)+0.39 *$ LOG $($ DHFO_IND $)+0.07 *$ LOG(DCOIL_IND $\left.)+1.64\right)$

DLOG(GVADIS $)=-0.001-0.57 *$ ECT_GVADIS(-1) +0.61*DLOG(GVADIS(-1))+0.67*DLOG(TDDIS $)+0.14 *$ DLOG(DELE_COMM $(-1))-0.06 *$ DP2000 + 0.05*D(DP2010)

ECT_GVADIS $=($ LOG(GVADIS $)-(1.0935 *$ LOG(TDDIS $)+0.1801 *$ LOG(DELE_COMM $)-1.2328))$

DLOG(GVAFIBU) $=0.03+0.56 *$ DLOG(GVAFIBU(-1) $)+0.22 *$ DLOG(DEOTH_TRA $)-0.24 *$ ECT_GVAFIBU(-1) $+0.06 * \mathrm{D}(\mathrm{DP} 2000)+0.03 * \mathrm{D}(\mathrm{DP} 2006)$

ECT_GVAFIBU $=$ LOG(GVAFIBU)-( $0.20 *$ LOG(DELE_COMM) $+0.45 *$ LOG(DEOTH_TRA) $+0.31 *$ LOG(TDFIBU) $+6.80+0.13 *$ DP $2000+0.06 *$ DP2 2006

DLOG $($ GVAGOV $)=0.005-0.22 *$ ECT_GVAGOV $(-1)+0.12 *$ DLOG $($ TDGOV $)+0.50 *$ DLOG $(G V A G O V(-1))+0.04 * \mathrm{DP} 1997+0.03 * \mathrm{DP} 1992$

ECT_GVAGOV=LOG $($ GVAGOV $)-(0.27 *$ LOG $($ TDGOV $)+0.38 *$ LOG $($ DELE_GOV $)+8.70-0.06 *$ DP2008)

$\operatorname{DLOG}(\mathrm{GVACON})=-0.01-0.36 *$ ECT_GVACON$(-1)+0.23 * \mathrm{DLOG}(\mathrm{TDCON})+0.32 * \operatorname{DLOG}(\mathrm{GVACON}(-1))+0.04 * \mathrm{D}(\mathrm{DP} 1998)$

ECT_GVACON $=$ LOG $($ GVACON $)-(0.14 *$ LOG $($ TDCON $)+0.98 *$ LOG(DDIS_IND $)+8.58+0.09 *$ DP1998) $)$

DLOG $($ GVAOILREF $)=0.02+0.22 *$ DLOG $($ GVAOILREF $(-1))+0.42 *$ DLOG(TDOILREF $)-0.30 *$ ECT_GVAOILREF(-1) $+0.18 * \mathrm{D}($ DSH8590)-0.11*D(DP2013) $+0.14 *$ DP1990

ECT_GVAOILREF $=$ LOG(GVAOILREF $)-(0.28 *$ LOG(TDOILREF $)+0.12 *$ LOG(DCOIL_IND) $+7.65+0.25 *$ DSH8590 + 0.14*DSH040506)

DLOG(GVAOTHS) $=0.01-0.58 *$ ECT_GVAOTHS(-1) $+0.16 *$ DLOG(TDOTHS) $+0.12 *$ DLOG(DELE_COMM)

ECT_GVAOTHS=LOG(GVAOTHS $)-(0.29 *$ LOG(TDOTHS $)+0.29 *$ LOG(DELE_COMM $)+7.27)$

DLOG $($ GVATRACOM $)=-0.02-0.43 *$ ECT_GVATRACOM $(-1)+0.14 *$ DLOG $($ TDTRACOM $)+0.74 *$ DLOG(DGAS_TRA $)+0.58 *$ DLOG $($ DDIS_TRA $)+0.37 *$ DLOG $($ GVATRACOM $(-1))(8)$ ECT_GVATRACOM=LOG(GVATRACOM $)-(0.33 *$ LOG(TDTRACOM $)+0.48 *$ LOG $($ DELE_COMM $)+1.14 *$ LOG(DGAS_TRA $)+1.12 * L O G\left(D D I S \_T R A\right)+4.92-0.07 * @$ TREND $\left.)\right)$

\section{Identities for sectoral aggregation of GVAs}

GVAAGR $=$ GVAAGR $(-1) *(0.5000000 *$ CONS $/$ CONS $(-1)+0.5000000 *$ POP $/$ POP(-1) $)+$ DIS_GVAAGR

GVAREAL $=$ GVAFIBU - GVAFIBUOTH

GVAIND $=$ GVAU + GVAMAN + GVAMINOTH + GVAOILMIN

GVAMIN $=$ GVAMINOTH + GVAOILMIN 


\section{Identities for GVAs in nominal terms}

GVAFIBU_Z $=$ GVAFIBUOTH_Z + GVAREAL_Z

GVAFIBUOTH_Z $=$ GVAFIBUOTH $*$ PGDPFIBUOTH $/ 100$

GVAREAL_Z $=$ GVAREAL $*$ PGDPREAL $/ 100$

GVASER $=$ GVADIS + GVATRACOM + GVAFIBU + GVAOTHS + GVAGOV

GVATRACOM_Z $=$ GVATRACOM $*$ PGDPTRACOM $/ 100$

GVAMAN $\mathrm{Z}=$ GVAMAN $*$ PGDPMAN $/ 100$

GVAOIL_Z $=$ GVAOILMIN_Z + GVAOILREF_Z + DIS_GVAOIL_Z

\section{Identities for intermediate, final and total demand \\ Intermediate demand components}

$\mathrm{IDCON}=\mathrm{A}_{1} * \mathrm{GVAAGR}+\mathrm{A}_{2} * \mathrm{GVACON}+\mathrm{A}_{3} * \mathrm{GVAU}+\mathrm{A}_{4} * \mathrm{GVAFIBU}+\mathrm{A}_{5} * \mathrm{GVAGOV}+\mathrm{A}_{6} * \mathrm{GVAOTHS}+\mathrm{A}_{7} * \mathrm{GVAMAN}+\mathrm{A}_{8} * \mathrm{GVAMINOTH}+\mathrm{A}_{9} * \mathrm{GVADIS}+\mathrm{A}_{10} * \mathrm{GVATRACOM}$

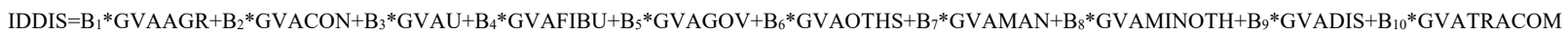

IDFIBUOTH $=\mathrm{C}_{1} * \mathrm{GVAAGR}+\mathrm{C}_{2} * \mathrm{GVACON}+\mathrm{C}_{3} * \mathrm{GVAU}+\mathrm{C}_{4} * \mathrm{GVAFIBU}+\mathrm{C}_{5} * \mathrm{GVAGOV}+\mathrm{C}_{6} * \mathrm{GVAOTHS}+\mathrm{C}_{7} * \mathrm{GVAMAN}+\mathrm{C}_{8} * \mathrm{GVAMINOTH}+\mathrm{C}_{9} * \mathrm{GVADIS}+\mathrm{C}_{10} * \mathrm{GVATRACOM}$ 


\section{Final demand components}

$\mathrm{FDCON}=\mathrm{A}_{1} * \mathrm{CONS}+\mathrm{A}_{2} * \mathrm{GC}+\mathrm{A}_{3} * \mathrm{IF}+\mathrm{A}_{4} * \mathrm{IS}+\mathrm{A}_{5} * \mathrm{X}$

FDDIS $=\mathrm{B}_{1} * \mathrm{CONS}+\mathrm{B}_{2} * \mathrm{GC}+\mathrm{B}_{3} * \mathrm{IF}+\mathrm{B}_{4} * \mathrm{IS}+\mathrm{B}_{5} * \mathrm{X}$

FDFIBUOTH $=\mathrm{C}_{1} * \mathrm{CONS}+\mathrm{C}_{2} * \mathrm{GC}+\mathrm{C}_{3} * \mathrm{IF}+\mathrm{C}_{4} * \mathrm{IS}+\mathrm{C}_{5} * \mathrm{X}$

FDGOV $=\mathrm{D}_{1} * \mathrm{CONS}+\mathrm{D}_{2} * \mathrm{GC}+\mathrm{D}_{3} * \mathrm{IF}+\mathrm{D}_{4} * \mathrm{IS}+\mathrm{D}_{5} * \mathrm{X}$

FDMAN $=\mathrm{E}_{1} * \mathrm{CONS}+\mathrm{E}_{2} * \mathrm{GC}+\mathrm{E}_{3} * \mathrm{IF}+\mathrm{E}_{4} * \mathrm{IS}+\mathrm{E}_{5} *$ XGNOIL

$\mathrm{FDSOC}=\mathrm{F}_{1} * \mathrm{CONS}+\mathrm{F}_{2} * \mathrm{GC}+\mathrm{F}_{3} * \mathrm{IF}+\mathrm{F}_{4} * \mathrm{IS}+\mathrm{F}_{5} * \mathrm{X}$

$\mathrm{FDU}=\mathrm{H}_{1} * \mathrm{CONS}+\mathrm{H}_{2} * \mathrm{GC}+\mathrm{H}_{3} * \mathrm{IF}+\mathrm{H}_{4} * \mathrm{IS}+\mathrm{H}_{5} * \mathrm{X}$

Here, the coefficients from $\mathrm{A} 1$ to $\mathrm{H} 5$ are Input-Output coefficients. We do not report numerical values of them due to the data confidentiality issue as they were obtained from OEGEM.

\section{Total demand components}

$\mathrm{TDCON}=\mathrm{IDCON}+\mathrm{FDCON}$

TDDIS $=$ IDDIS + FDDIS

TDFIBUOTH $=$ IDFIBUOTH + FDFIBUOTH

$\mathrm{TDGOV}=\mathrm{IDGOV}+\mathrm{FDGOV}$

TDMAN $=$ IDMAN + FDMAN

\section{Other demand components}

$\mathrm{TFE}=\mathrm{CONS}+\mathrm{IF}+\mathrm{GC}+\mathrm{IS}+\mathrm{X}$

$\mathrm{DOMD}=\mathrm{CONS}+\mathrm{IF}+\mathrm{IS}+\mathrm{GC}$

DOMD_Z $=$ CONS_Z + IF_Z + IS_Z + GC_Z

PCONS $=$ CONS_Z $/$ CONS $* 100$

DI Z $=(($ GDP $*$ PGDP / 100) $* 0.53-$ CEN_TOT $-($ GREVOTH - CEN_TOT - VAT_REV - HUVF - OVF $)+$ GCGPE $)+$ DIS_DI Z 


\section{Potential output identities for economic activities. Supply-side}

pot_gvaagr $=0.51 * \operatorname{LOG}(\mathrm{CAPAGR})+0.36 * \mathrm{LOG}(\mathrm{ETAGR})+3.18$

\section{Gap identities for economic activities}

Lower case means that a given variable is in the natural logarithmic expression Identities for investment and capital stocks 


\section{Fiscal block}

\section{Equations for government expenditure items}

DLOG $($ GWSA_Z $)=-0.16 *$ ECT_GWSA_Z(-1) $-0.01-0.14 *$ DLOG $($ GWSA_Z $(-2))+0.09 *$ DLOG $(G R E V)+0.34 *$ DB7677 + $0.33 *$ DP 1997

ECT GWSA Z $=$ LOG(GWSA Z)-(0.87*LOG(GREV)+1.08)

DLOG(GAE_Z $)=-0.45^{*}$ ECT_GAE_Z(-1) $+0.05-0.17 *$ DLOG $($ GAE Z $(-1))$

ECT_GAE_Z =LOG(GAE_Z)-( 0.85*LOG(GREV)- 0.66)

\section{Identities for government revenues and expenditures}

GREV $=$ GREVOIL + GREVOTH

GREVOIL $=0.8 *$ XGOIL $\$$ Z RXD + DIS GREVOIL 


\section{Monetary block}

DLOG(M2) $=0.07-0.29 *(\operatorname{LOG}(\mathrm{M} 2(-1))-1 * \operatorname{LOG}(\mathrm{GDP}(-1))-1 *$ LOG(PGDP(-1))-0.05*RLEND(-1)-0.03*@ TREND+7.45) + 0.36*DLOG(GDP) + 0.30*DLOG(PGDP)

$\mathrm{M} 0=\mathrm{M} 2-\mathrm{DTS}-\mathrm{DD}$

$\mathrm{M} 1=\mathrm{M} 2-\mathrm{DTS}$

$\mathrm{M} 3=\mathrm{M} 2+\mathrm{DQM}$

RLEND $=$ RLEND $(-1)+($ RSH - RSH(-1))

RRLEND $=$ RLEND $-\mathrm{DLOG}(\mathrm{CPI}) * 100$

$\mathrm{RCB}=\mathrm{RSH}$

\section{External block}

\section{Export-related}

$\mathrm{X}=\mathrm{XG}+\mathrm{XS}$

$\mathrm{XGOIL}=\mathrm{XGOIL} \_\mathrm{Z} / \mathrm{PX} * 100$

XG\$_Z $=$ XGOIL\$_Z + XGNOIL\$_Z 


\section{Import-related}

$\mathrm{M}=\mathrm{MG}+\mathrm{MS}+$ DIS_M

DLOG $(M G)=-0.15 * E C T \_M G-0.23 *$ DP1994 $-0.19 *$ DP2009 + 0.26*D(DP1992) + 2.18*DLOG(GVANOIL(-1)) + 0.13*D(DP1991) $-0.55 *$ DLOG(REER(-1))

\section{Other international trade identities}

\section{World trade index for refined oil demand}

$\mathrm{WTREF}=100 *\left(\mathrm{~A}_{1} *\right.$ DOILREF_ARG $/ 24.59+\mathrm{A}_{2} *$ DOILREF_AUS $/ 38.86+\mathrm{A}_{3} *$ DOILREF_AUT $/ 11.08+\mathrm{A}_{4} *$ DOILREF_BEL $/ 21.44+\mathrm{A}_{5} *$ DOILREF_BRA $/ 93.86$ $+\mathrm{A}_{6} *$ DOILREF_BGR $/ 3.15+\mathrm{A}_{7} *$ DOILREF_CAN $/ 92.39+\mathrm{A}_{8} *$ DOILREF_CHL $/ 12.09+\mathrm{A}_{9} *$ DOILREF_CHN $/ 378.63+\mathrm{A}_{10} *$ DOILREF_HRV $/ 3.05+\mathrm{A}_{11} *$ DOILREF CZE / $8.57+\mathrm{A}_{12} *$ DOILREF DNK / $6.20+\mathrm{A}_{13} *$ DOILREF FIN / $8.07+\mathrm{A}_{14} *$ DOILREF FRA $/ 71.55+\mathrm{A}_{15} *$ DOILREF DEU / $94.67+\mathrm{A}_{16} *$ DOILREF GRC $/ 12.18+\mathrm{A}_{17} *$ DOILREF HKG / $3.00+\mathrm{A}_{18} *$ DOILREF HUN $/ 6.08+\mathrm{A}_{19} *$ DOILREF IND / $134.24+\mathrm{A}_{20} *$ DOILREF IDN / 59.60 + $\mathrm{A}_{21} *$ DOILREF IRL $/ 6.77+\mathrm{A}_{22} *$ DOILREF_ITA / $54.43+\mathrm{A}_{23} *$ DOILREF_JPN $/ 169.48+\mathrm{A}_{24} *$ DOILREF_KOR $/ \overline{81.87}+\mathrm{A}_{25} *$ DOILREF_MYS $/ 23.48+\mathrm{A}_{26} *$ DOILREF_MEX $/ 73.86+\mathrm{A}_{27} *$ DOILREF_NLD $/ 23.17+\mathrm{A}_{28} *$ DOILREF_NOR / $8.55+\mathrm{A}_{29} *$ DOILREF_PHL $/ 11.46+\mathrm{A}_{30} *$ DOILREF_POL $/ 23.24+\mathrm{A}_{31} *$ DOILREF_PRT $/ 10.12+\mathrm{A}_{32} *$ DOILREF_ROM $/ 6.57+\mathrm{A}_{33} *$ DOILREF RUS / 109.32 + $\mathrm{A}_{34} *$ DOILREF ZAF / $22.76+\mathrm{A}_{35} *$ DOILREF T / $102.43+\mathrm{A}_{36} *$ DOILREF SGP / 10.68 + A $37^{*}$ DOILREF SVK / $3.07+\mathrm{A}_{38} *$ DOILREF_ESP $/ 59.73+\mathrm{A}_{39} *$ DOILREF_SWE $/ 14.04+\mathrm{A}_{40} *$ DOILREF_CHE $/ 11.24+\overline{\mathrm{A}}_{41} *$ DOILREF_TAI $/ 10.77+\overline{\mathrm{A}}_{42} *$ DOILREF_THA $/ 43.43+\mathrm{A}_{43} *$ DOILREF_TUR $/ 28.39+\mathrm{A}_{44} *$ DOILREF_UAM $/ 11.86+\mathrm{A}_{45} *$ DOILREF_GBR $/ 55.16+\mathrm{A}_{46} *$ DOILREF_USA / 756.93)

\section{World trade index for tourism demand}

WTOUR $=\left(\right.$ WTOUR $(-1) *\left(\mathrm{~B}_{1} *\right.$ MS\$ ZAF $/$ MS\$ ZAF(-1) + $\mathrm{B}_{2} *$ MS\$ USA $/$ MS\$ USA(-1) + $\mathrm{B}_{3} *$ MS\$ CAN $/$ MS\$ CAN $(-1)+\mathrm{B}_{4} *($ MS\$ MEX) $/($ MS\$ MEX $(-1))$

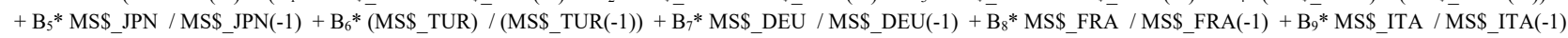
$+\mathrm{B}_{10}{ }^{*} \mathrm{MS} \$ \_$GBR $/$MS\$_GBR(-1)))

Here, we do not report numerical values of the coefficients from A1 to B10 due to data confidentiality, as they were obtained from OEGEM.

\section{Other balance of payment-related identities}

FDI\$OUT $=$ FDI\$OUT $(-1)^{*}(\operatorname{GDP} \$$ Z / GDP\$ Z(-1)) + DIS FDI\$OUT

FDI\$ $=$ FDI\$IN + FDI\$OUT

OTHCAP\$ $Z$ = NFDI\$ - PORT\$

BCAP\$ $=$ NFDI $\$$ FDI $\$$

BSER\$ $=$ XS\$ Z - MS\$ Z Z

$\mathrm{BVI} \$=\mathrm{XG} \$ \mathrm{Z}-\mathrm{MG} \$ \mathrm{Z}$

BVI\$_Z_MERCH $=$ XG\$_Z - MG\$_Z

PORT\$ $=$ PORT\$IN - PORT\$OUT

CROSS_DEPS $=$ CROSS_DEPS $(-1) * X G \$ Z Z / X G \$ Z Z(-1)+$ DIS_CROSS_DEPS 
LIAB_BIS_CON $=$ LIAB_BIS_CON $(-1)^{*}$ CROSS_LOANS / CROSS_LOANS $(-1)$

\section{Domestic prices block Consumer price indexes}

ECT_PPP $=$ LOG(CPI) $-(-0.5610 *$ LOG(NEER $)+0.8542 *$ LOG $($ WPC_WLD $)+3.2152)$

DLOG $($ CPICLOTH $)=0.002+0.14 *$ ECT_MD_R $+0.13 *$ DLOG $($ PMG $)+0.42 *$ DLOG $($ PGDPMANNO(-1) $)-0.31 *$ DLOG(GVAMANNO

$+0.34 * \operatorname{DLOG}(\mathrm{W}$ OLD $)+0.07 * \operatorname{DLOG}(\mathrm{GEXP}(-1))-0.05 * \mathrm{DP} 2000$

ECT_MD_R=LOG(M2(-1)) - $1 *$ LOG(GDP(-1)) - 1*LOG(PGDP(-1)) - 0.047*RLEND(-1) - 0.033*@TREND(50) + 7.46

DLOG $($ CPICOMM $)=-0.48-0.76 *$ ECT_CPICOM_ULC $(-1)+0.33 *$ DLOG $($ PMG $)+1.07 *$ DLOG $($ PGDPNOIL $)$

$-1.310 *$ DLOG(GVANOIL) $+0.14 *$ DLOG(WTRACOM $)+0.15 *$ DP2004

ECT_CPICOM_ULC=LOG(CPICOMM) $-(0.4625 *$ LOG(WTRACOM $)+0.6348 *$ LOG(PGDPNOIL) $-0.0411 * @$ TREND)

DLOG(CPIEDU $)=0.02-0.69 *$ ECT_CPIEDU_ULC $(-1)-0.38 *$ DLOG(GVAGOV) $-0.36 *$ DLOG(GVAGOV(-1)

$+0.04 *$ DLOG(GEXP(-1)) $-0.05 *$ DP2007 $+0.041 *$ DSH080910

ECT_CPIEDU_ULC=LOG(CPIEDU) $-\left(0.0731 *\right.$ LOG $\left(\mathrm{W} \_O L D\right)+0.3575 *$ LOG $($ PGDPSER $\left.)+2.2245\right)$

$\operatorname{DLOG}($ CPIFOOD $)=0.01-0.04 *$ ECT_PPP(-1) $+0.24 *$ DLOG $($ PMG $)+0.63 *$ DLOG $($ PGDPAGR $(-1))+0.41 *$ DLOG $($ PGDPAGR $)-0.21 *$ DLOG $($ GVAAGR $)+0.06 *$ DP2008

ECT_CPIHEAL_ULC=LOG(CPIHEAL) $-\left(0.46 *\right.$ LOG $($ PGDPSER $)+0.27 *$ LOG $\left(\mathrm{W} \_\right.$OLD $)+0.28-0.0078 * @$ TREND $-0.06 *$ DSHT2006 $)$

DLOG $($ CPIHH $)=0.02-0.10 *$ ECT_PPP(-1) $+0.16 *$ DLOG(PGDPMANNO) $-0.21 *$ DLOG(GVAMANNO) $-0.12 *$ DLOG $($ GVAMANNO(-1) $)+0.05 *$ DP2011 $-0.04 *$ DP2012

ECT_CPIHTL $=$ LOG $($ CPIHTL $)-(0.2229 *$ LOG $($ PMG $)+0.0929 *$ LOG $($ W_OLD $)+2.5551)$

DLOG(CPIMISC) $=0.11-0.07 *$ ECT_PPP(-1) $-0.73 *$ ECT_CPIMISC_ULC $(-1)+0.43 *$ GAP_GVAOTHS(-1) $+1.00 *$ DLOG(CPIMISC(-1))

$-1.62 * \operatorname{DLOG}(\operatorname{GVAOTHS}(-1))+0.04 * \operatorname{DLOG}($ WMAN(-1)) $+0.08 * \operatorname{DLOG}(\operatorname{GEXP}(-1))$

ECT_CPIMISC $=$ LOG $($ CPIMISC $)-(0.107 *$ LOG $($ WMAN $)+1.33 *$ LOG $($ PGDPNOIL $)-1.52-0.02 * @$ TREND $)$ 
DLOG(CPITRA $)=0.02+0.11 *$ ECT_MD_R $-0.08 *$ ECT_PPP $(-1)-0.13 *$ ECT_CPITRA_ULC $(-1)+0.14 *$ DLOG(PMG(-1)

$-0.21 *$ DLOG $($ GVATRACOM $)+0.10 *$ DLOG(PKER_TRA/PGDPNOIL*100) $+0.06 *$ DP2 2007

ECT_CPITRA_ULC $=$ LOG $($ CPITRA $)-(0.96 *$ LOG $($ PGDPTRACOM $)+0.33 *$ LOG $($ W_OLD $)-3.09)$

DLOG $($ CPIU $)=-0.006-0.27 *$ ECT_CPIU_ULC $(-1)+0.24 *$ DLOG $($ CPIU(-1) $)+0.14 *$ DLOG $($ PGDPU $)+0.08 *$ DLOG $($ GEXP $)+0.07 *$ DP2 $2011-0.04 *$ DP2006

ECT_CPIU_ULC $=$ LOG(CPIU) $-(0.3421 *$ LOG $($ WU $)+1.3222 *$ LOG $($ PGDPU $)+0.4965 *$ LOG $($ GEXP) $)-11.7286$

\section{Identity for the aggregate $\mathrm{CPI}$}

CPI $=0.1878 *$ CPIFOOD $+0.0068 *$ CPITOBC $+0.0620 *$ CPICLOTH $+0.2532 *$ CPIU $+0.0852 *$ CPIHH $+0.0234 *$ CPIHEAL $+0.0990 *$ CPITRA

$+0.0848 *$ CPICOMM $+0.0341 *$ CPIART $+0.0420 *$ CPIEDU $+0.0645 *$ CPIHTL $+0.0573 *$ CPIMISC + DIS_CP

\section{Equations for GDP deflators}

$\mathrm{IP}=(\mathrm{IP}(-1)) *($ GVAMAN / GVAMAN(-1)) + DIS_IP

DLOG $($ PGDPCON $)=0.02+0.34 *$ DLOG(PGDPNOIL $)+0.07 *$ DLOG(ULCCON $(-2))-0.42 *$ ECT_PGDPCON(-1) $+0.04 *$ DP2 2014

ECT_PGDPCON $=$ LOG(PGDPCON)-( 0.96*LOG(PGDPNOIL) +0.14 LOG(PDIS_IND) -0.57

DLOG $($ PGDPDIS $)=0.002+0.26 *$ DLOG(PGDPDIS(-1) $)+0.41 *$ DLOG(PGDPNOIL $)-0.23 *$ ECT_(PGDPDIS(-1) $+0.06 *$ DP $1984+0.04 *$ DP2008 + 0.04*DP2000 ECT_PGDPDIS $=$ LOG(PGDPDIS $)-(0.73 *$ LOG $($ PGDPNOIL $)+0.08 *$ LOG $($ PELE_COMM $)+0.59)$

ECT_PGDPFIBU=LOG(PGDPFIBU) $-($ (1.5*LOG(PGDPNOIL) + 0.11LOG(PE_FIBU) - 2.0- 0.02@TREND)

DLOG(PGDPMANNO) $=-0.01+0.79 *$ DLOG(PGDPNOIL) $+0.28 *$ DLOG(PGDPNOIL(-1)) $+0.30 *$ DLOG(PGDPNOIL(-2)) $-0.52 *$ ECT_PGDPMANNO(-1) $-0.05 *$ DP2009 ECT_PGDPMANNO= LOG(PGDPMANNO)-( $0.72 *$ LOG(PGDPNOIL $)+1.28+0.13 *$ DSH9293)

ECT_PGDPGOV=LOG(PGDPGOV) $-(0.79$ LOG $($ PGDPNOIL $)+0.13 *$ LOG $($ PELE_GOV $)-0.77+0.01 * @$ TREND

DLOG(PGDPOILREF $)=0.07-0.50 *$ ECT_PGDPOILREF(-1) $-0.34 *$ DP2015 $-0.34 *$ DP1998 + 0.28*DP2010

ECT_PGDPOILREF=LOG(PGDPOILREF)-( 0.79*LOG(PGDPOIL)+0.68*LOG(PCOIL_IND)+ 0.12*LOG(ULCOILREF)-2.82)

DLOG(PGDPOTHS $)=0.001+0.07 *$ DLOG(ULCOTHS(-1)) $+0.12 *$ GAP_GVAOTHS(-1) $-0.25 *$ ECT_PGDPOTHS(-1) $-0.03 *$ D(DP2007)

ECT_PGDPPTHS $=$ LOG(PGDPOTHS $)-(0.65 *$ LOG $($ PGDPNOIL $)+0.04 *$ LOG $($ PE_OTHS $)+1.42-0.04 *$ DP2007)

DLOG $($ PGDPTRACOM $)=-0.01+0.45 *$ DLOG $($ PGDPNOIL $)+0.05 *$ DLOG $($ PE_TRACOM $)+0.08 *$ DLOG(ULCTRACOM $)-0.18 *$ ECT_PGDPTRACOM $(-1)+0.15 *$ DP2000

ECT_PGDPTRACOM $=$ LOG $($ PGDPTRACOM $)-(0.12 *$ LOG $($ PGDPNOIL $)+0.24 *$ LOG $($ PE_TRACOM $)+2.53)$

DLOG $($ PGDPU $)=0.02+0.29 *$ DLOG(PGDPNOIL $)+0.14 *$ DLOG $($ PE_U $)+0.03 *$ DLOG(ULCU $)+0.11 *$ GAP_GVAU- 0.98*ECT_PGDPU(-1) $-0.05 *$ D(DP2008)

ECT_PGDPU=LOG(PGDPU)-( 0.32*LOG(PGDPNOIL) + 0.14*LOG(PE_U) + 0.09*LOG(ULCU) + 2.04- 0.04*DP2008) 


\section{Identities for energy prices}

PE_CON $=($ DGAS_TRA $/($ DEN_TOT_TRA + DELE_CPS + DELE_IND $)) *$ PGAS_TRA $+($ DDIS_TRA $/($ DEN_TOT_TRA + DELE_CPS + DELE_IND $))$

$*$ PDIS_TRA + (DKER_TRA / (DEN_TOT_TRA + DĒLE_CPS + DELEE_IND)) * PKER_TRA + (DELEE_CPS / (DEN_TOT_TRA + DELE_CPS + DELE_IND)

* PELE_CPS + (DELE_IND / (DEN_TOT_TRA + DELE_CPS + DELE_IND)) * PELE_IND

PE GOV $=($ DELE CPS $/($ DELE CPS + DGAS TRA + DDIS_TRA $)) *$ PELE_CPS + (DGAS_TRA / (DELE_CPS + DGAS TRA + DDIS TRA $))$

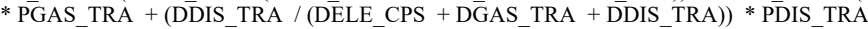

PE MANNO $=($ DCOIL IND $/($ DEN TOT IND + DGAS TRA + DDIS TRA $)) *$ PCOIL IND + (DDIS IND $/($ DEN TOT IND + DGAS TRA + DDIS TRA $))$

* PDIS IND + (DHFO IND / (DEN TOT IND + DGAS TRA + DDIS TRA)) * PHFO IND + (DOTH IND / (DEN TOT IND + DGAS TRA + DDIS TRA))

$*$ POTH_IND + (DNGA_IND / (DEN_TOT_IND + DGAS_TRA + DDIS_TRA $)) *$ PNGA_IND + (DELE_IND $/($ DEN_TOT_IND + DGAS_TRA + DDIS_TRA $)$

$*$ PELE_IND $+($ DGAS_TRA / (DEN_TOT_IND + DGAS_TRA + DDIS_TRA) $) *$ PGAS_TRA + (DDIS_TRA / (DEN_TOT_IND + DGAS_TRA + DDIS_TRA)) * PDIS_TRA

PE_OILREF $=($ DCOIL_IND $/($ DCOIL_IND + DELE_IND $)) *$ PCOIL_IND $+($ DELE_IND $/($ DCOIL_IND + DELE_IND $)) *$ PELE_IND

PE TRACOM $=($ DGAS TRA $/($ DEN TOT TRA + DELE CPS $)) *$ PGAS TRA + (DDIS TRA $/($ DEN TOT TRA + DELE CPS $))$

$*$ PDIS TRA + (DKER TRA / (DEN TOT TRA + DELE CPS)) * PKER TRA + (DELE CPS / (DEN TOT TRA + DELE CPS)) * PELE CPS

PE_U $=($ DCOIL_IND $/($ DEN_TOT_IND) $) *$ PCOIL_IND + (DDIS_IND / (DEN_TOT_IND) $) *$ PDIS_IND + (DHFO_IND / (DEN_TOT_IND) $)$

$*$ PHFO_IND $+($ DOTH_IND $/($ DEN_TOT_IND) $) *$ POTH_IND + (DNGA_IND $/($ DEN_TOT_IND $)) *$ PNGA_IND + (DELE_IND $/($ DEN_TOT_IND) $) *$ PELE_IN

\section{Labor and wages block Equations for sectoral employment}

DLOG(ETAGR) $=0.04-0.57 *$ ECT_ETAGR(-1) $+1.98 *$ DLOG(GVAAGR)-0.78*DLOG(WAGR/PGDPAGR*100)- 0.17*DLOG(ETAGR(-1)

ECT_ETAGR=LOG(ETAGR) $-(0.93 *$ LOG(GVAAGR $)-0.78 *$ LOG(WAGR/PGDPAGR*100) + 0.91+ 0.03*@TREND)

DLOG(ETCON)=-0.02-0.26*ECT_ETCON(-1) -0.69*DLOG(WCON/PGDPCON*100)-0.15*D(DP2008)-0.14*D(DP2009)-0.27*DP2003-0.23*DLOG(ETCON(-2))

ECT CON=LOG(ETCON $)-(1.06 * \operatorname{LOG}(\mathrm{GVACON})+0.55 * \mathrm{LOG}($ WCON/PGDPCON*100)-0.59)

DLOG(ETDIS) $=0.03-0.96 *$ ECT ETDIS(-1) + 0.19*DLOG(GVADIS)+ 0.23*DLOG(GVADIS(-2))- 0.53*DLOG(WDIS/PGDPDIS*100)

$-0.13 *$ DLOG(WDIS(-1)/PGDPDIS(-1) *100)+ 0.43*DLOG(ETDIS(-2))- 0.09*DP2013

ECT_ETDIS= LOG(ETDIS) $-(0.26 *$ LOG(GVADIS) $-0.38 *$ LOG(WDIS/PGDPDIS*100)+7.87)

DLOG $($ ETFIBU $)=0.002-0.48 *$ ECT_ETFIBU $(-1)-0.39 *$ DLOG $($ WFIBU/PGDPFIBU $* 100)-0.16 *$ DP2013

ECT_ETFIBU $=$ LOG(ETFIBU) $-(0.65 *$ LOG(GVAFIBU) $-0.52 *$ LOG(WFIBU/PGDPFIBU*100) + 3.5)

$\operatorname{DLOG}($ ETGOV $)=0.007-0.20 *$ ECT ETGOV $(-1)+0.68 *$ DLOG $($ GVAGOV $)+0.07 *$ DP2013 + $0.06 *$ DP2008

ECT_ETGOV=LOG(ETGOV_SAMA)-(1.28*LOG(GVAGOV)- 0.25*LOG(GWSA_Z/PGDPGOV*100)- 6.09)

DLOG(ETMANO) $=0.02-0.13 *$ ECT_ETMANNO(-1) $-0.21 *$ DLOG $($ WMAN $* 100 /$ PGDPMAN $)+0.12 *$ DLOG(WMAN(-1)* 100/PGDPMAN $(-1))$

$+0.11 *$ DLOG(ETMANNO(-1)) $-0.39 *$ DP $1983-1.03 *$ DP1984- 0.35*DB1011 + 0.18*DP2001

ECT_ETMANNO $=$ LOG $($ ETMANNO $)-(0.27 *$ LOG $(G V A M A N N O)-1.52 *$ LOG $($ WMAN*100/PGDPMAN $)+16.97)$

DLOG(ETOTHS) $=0.001-1.44 *$ ECT_(ETOTHS_FFF(-1) $)+0.76 *$ DLOG(GVANOIL)- 0.45*DLOG(W_CEIC/PGDPOTHS*100)- 0.07*D(DP2009)+ 0.07*D(DP2014)

ECT_ETOTHS= LOG(ETOTHS) $-(1.11 *$ LOG(GVAOTHS) $-0.60 *$ LOG(W_CEIC/PGDPOTHS*100)+1.46-0.09*DP2009+0.10*DP2014)

DLOG $($ ETMINOTH $)=0.03-0.13 *$ ECT_ETMINOTH(-1) $-0.19 *$ DLOG $($ WMIN $* 100 /$ PGDPMINOTH $)-0.18 *$ DB0910 + 0.17*DB1415 + 0.12*DP2002

ECT ETMINOTH: LOG(ETMINOTH)-(0.23*LOG(GVAMINOTH)-1.61*LOG (WMIN/PGDPMINOTH*100)+21.9)

DLOG $($ ETTRACOM $)=0.05-0.09 *$ ECT_ETTRACOM(-1) $-0.09 *$ DLOG(WTRACOM/PGDPTRACOM*100)-0.14*DP2012+0.11*DP2007 - $0.08 *$ DB1314

ECT_TRACOM $=$ LOG(ETTRACOM) $-(0.65 *$ LOG $($ GVATRACOM $)-0.85 *$ LOG $($ WTRACOM/PGDPTRACOM*100 $)+7.53)$

$\mathrm{DLOG}(\mathrm{ETU})=-0.35 * \mathrm{ECT}$ ETU(-1) $-0.19 * \mathrm{DLOG}(\mathrm{WU} / \mathrm{PGDPU} * 100)+0.55 * \mathrm{DLOG}(\mathrm{GVAU})+0.20 * \mathrm{DB} 1415-0.21 * \mathrm{DB} 1213+0.14 * \mathrm{DP} 2009$

ECT ETU $=$ LOG(ETU) $-(0.42 *$ LOG(GVAU $)-0.49 *$ LOG(WU/PGDPU*100) +5.68$)$ 


\section{Identities for labor market}

$\mathrm{ET}=\mathrm{ETNOIL}+\mathrm{ETOIL}+$ DIS_ET

$\mathrm{ETP}=\mathrm{ETPS}+\mathrm{ETPNS}$

$\mathrm{ETNOIL}=\mathrm{ETGOV}+\mathrm{ETAGR}+\mathrm{ETU}+\mathrm{ETCON}+\mathrm{ETMANNO}+\mathrm{ETMINOTH}+\mathrm{ETDIS}+\mathrm{ETTRACOM}+\mathrm{ETFIBU}+\mathrm{ETOTHS}+\mathrm{DIS} \_$ETNOIL

$\mathrm{ETOIL}=$ ETMANO + ETOILMIN

ETSER $=$ ETDIS + ETTRACOM + ETFIBU + ETOTHS + ETGOV

\section{Identities for unit labor cost by economic activity}

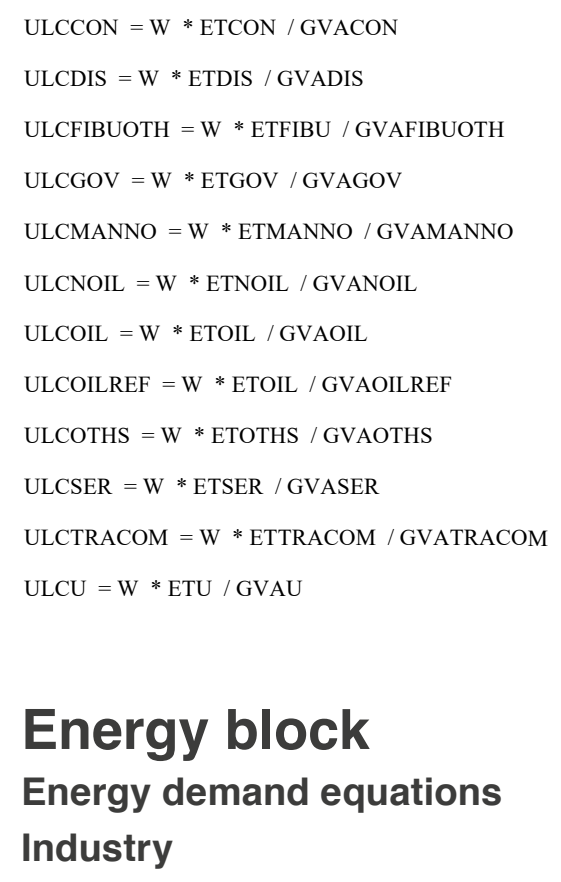

$\mathrm{ULCGOV}=\mathrm{W} *$ ETGOV $/$ GVAGOV

\section{Energy block}

\section{Energy demand equations Industry}

DLOG $($ DCOIL_IND) $=-0.08+0.39 *$ DLOG(DCOIL_IND(-1) $)+2.06 *$ DLOG(GVAIND(-1) $)-1.59 *$ DLOG(PCOIL_IND/PGDPIND*100)

$-1.16 *$ ECT DCOIL IND(-1) + $1.15 *$ DP2009 $-0.50 *$ DP2 2006

ECT_DCOIL_IND=LOG(DCOIL_IND) $-(0.81 *$ LOG(GVAIND) $-0.77 *$ LOG(PCOIL_IND/PGDPIND*100)

ECT_DDIS_IND =LOG(DDIS_IND) $-(-0.13 *$ LOG(PDIS_IND/PGDPMANNO*100) + 0.18*LOG(GVAMANNO) $-1.84+0.04 * @$ TREND)

DLOG(DELE_IND) $=-0.15-0.11 *$ DLOG(PELE_IND/PGDPMANNO*100) $-0.95 *$ ECT_DELE_IND(-1) $+7.41 *$ DLOG(POP1564) $-0.30 *$ DSH050607 + 0.61*DP1990 - 0.17*DP2004 
DLOG(DOTH_IND) $=-0.01+0.09 *$ DLOG(DOTH_IND(-2) $)+0.23 *$ DLOG $(G V A M A N N O(-1))-0.16 *$ DLOG(POTH_IND/PGDPMANNO*100) $+0.83 *$ DLOG(NGL) $-0.97 *$ ECT_DOTH_IND(-1) $+0.16 *$ DP1993

ECT DOTH IND $=$ LOG(DOTH IND) $-(0.14 *$ LOG(GVAMANNO) $-0.11 *$ LOG(POTH IND/PGDPMANNO*100) $+0.98 *$ LOG(NGL) -8.66$)$

\section{Transport}

DLOG $($ DDIS_TRA $)=0.01-0.25 *$ DLOG(DDIS_TRA(-2) $)+0.73 *$ DLOG $($ GVANOIL $)-0.09 *$ DLOG(PDIS_TRA(-1)/PGDPNOIL(-1)*100) $-0.30 *$ ECT_DDIS_TRA(-1) $-0.24 *$ DP1995

ECT_DDIS_TRA $=$ LOG(DDIS_TRA) $-(0.70 *$ LOG(GVANOIL) $-0.15 *$ LOG(PDIS_TRA/PGDPNOIL*100) -6.07$)$

DLOG $($ DGAS_TRA $)=0.03-0.09 *$ DLOG $($ PGAS_TRA/CPI*100) $-0.57 *$ ECT_DGAS_TRA(-1) $-0.14 *$ DP1989

DLOG(DKER_TRA $)=-0.03-0.12 *$ DLOG $($ PKER_TRA(-1)/PGDPNOIL $(-1) * 100)-0.24 *$ ECT_DKER_TRA(-1) $+0.12 *$ DP2015 + 0.08*DP2000

ECT_DKER_TRA $=$ LOG(DKER_TRA) $-(0.30 *$ LOG(GVANOIL) $-0.10 *$ LOG(PKER_TRA/PGDPNOIL*100) -3.71$)$

\section{Residential}

DLOG(DELE_RES/POP) $=0.004-0.09 *$ ECT_DELE_RES(-1) $-0.13 *$ DLOG(PELE_RES_INV*100/CPI) $-0.19 *$ DLOG(PELE_RES_INV(-1)*100/CPI(-1))

$+0.33 *$ DLOG(GVANOIL(-2)/POP(-2)) + 0.57*DLOG(DELE RES(-2)/POP(-2)) + 0.09*DSH9900 + 0.06*DP2006

ECT_DELE_RES $=$ LOG(DELE RES/POP) $-(-0.35 *$ LOG(PELE RES INV*100/CPI $)+1.01 *$ LOG $($ GVANOIL/POP $)-9.51+0.27 *$ DSH0002)

DLOG $($ DKER_RES $)=0.04-0.13 *$ DLOG(PKER_RES/CPI*100) $-0.58 *$ ECT_DKER_RES(-1) $-0.15 *$ DP1998

ECT DKER_RES $=$ LOG(DKER RES) $-(0.43 *$ LOG(GVANOIL $)-0.20 *$ LOG(PKER_RES/CPI*100) $+0.39 *$ LOG(POP) $-9.75+0.51 *$ DSH9091)

DLOG(DLPG RES $)=0.04-0.20 *$ ECT DLPG RES(-1) $-0.09 *$ DLOG(PLPG_RES/CPI*100) $+0.16 *$ DP2011 $-0.13 *$ DSH121314

ECT_DLPG_RES $=$ LOG(DLPG_RES) $-0.27 *$ LOG $($ GVANOIL $)+0.17 *$ LOG $($ PLPG_RES/CPI*100) +2.53$)$

\section{Commercial and public services}

$\operatorname{DLOG}($ DELE_COMM $)=0.09-0.20 *$ DLOG $($ PELE_COMM $(-2) /$ PGDPTRACOM $(-2) * 100)-0.72 *$ ECT_DELE_COMM(-1) $+0.12 *$ DP2012 $+0.10 *$ DP2003

ECT DELE COMM $=($ LOG(DELE COMM $)-(0.25 *$ LOG(GVATRACOM $)-0.18^{*}$ LOG(PELE COMM/PGDPTRACOM*100) $-5.45+0.08 * @$ TREND $)$

DLOG $($ DELE GOV $)=-2.68+1.03 *$ DLOG $($ DELE GOV(-2) $)-0.06 *$ DLOG(PELE GOV(-1)/PGDPNOIL(-1)*100) $-0.33 *$ ECT DELE GOV(-1) $-0.09 *$ DP2012 $-0.08 *$ DP2005 ECT_DELE_GOV $=$ LOG(DELE_GOV) $-(0.61 *$ LOG(GVANOIL) $-0.07 *$ LOG(PELE_GOV/PGDPNOIL*100) + 0.02*@TREND)

\section{Agriculture and forestry}

DLOG $($ DELE_AGR $)=0.05-0.30 *$ DLOG $($ ETAGR $)-0.23 *$ DLOG $($ ETAGR $(-1))-0.31 *$ ECT_DELE_AGR(-1) $-0.11 * \mathrm{D}($ DP2003) $+0.31 *$ DB0910

ECT_DELE_AGR $=$ LOG(DELE_AGR) $-(0.80 *$ LOG(GVAAGR $)-0.63 *$ LOG(PELE_AGR/PGDPAGR*100) $-0.70 *$ LOG(ETAGR) - 4.89+ 0.08*@TREND - 0.27*DP2003) 


\section{Energy demand identities feeding into the GVA equations by economic activity}

DEN GOV $=$ DELE GOV+DELE COMM + DGAS TRA + DDIS TRA

Consumption of energy products in million Saudi riyals (SAR) Industry

CCOIL_IND $=$ DCOIL_IND $*$ PCOIL_IND

\section{Residential}

CLPG_RES $=$ DLPG_RES $*$ PLPG_RES

\section{Transport}

CGAS TRA $=$ DGAS TRA $*$ PGAS TRA 
Commercial and public services and agriculture and forestry

CELE_CPS $=$ DELE_CPS $*$ PELE_CPS

CELE_AGR $=$ DELE_AGR $*$ PELE_AGR (284)

CEN_TOT_CPA $=$ CELE_CPS + CELE_AGR

\section{Entire economy}

CEN_TOT $=$ CEN_TOT_IND + CEN_TOT_RES + CEN_TOT_TRA + CEN_TOT_CPA

\section{Population and age cohorts block}

\section{Identities for population and age cohorts}

POPS $=$ POPSM + POPSF

POPNS $=$ POPNSM + POPNSF

POP014 = POPM014 + POPF014

POP2529 $=$ POPM2529 + POPF2529

POP4549 $=$ POPM4549 + POPF4549

Identities for investments and capital stocks (this subsection is part of the Real block above)

$\mathrm{IF}=\mathrm{IFOIL}+\mathrm{IFNOILP}+\mathrm{GI}$ 


\section{KGEMM Simulations}

A s mentioned earlier, MEMs are evaluated and validated using in-sample and out-ofsample simulations, and policy analysis, among other validation methods. In this section, we run KGEMM for in-sample forecasting and policy analysis to evaluate its predictive ability. Hasanov and Joutz (2013) provide an overview of the literature that covers in-sample and out-of-sample forecasts, and other methods for evaluating the predictive ability of MEMs. This includes Calzolari and Corsi (1977), Beenstock et al. (1986), Klein et al. (1999), Fair (1984, 1994, 2004), Bårdsen and Nymoen (2008).

MEMs can be run using either the static simulation method, in which a model takes historical lagged values or the dynamic simulation method, in which a model takes predicted lagged values. The predicted lagged values are the combination of historical lagged values and any errors in the model's predictions. The smaller the prediction errors of the model, the better the model can perform/approximate in simulations. Therefore, it would be advisable to run the model with dynamic simulation to see how significant or insignificant its prediction errors are in simulating the in-sample or out-of-sample values of the endogenous variables. Static, dynamic, deterministic and stochastic MEM simulation methods have been comprehensively discussed in Klein et al. (1999) and Fair (1984, 1994, 2004), among others. This section employs the dynamic simulation method.

\section{In-sample simulation}

As mentioned previously, an in-sample simulation exercise is an evaluation/validation method to check how well a model can approximate historical data. We run KGEMM for the period 1998-2018 to check its in-sample predictive ability of the historical data. ${ }^{5}$
The results of the in-sample simulations are plotted in Appendix C. The Appendix illustrates only selected key endogenous variables from each block. Interested readers can refer to the details of the in-sample forecasting results for each of the variables in Appendix C. However, a visual inspection of the figures shows that the model closely approximates the historical time path of the endogenous variables. It performs especially well in capturing the historical turning points and sudden changes of the indicators.

It can be concluded that KGEMM's in-sample predictive ability for the historical values of the endogenous variables is quite high. The literature suggests that if a model successfully approximates historical developments, then there is a high probability that the model will also perform well in out-of-sample simulations or policy analyses.

\section{Out-of-sample simulation: Effects of the EPR on the macroeconomy}

This sub-section uses KGEMM to simulate the macroeconomic effects of policy changes. It should first be stated that these simulations aim to test the model's ability to address policy changes, but not to make recommendations on policy decisions. Different policies can be simulated in KGEMM. Here, we consider Saudi Arabia's energy price reform (EPR) for two reasons. The first is that the EPR is one of the key ongoing initiatives of SV2030's Fiscal Balance Program (FBP), the objective of which is to achieve an efficient consumption of the country's energy resources (SV2030 2019a). The second reason is that KGEMM has a detailed energy block, unlike conventional MEMs.

(5) The reason for starting in 1998 is due to fact that the data for some variables in the model is only available from that year. We run the second version of KGEMM in this section. 
We simulate KGEMM for two scenarios. The first is the business as usual (BaU) scenario and the second is the EPR implementation scenario, which we call Scenario 1 (S1). The scenario analysis covers the period 2019-2025. The analysis ends in 2025 because the revisions to the FBP in 2017 and 2018 highlight that the EPR, i.e., the gradual removal of domestic energy subsidies to reach reference prices, will continue until 2025 (SV2030 2017, 2018).

In the $\mathrm{BaU}$, it is assumed that the Saudi Arabian economy moves forward as it did in 2018. This means that the $\mathrm{BaU}$ includes the fiscal reform items of 2017 and 2018 in order to provide more realistic simulations. These items include a 5\% value added tax, expat levies, Umrah and Hajj visa fees, other visa fees, traffic fines, an idle land tax, a luxury goods tax, other non-oil revenues, as well as household and industry support, as communicated in official documents. Budget expenditures are treated exogenously in $\mathrm{BaU}$ since they have to take the respective values for each year of the period under consideration, in line with SV2030 (2019a) assumptions.
In $\mathrm{S} 1$, everything is the same as in $\mathrm{BaU}$, except for the assumption that the domestic prices of energy products will increase twofold by 2025 . Table 2, below, reports Saudi Arabia's energy products and their domestic prices in 2018.

For brevity, we use non-oil value added and CPI inflation as macroeconomic indicators.

Figure 3 illustrates the $\mathrm{BaU}$ and $\mathrm{S} 1$ simulation results for the aforementioned indicators.

The figure shows that non-oil GDP has lower values in the EPR scenario compared to the BaU. However, the growth rates of the variable are positive over the period in both scenarios. The lower values in the EPR scenario are expected. This is caused by both supply-side and demand-side factors. From the supply-side, EPR increases the production cost of the goods and services in the economy, in line with the share of energy in the total production cost.

There are two options that producers can follow when they face higher production costs. First, they

Table 2. Energy products in KGEMM and their domestic prices in 2018.

\begin{tabular}{|c|c|c|c|c|c|}
\hline Energy product & US\$/L & Energy product & US\$/L & Energy product & US\$/L \\
\hline Industry crude oil & 0.04 & Residential LPG & 0.20 & Transport gasoline & 0.41 \\
\hline Industry diesel & 0.13 & Residential keros & 0.17 & Transport diesel & 0.10 \\
\hline Industry HFO & 0.02 & Residential electri & $y 0.05^{*}$ & Transport kerosene & 0.17 \\
\hline Industry electricity & $0.05^{\star}$ & & & $\begin{array}{l}\text { Commercial and } \\
\text { public services } \\
\text { electricity }\end{array}$ & $0.07^{*}$ \\
\hline Industry natural gas & $1.25^{\star \star}$ & & & $\begin{array}{l}\text { Agricultural and } \\
\text { forestry electricity }\end{array}$ & $0.05^{\star}$ \\
\hline $\begin{array}{l}\text { Industry other } \\
\text { products }\end{array}$ & 0.25 & & & & \\
\hline
\end{tabular}


Figure 3. Macroeconomic effects of EPR.
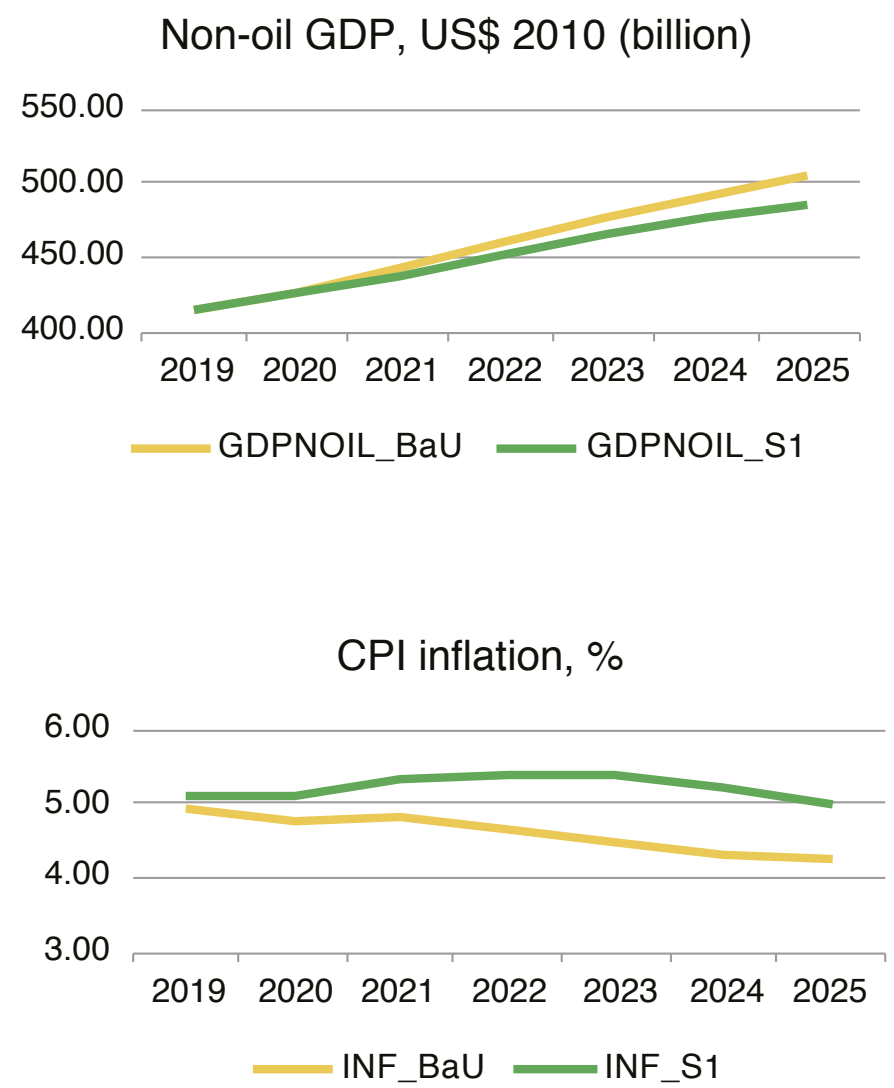

can maintain the same volume of production but increase the prices for their goods and services. Higher prices will lead to lower consumer demand and, consequently, a decline in production compared to BaU. Second, producers adjust, i.e., decrease production volumes according to the increased costs coming from the direct and indirect effects of the EPR.

$\mathrm{CPI}$ inflation is higher in the EPR scenario than in $\mathrm{BaU}$, as Figure 3 shows. The explanation for nonoil GDP can also be used to explain the higher CPI inflation in the EPR scenario compared to BaU. Increased domestic prices of the energy products can increase inflation in two ways. The first is that higher energy product prices result in higher production costs and, thus, higher producer prices (the consumer price is a markup on the producer cost/price). The second is that some energy products, such as electricity, gasoline, and diesel, are components of the consumer basket. Evidently, the higher the prices of these energy products, the higher the CPI. Figure 3 shows that inflation in the EPR scenario has an inverted U-shaped pattern, i.e., it increases until the middle of the EPR period (2020); it then decreases but remains higher than $\mathrm{BaU}$ inflation. One of the explanations for such a pattern is lower demand in the EPR scenario compared to $\mathrm{BaU}$. In the early years of the EPR, inflation rises in accordance with energy prices. Over time, the EPR lowers aggregate demand in the economy, as explained above, and reduced demand will, in turn, drive inflation down in the EPR scenario but it is expectedly higher than that in BaU. 
Figure 3 shows that the EPR will lower non-oil GDP while increasing inflation. This is to be expected from the EPR in the short run, such as the period 2019-2025. Assessments indicate that the economy will benefit from the EPR and other reforms in the long run. For example, our extended assessment until 2040 clearly shows that non-oil GDP in the EPR scenario will overtake that of BaU, while inflation in the EPR scenario settles close to the BaU scenario, as Figure 4 illustrates.

The higher non-oil GDP in the EPR scenario compared to the $\mathrm{BaU}$ scenario can be mainly explained by investment and efficiency effects. Notably, the EPR, fiscal and other reforms will increase government revenues, which will be invested in developing the non-oil sector, the main goal of SV2030. Efficiency effects assume that the reforms will make the economic agents behave rationally and be more efficient, leading to lower costs and higher outputs in the long run. We think the main reason that inflation in the EPR scenario settles near to the BaU level is the completion of the EPR and other reforms by 2025.

To conclude, the EPR would burden the economy in the short run. However, the economy will gain from it in the long run, mainly through increased investments and greater efficiency.

Figure 4. Non-oil GDP and inflation (2019-2040).
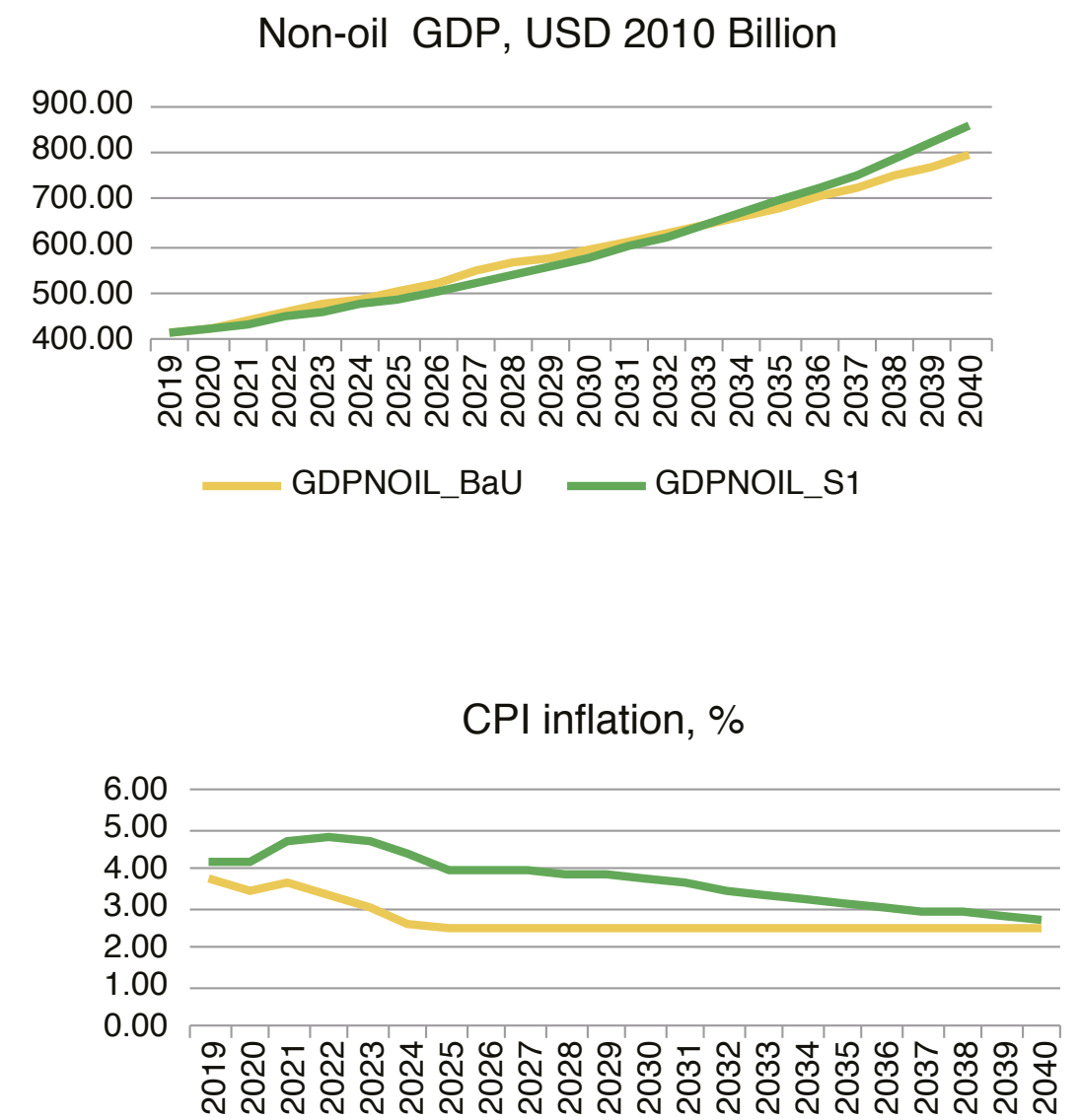

$=$ INF_BaU INF_S1 


\section{References}

Ackerman, Frank. 2002. "Still dead after all these years: interpreting the failure of general equilibrium theory." Journal of Economic Methodology 9(2): 119-139.

Alam, M. Shahid. 1982. "The basic macroeconomics of oil economies." The Journal of Development Studies 18(2): 205-216.

Arora, Vipin. 2013. "An Evaluation of Macroeconomic models for use at EIA." U.S. Energy Information Administration.

Banerjee, Abhijit V. 1992. "A simple model of herd behavior." The Quarterly Journal of Economics 107(3): 797-817.

Bårdsen, Gunnar, and Ragnar Nymoen. 2008. "Macroeconometric modelling for policy." Working Paper, 30 April.

Bårdsen, Gunnar, Øyvind Eitrheim, Eilev S. Jansen, and Ragnar Nymoen. 2005. The Econometrics of Macroeconomic Modelling. Oxford: Oxford University Press.

Bårdsen, Gunnar, Eilev S. Jansen, and Ragnar Nymoen. 2004. "Econometric evaluation of the New Keynesian Phillips curve." Oxford Bulletin of Economics and Statistics, 66 (s1), 611-686.

Bayoumi Tamim, Hamid Faruqee, Douglas Laxton, Philippe D. Karam, Alessandro Rebucci, Jaewoo Lee, Ben Hunt, and Ivan Tchakarov. 2004. "GEM: A new international macroeconomic model." International Monetary Fund, 239.

Beenstock, Michael, Peter Warburton, Paul Lewington, and Alan Dalziel. 1986. "A macroeconomic model of aggregate supply and demand for the UK." Economic Modelling 3 (4): 242-268.
Bjerkholt, Olav. 1993. "Reviews of Macroeconomic Modeling Needs of the Ministry of Economy and Planning in the Kingdom of Saudi Arabia." Research Department, Statistics Norway 93: 25.

Blanchard, Olivier. 2018. "On the future of macroeconomic models." Oxford Review of Economic Policy 34 (1-2): 43-54.

Blazquez, Jorge, Lester C. Hunt, and Baltasar Manzano. 2017. "Oil subsidies and renewable energy in Saudi Arabia: A general equilibrium approach." The Energy Journal 38 no. S11: 29-45.

Bontemps, Christophe, and Grayham E. Mizon. 2008. "Encompassing: Concepts and Implementation." Oxford Bulletin of Economics and Statistics 70: 721-750.

Bodkin, Ronald G., Lawrence R. Klein, and Kanta Marwah. 1991. A History of Macroeconometric Model-Building. Edward Elgar Publishing, number 51.

Boulanger, Paul-Marie, and Thierry Bréchet. 2005. "Models for policy-making in sustainable development: The state of the art and perspectives for research." Ecological Economics 55(3): 337-350.

Calzolari, Giorgio, and Paolo Corsi. 1977.

"Stochastic simulation as a validation tool for econometric models." Published in Models for regional planning and policy-making: proceedings of the joint IBM/IIASA conference: 359-369.

Campos Julia, Ericsson R. Neil, and Hendry F. David. 2005. "General-to-specific Modeling: An Overview and Selected Bibliography." Board of Governors of the Federal Reserve System, International Finance Discussion Papers, No. 838 August. 
Cappelen, Ådne, and Knut A. Magnussen. 1996.

"The Selection Model: A General Equilibrium Model for Saudi Arabia." Research Department, Statistics Norway 96(14).

Clements, Michael P., and David F. Hendry. 2011. "Forecasting from Mis-specified Models in the Presence of Unanticipated Location Shifts." In Oxford Handbook of Economic Forecasting: Michael P. Clements and David. F. Hendry (eds.), 271-314. Oxford: Oxford University Press

Cobb, Charles W., and Paul H. Douglas. 1928. "A theory of production." The American Economic Review 18(1): 139-165.

Colander, David. 2006. Post Walrasian Macroeconomics: Beyond the dynamic stochastic general equilibrium model. Cambridge: Cambridge University Press.

Colander, David, Peter Howitt, Alan Kirman, Axel Leijonhufvud, and Perry Mehrling. 2008. "Beyond DSGE models: toward an empirically based macroeconomics." American Economic Review 98 (2): 236-40.

Coletti, Donald, and Stephen Murchison. 2002. "Models in policy-making." Bank of Canada Review Summer: 19-26.

Davidson, James E.H., David F. Hendry, Frank Srba, and Stephen Yeo. 1978. "Econometric modelling of the aggregate time series relationships between consumers' expenditure and income in the United Kingdom." Economic Journal 88, (352) 661-692. https://doi.org/10.2307/2231972

De Brouwer, Gordon, and Neil R. Ericsson. 1995. "Modelling inflation in Australia." International Finance Discussion Papers 530.
De Santis, Roberto A. 2003. "Crude oil price fluctuations and Saudi Arabia's behaviour." Energy Economics 25(2): 155-173. https://doi.org/10.1016/ S0140-9883(02)00106-8

Dickey, David A., and Wayne A. Fuller. 1981. "Likelihood Ratio Statistics for Autoregressive Time Series with a Unit Root." Econometrica 49. (4)

Doornik, Jurgen A, 2009. "Autometrics." The Methodology and Practice of Econometrics: A Festschrift in Honour of David F. Hendry.

Doornik, Jurgen A. and David F. Hendry. 2009. Modelling Dynamic Systems: PcGive Volume II. London: Timberlake Consultants.

Doornik Jurgen A., and David F. Hendry. 2018. Empirical Econometric Modelling, PcGive 15. London: Timberlake Consultants.

Douglas, Paul H. 1976. "The Cobb-Douglas production function once again: its history, its testing, and some new empirical values." Journal of Political Economy 84(5): 903-915.

Enders, Walter. 2015. "Applied Econometrics Time Series." Wiley Series in Probability and Statistics. Tuscaloosa, AL, USA: University of Alabama.

Engle, Robert F., and David F. Hendry. 1993. "Testing superexogeneity and invariance in regression models." Journal of Econometrics 56(1-2): 119-139. https://doi. org/10.1016/0304-4076(93)90103-C

Engle, Robert F., David F. Hendry, and Jean-Francois Richard. 1983. "Exogeneity." Econometrica: 51(2): 277-304. 
Engle, Robert F., and Clive W.J. Granger. 1987. "Co-integration and error correction: Representation, estimation and testing." Econometrica 55:(2) 251-276.

Ericsson, Neil R. 1992. "Parameter constancy, mean square forecast errors, and measuring forecast performance: An exposition, extensions, and illustration." Journal of Policy Modeling 14(4): 465-495.

- - . 1993. "On the limitations of comparing mean square forecast errors: Clarifications and extensions." Journal of Forecasting 12(8) 644-651.

Ericsson, Neil R., and John S. Irons, eds. 1994. Testing Exogeneity. Oxford University Press.

- - - 1995. "The Lucas critique in practice." Macroeconometrics, ed. Hoover K.D. Recent Economic Thought Series, vol 46. Springer, Dordrecht 263-324.

Ericsson, Neil R., Julia Campos, and HongAnh Tran. 1990. "PC-GIVE and David Hendry's Econometric Methodology." Revista de Econometria 10: 7-117

Ezzati, Ali. 1976. "Future OPEC price and production strategies as affected by its capacity to absorb oil revenues." European Economic Review. 8(2): 107-138.

Fair, C. Ray. 1984. Specification, Estimation, and Analysis of Macroeconometric Models. Harvard University Press.

---. 1994. Testing Macroeconometric Models. Cambridge, Massachusetts, and London, England: Harvard University Press.
--- 2004. Estimating How The Macroeconomy Works. Cambridge, Massachusetts, and London, England: Harvard University Press

- - . 2019. "Some Important Macro Points." Cowles Foundation Discussion Paper no. 2165.

Favero, Carlo A. 2001. Applied Macroeconometrics. Oxford University Press.

Favero, Carlo, and F. David Hendry. 1992. "Testing the Lucas critique: A review." Econometric Reviews 11(3): 265-306.

Gonand, Frédéric, Fakhri J. Hasanov, and Lester C. Hunt. 2019. "Estimating the impact of energy price reform on Saudi Arabian intergenerational welfare using the MEGIR-SA model." The Energy Journal 40(3): 55-77.

Haavelmo, Trygve. 1943a. "Statistical testing of business-cycle theories." The Review of Economic Statistics: 25(1) 13-18.

Haavelmo, Trygve. 1943b. "The statistical implications of a system of simultaneous equations." Econometrica 11(1): 1-12.

Haavelmo, Trygve. 1944. "The probability approach in econometrics." Econometrica (12)1-115.

Hansen, Peter Reinhard. 2000. "Structural changes in cointegrated processes." Ph.D. thesis, University of California, San Diego.

Hara, Naoko, Hibiki Ichiue, Satoko Kojima, Koji Nakamura, and Toyoichiro Shirota. 2009. "Practical use of macroeconomic models at central banks."

Bank of Japan Review No. 09-E-1.

Harvey, David, and Paul Newbold. 2000. "Tests for multiple forecast encompassing." Journal of Applied Econometrics (5): 471-482. 
Harvey, David I., Stephen J. Leybourne, and Paul Newbold. 1998. "Tests for forecast encompassing." Journal of Business and Economic Statistics 16: 254-259.

Hasanov, Fakhri, and Frederick Joutz. 2013. "A macroeconometric model for making effective policy decisions in the Republic of Azerbaijan." International Conference on Energy, Regional Integration and Socio-economic Development 6017, EcoMod.

Hendry, David F. 1993. Econometrics: Alchemy or Science? Essays in Econometric Methodology. Oxford: Blackwell Publishers.

-- - 1995. Dynamic Econometrics. Oxford: Oxford University Press.

- - . 2000. "Epilogue: The Success of Generalto-specific Model Selection." In Econometrics: Alchemy or Science? Essays in Econometric Methodology David F. Hendry (ed.) Oxford: Oxford University Press: 467-490.

- - - 2018. "Deciding between alternative approaches in macroeconomics." International Journal of Forecasting 34(1): 119-135.

Hendry, David F., and Søren Johansen. 2015.

"Model discovery and Trygve Haavelmo's legacy." Econometric Theory. 31(1): 93-114.

Hendry, David F., and John N.J. Muellbauer. 2018. "The future of macroeconomics: macro theory and models at the Bank of England." Oxford Review of Economic Policy. 34(1-2): 287-328.

Hendry, David F., and Hans-Martin Krolzig. 1999. "Improving on 'Data mining reconsidered' by K.D. Hoover and S.J. Perez." The Econometrics Journal 2(2): 202-219.
Hendry, David F., and Hans-Martin Krolzig. 2001. Automatic Econometric Model Selection Using PcGets 1.0. London: Timberlake Consultants Press.

Hendry, David, F., Adrian R. Pagan, and John D. Sargan. 1984, "Dynamic Specification," in Handbook of Econometrics (Vol. 2), eds. Zvi Griliches and Michael. D. Intriligator, Amsterdam: North-Holland, pp. 1023-1100

Hendry, David, and Grayham Mizon. 2014. "Unpredictability in economic analysis, econometric modeling and forecasting." Journal of Econometrics 182(1): 186-195.

- - . 2000. "Reformulation empirical macroeconomic modelling." Oxford Review of Economic Policy 16 (4): 138-159.

Herbst, Andrea, Felipe Toro, Felix Reitze, and Eberhard Jochem. 2012. "Introduction to energy systems modelling." Swiss Journal of Economics and Statistics 148(2) 111-135.

Herbst, Edward, and Frank Schorfheide.

2012. "Evaluating DSGE model forecasts of comovements." Journal of Econometrics 171(2) 152-166.

Hoover, Kevin D., and Stephen J. Perez. 1999. "Data mining reconsidered: encompassing and the general-to-specific approach to specification search." The Econometrics Journal 2(2): 167-191.

Hoover, Kevin D., Søren Johansen, and Katarina Juselius. 2008. "Allowing the Data to Speak Freely: The Macroeconometrics of the Cointegrated Vector Autoregression." American Economic Review 98(2): 251-55. 
Hurtado, Samuel. 2014. "DSGE models and the Lucas critique." Economic Modelling 44: S12-S19.

Isard, Peter. 2000. "The Role of MULTIMOD in the IMF's Policy Analysis." PDP/00/0-5. International Monetary Fund.

Jadhav, Narendra. 2004. "Macroeconometric Modelling for Policy Making: Retrospect and Prospects." RBI Occasional Papers.

Johansen, Per R., and Knut A. Magnussen. 1996. "The Implementation Model: A Macroeconomic Model for Saudi Arabia." Research Department, Statistics Norway 96 (13).

Johansen, Søren. 1988. "Statistical analysis of cointegration vectors." Journal of Economic Dynamics and Control 12(2-3): 231-254.

Johansen, Søren, and Katarina Juselius. 1990. "Maximum likelihood estimation and inference on cointegration-with applications to the demand for money." Oxford Bulletin of Economics and Statistics 52(2): 169-210.

King Abdullah Petroleum Studies and Research Center (KAPSARC). 2017. "The KAPSARC Global Energy Macroeconometric Model." https://www. kapsarc.org/research/projects/the-kapsarc-globalenergy-macroeconometric-model-kgemm/

Klein, Lawrence Robert, Aleksander Welfe, and Władysław Welfe. 1999. Principles of Macroeconometric Modeling. Amsterdam: North-Holland.

Krolzig, Hans-Martin, and David F. Hendry. 2001. "Computer automation of general-to-specific model selection procedures." Journal of Economic Dynamics and Control 25(6-7): 831-866.
Kwiatkowski, Denis, Peter C.B. Phillips, Peter Schmidt, and Yongcheol Shin. 1992. "Testing the null hypothesis of stationarity against the alternative of a unit root: How sure are we that economic time series have a unit root?" Journal of Econometrics 54 (1-3): 159-178.

Laxton, Douglas, Hamid Faruqee, Peter Isard, Eswar Prasad, and Bart Turtelboom. 1998."Multimod mark III: the core dynamic and steady state model." International Monetary Fund, Occasional Papers no. 164.

Ljungqvist, Lars. 2008. "Lucas critique." The New Palgrave Dictionary of Economics. Second Edition. Edited by Steven N. Durlauf and Lawrence E. Blume. Palgrave Macmillan.

Looney, Robert E. 1986. "Socio-economic tradeoffs in Saudi Arabia's third five year plan (1980-1985)." Socio-Economic Planning Sciences 20(4) (1986): 181-192.

- - . 1988. "Saudi Arabia's fiscal options: 19861992." Socio-Economic Planning Sciences 22(3): 109-123.

Mizon, Grayham E. 1984. The encompassing approach in econometrics. Australian National University, Faculty of Economics and Research School of Social Sciences.

- - - 1995. "Progressive Modeling of Macroeconomic Time Series: the LSE Methodology." In Macroeconometrics: Developments, Tensions and Prospects: 107-180. Dordrecht: Springer.

Mizon, Grayham E., and Jean-Francois Richard. 1986. "The encompassing principle and its application to testing non-nested hypotheses." Econometrica 54(3): 657-678. 
Nakov, Anton, and Galo Nuno. 2013. "Saudi Arabia and the oil market." The Economic Journal 123(573) 1333-1362.

Oxford Economics. 2018. "Global Economic Model." https://www.oxfordeconomics.com/ global-economic-model

Pagan, Adrian. 2003a. "Report on modelling and forecasting at the Bank of England/Bank's response to the Pagan report." Bank of England. Quarterly Bulletin 43, no.1: 60.

Pagan, Adrian. 2003b. "An examination of some tools for macro-econometric model building." In METU Lecture, ERC Conference VII, Ankara.

Park, Joon Y. 1990. "Testing for Unit Roots and Cointegration by Variable Addition," Advances in Econometrics, Vol. 8, ed. by G. F. Rhodes and T. B. Fomby. Greenwich, CT: JAI Press, 107-133.

Park, Joon Y. 1992. "Canonical cointegrating regressions." Econometrica. 60(1) 119-143.

Perron, Pierre. 1989. "The great crash, the oil price shock, and the unit root hypothesis." Econometrica. 57(6) 1361-1401.

Perron, Pierre. 2006. "Dealing with structural breaks." Palgrave Handbook of Econometrics Volume 1: Econometric Theory, no. 2 Edited by $\mathrm{H}$. Hassani, Terence C. Mills, Kerry Patterson. 278352. Palgrave Macmillan UK

Perron, Pierre, and Timothy J. Vogelsang. 1992a. "Nonstationarity and level shifts with an application to purchasing power parity." Journal of Business \& Economic Statistics 10(3): 301-320.
- - - 1992b. "Testing for a unit root in a time series with a changing mean: corrections and extensions." Journal of Business \& Economic Statistics 10(4): 467-470.

Pesaran, M. Hashem, Yongcheol Shin, and Richard J. Smith. 2001. "Bounds testing approaches to the analysis of level relationships". Journal of Applied Econometrics.(3), 289-326.

Pesaran, M. Hashem, and Yongcheol Shin. 1999. "An Autoregressive Distributed-Lag Modelling-UK spelling Approach to Cointegration Analysis". In Econometrics and Economic Theory in the 20th Century: The Ragnar Frisch Centennial Symposium. Edited by Steinar Strøm. Cambridge University Press: Cambridge, UK.

Phillips, Peter C.B. and Bruce E. Hansen. 1990.

"Statistical inference in instrumental variables regression with I (1) processes". The Review of Economic Studies 57(1), 99-125.

Phillips, Peter C.B. and Pierre Perron. 1988.

"Testing for a Unit Root in Time Series Regression," Biometrika.

Phillips, Peter C.B. and Sam Ouliaris. 1990. "Asymptotic properties of residual based tests for cointegration." Econometrica 58(1): 165-193.

Ra Sungsup, and Rhee, Chang Yong. 2005. "Nepal Macroeconometric Model". Asian Development Bank, Nepal Resident Mission, Working Paper Series No. 1 June

Rudebusch, Glenn D. 2005. "Assessing the Lucas critique in monetary policy models." Journal of Money, Credit and Banking: 37(2) 245-272.

Romer, Paul. 2016. "The trouble with 
macroeconomics." The American Economist 20: $1-20$.

Saikkonen, Pentti. 1992. "Estimation and testing of cointegrated systems by an autoregressive approximation." Econometric Theory 8(1): 1-27.

Saudi Vision 2030 (SV2030). 2017. "Fiscal Balance Program." (FBP). https://vision2030.gov.sa/en/ bb2020

- - - 2018. Fiscal Balance Program, Kingdom of Saudi Arabia Vision 2030. 2018 Update. http:// vision2030.gov.sa/en/bb2020

-- . 2019a. Fiscal Balance Program, Kingdom of Saudi Arabia Vision 2030. 2019 Update. http:// vision2030.gov.sa/en/bb2020

- - . 2019b. "National Transformation Program." (NTP) https://vision2030.gov.sa/en/ntp

Stiglitz, Joseph E. 2018. "Where modern macroeconomics went wrong." Oxford Review of Economic Policy 34(1-2): 70-106.

Stock, James H., and Mark W. Watson. 1993. "A simple estimator of cointegrating vectors in higher order integrated systems." Econometrica. 61(4): 783-820.

Valadkhani, Abbas. 2004. "History of Macroeconometric Modelling: Lessons from Past Experience." Journal of Policy Modeling. 26(2): 265-81.
Vogelsang, Timothy J., and Pierre Perron. 1998. "Additional tests for a unit root allowing for a break in the trend function at an unknown time." International Economic Review 39(4): 1073-1100.

Wallis, Kenneth Frank. 2000. "Macroeconometric Modelling." In Macroeconomic Policy: Iceland in an Era of Global Integration, edited by Gudmundsson, Már \& Snævarr, Sigurdur: 399-414. Reykjavik: University of Iceland Press.

Wallis, Kenneth Frank. 1993. "On macroeconomic policy and macroeconometric models." Economic Record. 69(2): 113-130. https://doi. org/10.1111/j.1475-4932.1993.tb01808.x

Wren-Lewis, Simon. 2018. "Ending the microfoundations hegemony." Oxford Review of Economic Policy. 34(1-2): 55-69.

Yoshida, Tomoo. 1990. "On the stability of the Japanese money demand function: estimation results using the error correction model." Bank of Japan Monetary and Economic Studies. 8(1): 1-48.

Zivot, Eric, and Donald W. K. Andrews. 1992. "Further evidence on the great crash, the oil-price shock and the unit-root hypothesis." Journal of Business and Economic Statistics 10(3) 251-70. 


\section{Appendix A. KGEMM Methodology and Philosophy}

Energy, financial, macroeconomic, econometric, forecasting and policy models need to perform well in a complex environment with numerous interrelated actions and decisions occurring simultaneously by heterogeneous agents. Modern economies are evolving; there are both gradual and sudden structural changes and shifts due to institutional, technological, financial, and international competitiveness, and political, social and legal changes. The philosophy underlying the econometric methodology for the development and use of KGEMM is derived from the principles espoused by Haavelmo (1943a, 1943b, 1944) on the theory of reduction, followed by the general-to-specific or LSE tradition developed by many, including Hendry and Johansen (2015). Empirical (policy and forecasting) models are supposed to capture these factors in an environment where the data are non-stationary; the degree of misspecification is unknown for the data generation process (DGP), but it is no doubt large. The data available may be inaccurate, a proxy for theoretical constructs and agent's decision-making criteria, produced with a lag, and subject to revision. The methodology for KGEMM begins with a focus on understanding and replicating the Saudi Arabian macroeconomy and energy.

Model building is an attempt to characterize the properties of observed energy-economic data using simple parametric relationships, which remain reasonably constant over time, account for the findings of previous models, and are interpretable in an energy-economic sense. There are three key aspects in applied empirical model building: data properties, including integration and cointegration; dynamic specification, including the use of equilibrium correction models; and model evaluation and model design.

This Appendix is divided into four sections. Section 1 lays out the typology of macroeconomic modeling techniques and how their methodologies relate to one another. The second section discusses the econometric philosophy underlying KGEMM's methodology. The third section explains the econometric methodology that the KGEMM team uses to develop the behavioral equations of the model. The fourth section details other issues of the model's development and how it can be used for policy analysis.

\section{A typology of the macroeconomic modeling techniques}

Pagan $(2003 a, 2003 b)$ lays out a useful structure for understanding the empirical modeling frontier and the strategic trade-offs faced by researchers. The frontier defines the tension between building models that are consistent or coherent theoretically and empirically. Below are two quotes from his paper and a slight modification of his frontier diagram.

"Macroeconomic model building has always faced the challenge of how one trades off theoretical and empirical coherence. If one thinks of a curve which summarizes this trade-off, where we locate on it ultimately depends on preferences. But how does one get to this point? Broadly two strategies have been employed. One is to start with statistical models that closely fit the data, and then try to impose a theoretical structure upon them - what we will term the 'bottoms-up' approach. The other is to embellish the framework laid out by some miniature theoretical model - what we will call the 'top-down' approach. The first generation of macro models tended to follow the first strategy, although in many ways the vision of the 
Cowles Commission was the latter. Recently there has been a return to the original vision, particularly in central banks that have attained independence and have an inflation target."

"I want to start the lecture with a graph. Over the years I have found it useful to think about the activities engaged in by econometric researchers with this representation. It shows the frontier curve that connects up the degree to which our current modelling methods aim to exhibit coherence with the ideas of economic theories and the degree to which they attempt to cohere with the data. At each end of the frontier the coherence is perfect for one of these characteristics and zero for the other. Crudely speaking, we might say that economics has primacy for those modelling strategies located at the top left hand corner while statistics is dominant at the bottom right hand end. For this reason, I will refer to the models at the top end as 'economic' and those at the bottom as 'statistical.' Those along the frontier are hybrid models. Another way of expressing this is to say that, at the bottom we have models that simply summarize the data, and at the top we have models that aim to interpret the data. Along the curve we have work that attempts to trade off the two objectives. When we are inside the frontier it is possible to improve modelling on either one or both dimensions."

Pagan's original diagram has been augmented to illustrate where the computable general equilibrium models (CGE) and mixed complementarity models (MCP) fit on the frontier. They are located in the upper left corner because their specifications are based solely on theoretical and technological specifications. The data requirements of these models are typically very large and depend on social accounting matrices and input-output tables obtained from five year and/or infrequent censuses. Thus they are a snapshot for a single year. Arbitrary bridge equations have been used when two or more censuses are linked.

Figure 3.1 Adrian Pagan's 'empirical' modeling frontier and research strategy trade-offs.

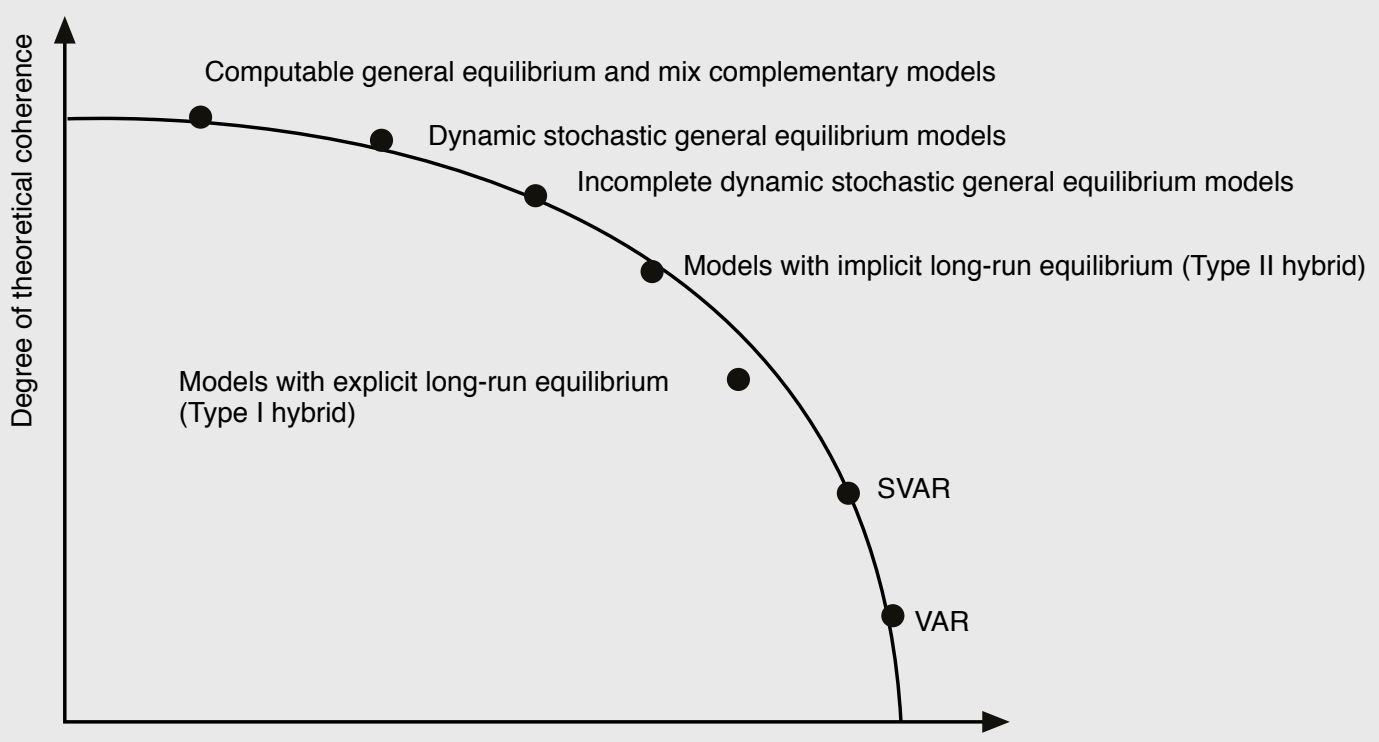

Source: Adapted from Pagan (2003a). 
Pagan notes that 'economic' models are popular in academia and are mostly relevant for 'storytelling,' while 'statistical' models are mostly relevant to approximate data, and hence are widely used in predictions/ forecasting. Pagan further states that models involved in policy decision-making need to bring together a degree of theoretical and empirical coherence. In other words, the models used for policy purposes should be neither economic nor statistical; they should be hybrid models based on ECMs. Other studies also discuss the relevance of the hybrid models for policy decision-making (see, e.g., Hara et al [2009] inter alia).

\section{Econometric philosophy underlying KGEMM}

Haavelmo (1943a, 1943b, 1944) provides the first rigorous treatment of causality. His fundamental contributions to understanding the formulation and identification of causal models linked economic theory and econometrics. Yet their reception and interpretation within the econometrics community is still debated along the trade-offs of theoretical coherence and empirical coherence suggested by Pagan (2003a). Table 3.1 illustrates the different approaches between economists and statisticians. The current dominant orthodoxy can be summarized as economic analysis that formulates the correct (theoretical) model and econometrics, which merely has the task of estimating the parameters of interest from the best available data. This approach is wrong on several fronts. There is frequently no one correct theory, alternative theories can be observationally equivalent, theoretical models treat dynamics in an ad hoc manner, and the available data may not be the same as the theoretical constructs.

Haavelmo recommended applying the general principles of analyzing statistical models instead of the economists' methods. The applied econometrician must use a probability approach to their craft. He suggested they should start by assuming a probability structure to the data. This is effectively conjecturing the existence of a DGP and taking the data properties issue seriously. A critical feature of the DGP's components is that it can include competing theories. Thus, in the end, the researcher discovers if one theory dominates the other(s) or different aspects seem relevant, leading to theoretical and empirical discoveries.

Table A.1 Approaches and/or methodology for research.

Economists

Formulate an economically well-specified model as the empirical model.

Apply statistical techniques to estimate the parameters.
Statisticians

Formulate a statistically well-specified model for the data based on the DGP.

Analyze the statistical model to answer the economic questions of interest.

Methodology for research

Use statistics passively as a tool to obtain derived results.
The statistical model is taken seriously and used actively as a means of analyzing the underlying DGP of the economic phenomenon. 
In reality, the DGP is unknown. The general principles suggest an iterative approach or progressive research strategy.

- Conjecture the DGP.

- Develop the associated probability theory.

- Use theory for modeling the empirical evidence.

- Revise the starting point when the results do not match consistently.

The approach to deriving a model, or the context of model discovery, is based on the theory of reduction. This explains the origin of empirical models based on reduction steps or operations, which are conducted on the DGP. Ideally, this implies the application of statistical models instead of the researcher imposing theoretical models based on systems of equations.

A second area Haavelmo cautioned empirical modelers about was that measured or available data from official sources are often far from the definitions of the true variables. Moreover, even if they were close, this would not necessarily mean that they correspond to the variables from economic theory. For example, when modeling private consumption what is the relevant period for making decisions regarding expenditures on services, non-durables and durables? Is that consistent with how the data are collected?

\section{Data from official sources depend on:}

- The measurement system.

- Frequency of collection or data intervals.

- Discrepancy with decision-making intervals.

- Sample length.

- Survey of samples versus population.

- Data revisions - accuracy of preliminary estimates.

- Seasonality adjustments.

- Timeliness.

- Level of aggregation.

- Protection of confidential personal and industry information. 


\section{In 1989 Haavelmo stated:}

"The basis of econometrics, the economic theories that we have been led to believe in by our forefathers, were perhaps not good enough. It is quite obvious that if the theories we build to simulate actual economic life are not sufficiently realistic, that is, if the data we get to work on in practice are not produced in a way theory suggests, then it is rather meaningless to confront actual observations with relations that describe something else."

The purpose of empirical investigations is to test a theory. A prerequisite for valid inferences about the theory is that there must be a close correspondence between measured variables and the true variables. In the words of Haavelmo:

"It is then natural to adopt the convention that a theory is called true or false according as the hypotheses implied are true or false, when tested against the data chosen as the 'true' variables. Then we may speak interchangeably about testing hypotheses or testing theories."

Data issues will persist but are likely to improve as statistical agencies build up their capacity, processes and delivery of data. Despite the problems in collecting and measuring macroeconomic data, the information is valuable. It can help in decision-making by governments, firms, individuals regarding commerce and public finance. Theoretical arguments are needed to understand the relationships among variables regardless of the weak to poor correspondences that exist between the theoretical variables and the measured data. The cautions about realism in the data and the value of empirical data are serious, but may be framed in terms of the signal to noise ratio in the data.

Hendry (2018) emphasizes that the debate can be addressed by nesting the theory-driven and datadriven approaches. This enables the researcher to retain insights from theory while exploring the empirical interactions when evaluating the theoretical and data evidence. Moreover, the combination of a clearly mapped out scientific method with advances in computing power and statistical programs, Autometrics, in particular provide econometricians the ability to distinguish between correlation and causation in developing empirical models. Autometrics is written to follow the theory of reduction through the general-to-specific approach of model testing and evaluation.

Models are designed to satisfy selection criteria through hypothesis tests. These can be from explicit theory and/or 'long-run ratios.' The reduction from a general model to a specific one relates to no loss of relevant information. Starting from a specific model and then branching out to address econometric issues like serial correlation and dynamics produces path-dependent models. The fundamental concepts from econometrics are natural vehicles for the theory of reduction and correspond to no loss of relevant information. 


\section{Consider:}

- Parameters of interest

- Innovation

- Autocorrelation

- Exogeneity

- Invariance

- Identification

- Granger non-causality

- Common factors

- Cointegration

All of these concepts are related to the evaluation of information and the formation of null hypotheses for diagnostic testing, for model evaluation and design criteria for model selection. The reduction process is inherently iterative: many reduction paths could be considered, which may lead to different terminal specifications. Retain those models which survive. If multiple models survive 'testimation,' then a new general model is formed. In that case, conduct encompassing tests between these (possibly non-nested) specifications. If no single specific model is chosen, selection can be done by information criterion and subsample reliability.

The reduction approach is based on explicit model design criteria. This is based on an approximation of the local data generating process (LDGP). The LDGP is a reduction of the DGP that should include all possible relevant variables. Hypothesis tests examine the information losses from testing reductions. These can include tests for autocorrelation, heteroscedasticity, omitted variables, multicollinearity and non-constancy. The objective is to find a congruent model.

This is superior to the 'symptomatology' approach in traditional econometrics where the theoretical model is directly imposed on data. The approach is invalid: there is no unique alternative to any null. Often, following adjustments of the linear model assumptions, the outcome is path dependent. 


\section{The reductions can be organized into 11 stages:}

- Data transformation and aggregation.

- Parameters of interest - are introduced by the transformations and identifiable.

- Data partition is probably the most fundamental determinant of empirical modeling's success or not.

- Marginalization without loss of information.

- Sequential factorization for creating the innovation process.

- Mapping to $\mathrm{I}(0)$ or stationary space for valid inference.

- Conditional factorization into endogenous and 'exogenous' or non-modelled variables.

- Constancy of parameters and models.

- Lag truncation.

- Functional form or how can the DGP be approximated through model design criteria.

Derive the local data-generating process (LDGP) as a reduction of the DGP or nested within it. The properties of the LDGP are given or explained by the reduction process.

\section{Congruency}

We often read a model is (non) congruent. This is an important concept in our econometric philosophy and methodology.

Empirical models are at best approximations of the true data-generating process. The econometric model should exhibit certain desirable properties that render it a valid representation of the true DGP. Hendry (1995) and Mizon (1995) suggest the following six criteria according to the LSE methodology:

- There are identifiable structures in the empirical model that are interpretable in light of economic theory.

- The residuals must be white noise for the model to be a valid simplification of the DGP.

The empirical model must be admissible on accurate observations. For example, nominal interest rates and prices cannot be negative.

The conditioning variables are at least weakly exogenous for the parameters of interest in the model. Forecasting models require strong exogeneity, while policy models require super exogeneity. 
The parameters of interest must be constant over time and remain invariant to certain classes of interventions. This relates to the purpose of the model in the previous criteria.

The model must be able to explain the results from rival models; it is able to encompass them.

\section{The econometric methodology KGEMM uses}

The theory of reduction is operationalized through the general-to-specific approach advocated by Campos, Ericsson and Hendry $(1993,1995,2000,2005)$. The approach begins with a general hypothesis about the relevant explanatory variables and dynamic process (i.e., the lag structure of the model). The general hypothesis is considered acceptable to all schools of thought. This is referred to as the general unrestricted model or GUM. The autoregressive distributed lag (ADL) model begins with a regression of the variable of interest, $\mathrm{y}_{\mathrm{t}}$, on lagged values of itself and current and lagged values of the explanatory variables, $\mathrm{z}_{\mathrm{t}}$.

$y_{t}=a_{0}+\sum_{i=1}^{p} a_{i} y_{t-i}+\sum_{j=0}^{m} b_{j} z_{t-j}+\varepsilon_{t}$

The error term is assumed to be white noise. In this case, the model is referred to as an ADL ( $p, m)$ because it contains $p$ lagged dependent variables and $m$ lagged explanatory variables. In the single equation, we are implicitly assuming a conditional model where the $z$ variables are assumed to be weakly exogenous. The intercept can be expanded to include other deterministic variables like seasonal dummy variables, trend, shift dummy variables and one-off effects. This single equation representation can be generalized to a vector autoregression.

The model is then narrowed by testing for simplifications to or restrictions on the general model. The final or specific model attempts to characterize the properties of the sample data in simple parametric relationships, which remain reasonably constant over time. It also accounts for the findings of previous models and is interpretable economically and financially. Rather than using econometrics to illustrate theory, the goal is to 'discover' which alternative theoretical views are tenable and test them scientifically.

At this point, we have not made any assumptions on the order of integration for the $y$ and $z$ variables. The later assumptions can be evaluated in specifications of the model in order to avoid the problems of nonsense and spurious regressions.

Before estimating a GUM of an ADL or vector autoregressive regression (VAR) system, the first step involves examining the time series properties of the individual data series. We look at patterns and trends in the data and test for stationarity and the order of integration. Second, we form the GUM of the ADL equation or VAR. This step involves testing for the appropriate lag length of the system, including residual diagnostic tests and tests for model/system stability. Third, we examine the equation or system for potential cointegration relationship(s). Data series which are integrated of the same order may be combined to form economically meaningful series which are integrated of lower order. The cointegrating relations are tested for interpretation as an equilibrium correction mechanism. In the case of a system, we test for weak exogeneity. Based on these results, a conditional ECM of the endogenous variables may be specified, and further reduction tests are performed and economic hypotheses tested. 
There are two types of testing. The first is model evaluation, which is somewhat 'mechanistic.' These tests are performed in the context of testing for model congruency with respect to the data and economic theory. Criteria represent the null hypotheses and the associated test statistics are used to test the hypotheses. Model evaluation tests should be interpreted as destructive activity on the model. They are necessary (not sufficient) conditions for inference testing, forecasting and policy analysis. An example would include the appropriate lag length to use in capturing the dynamics of the relationships between the variables.

The second type of testing is referred to as model design. After a statistical model has been estimated, these tests are sources of value added or 'art' conducted by the econometrician. Examples include hypotheses for unit elasticities, relative price elasticities and symmetric responses are part of the toolkit or pallet.

In Autometrics, Doornik (2009) implements the general-to-specific modeling algorithm following on the program by Hendry and Krollzig (2001). There are five basic steps:

- Specification of the GUM by the empirical modeler.

- Tests for misspecification usually through residual diagnostics.

Begin model reduction process. Investigation of possible paths for variable selection. Elimination of 'irrelevant' variables.

- Test terminal models or paths for congruency.

- Evaluate terminal models for the final model(s) through encompassing tests.

Table 3.2 below organizes the arguments against data mining by class on the left and refutations on the right. 
Table 3.2 A Data mining: Four pejorative senses and four refutations.

Class or sense of data mining

1. Repeated testing

Select spurious regressors to maximize t-ratios.

$\Rightarrow t-$ ratios $\downarrow, \sigma \uparrow$ as $T \uparrow$

\section{Counter evidence}

Recursive estimation and additional data

We can use larger critical values

$\Rightarrow t-$ ratios $\uparrow, \sigma$ remains constant as $T \uparrow$

\section{Data independence}

$y=f(x)$ and $\operatorname{corr}(x, z) \neq 0$

$\Rightarrow y$ and $z$ are correlated

\section{Super exogeneity and encompassing}

Models are empirically constant

The parameters relating to models are empirically constant

The parameters relating $y$ to $z$, even if the

$\operatorname{corr}(x, z)$ is changing

Thus we can include $\mathrm{x}$ and $\mathrm{z}$ in our models

Gets and Autometrics: Encompassing

General-to-Specific modeling

z's are chosen for 'sensible' coefficient estimates.

There could be omitted variables?

\section{Overparameterization}

Overfitting and degrees of freedom issues
High information content of data

Autometrics and Gets can detect this

There have been four generations in the evolution of this argument:

- The general-to-specific approach performed manually. LSE or Hendry prior to 1999.

The algorithmic approach of Hoover and Perez (1999) was an attempt to systematize the LSE approach. This was based on a mixed empirical Monte Carlo framework.

- Hendry and Krolzig (1999) PcGets.

- Doornik (2009) Autometrics.

These mechanistic models appear to be immune to the standard criticisms. However, they do require that the initial general model GUM is appropriate. Also, they, PcGets and Autometrics, do not recognize the possible data transformations. These are model design issues where the applied econometrician provides value-added before and/or after the reduction program, Autometrics is run.

The model's econometric specification, especially ECMs, are estimated using the principles outlined above using the Autometrics program in OxMetrics. The software is designed to mimic the principles of generalto-specific in testing. Final equations will be transferred/coded into EViews to use in model building. The program will cut the equation development and testing time to a fraction of what it otherwise would be. The software is designed to follow the scientific method underlying the theory of reduction, taking advantage of advances in computing power and econometric techniques. 


\section{Other issues of model development and application for policy analysis}

\section{Invariance and the Lucas critique}

"The 'Lucas critique' is a criticism of econometric policy evaluation procedures that fail to recognize that optimal decision rules of economic agents vary systematically with changes in policy. In particular, it criticizes using estimated statistical relationships from past data to forecast the effects of adopting a new policy, because the estimated regression coefficients are not invariant and will change along with agents' decision rules in response to a new policy. A classic example of this fallacy was the erroneous inference that a regression of inflation on unemployment (the Phillips curve) represented a structural trade-off for policy to exploit." (Ljungqvist 2008).

This brief note describes what the Lucas critique implies and testing for it. The fundamental point, and Lucas himself agrees with this, is that the Lucas critique is a possibility theorem; it is not a truism. The lack of invariance in the parameters of a conditional model can arise from multiple sources.

The basis for the Lucas critique can be illustrated with a simple relationship. In the example below, consider the $\mathrm{x}$ variable as a policy variable and $\mathrm{y}$ as the variable policy is trying to influence.

$$
y_{t}=\beta_{0} x_{t}+u_{t}
$$

Assume this is estimated by OLS. The properties of the disturbance term depend on the data-generating process (DGP). The simple relationship is a special case of a more general model. For example, it could have come from a first order Gaussian VAR for the two time series.

$$
\left(\begin{array}{l}
y_{t} \\
x_{t}
\end{array}\right)=\left(\begin{array}{l}
\pi_{10} \\
\pi_{20}
\end{array}\right)+\left(\begin{array}{ll}
\pi_{11} & \pi_{12} \\
\pi_{21} & \pi_{22}
\end{array}\right)\left(\begin{array}{l}
y_{t-1} \\
x_{t-1}
\end{array}\right)+\left(\begin{array}{l}
\varepsilon_{y t} \\
\varepsilon_{x t}
\end{array}\right)
$$

The joint distribution for error terms is white noise with a mean of zero and possible non-zero variancecovariance matrix. This means there is no autocorrelation.

$$
\left(\begin{array}{c}
\varepsilon_{y t} \\
\varepsilon_{x t}
\end{array}\right) \sim N\left(\mathbf{0},\left(\begin{array}{cc}
\sigma_{y}^{2} & \sigma_{x y} \\
\sigma_{x y} & \sigma_{x}^{2}
\end{array}\right) \mid y_{t-1}, x_{t-1}\right)
$$

The simple relationship above given the Gaussian distribution and the assumption that the conditional distribution for $\mathrm{y}_{\mathrm{t}}$ conditional on $\mathrm{x}_{\mathrm{t}}$ is given by

$y_{t}=\beta_{0}^{*} E\left[x_{t} \mid J_{t-1}\right]+\varepsilon_{t}$

$$
x_{t}=\pi_{22} x_{t-1}+\varepsilon_{x t}
$$

Here the original unrestricted VAR model has been transformed into a conditional model in the first equation and a marginal model in the second equation. This is just an application of Bayes' theorem. The series $\mathrm{x}$ is stationary implying that $-1<\pi_{22}<1$. Recall the terms $\varepsilon_{\mathrm{t}}$ and $\varepsilon_{\mathrm{xt}}$ are independent white noise processes. The term $\mathcal{J}_{\mathrm{t}-1}$ denotes the information set available to form rational expectations. In this example, the notation can be rewritten as $\mathrm{E}\left[\mathrm{x}_{\mathrm{t}} \mid \mathcal{J}_{\mathrm{t}-1}\right]=\mathrm{E}\left[\mathrm{x}_{\mathrm{t}} \mid \mathrm{x}_{\mathrm{t}-1}\right]$. The conditional expectation for the disturbance given current $\mathrm{x}_{\mathrm{t}}$ is zero, $\mathrm{E}\left[\varepsilon_{\mathrm{t}} \mid \mathrm{x}_{\mathrm{t}}\right]=0$. Then $\mathrm{y}_{\mathrm{t}}$ is a normal variable with a mean: 
$E\left[y_{t} \mid x_{t-1}\right]=\pi_{22} \beta_{0}^{*} x_{t-1}$

Moreover $\mathrm{x}_{\mathrm{t}}$ is a normal variable with mean.

$E\left[x_{t} \mid x_{t-1}\right]=\pi_{22} x_{t-1}$.

Then the conditional mean of $y_{t}$ given $x_{t}$ is given by

$E\left[y_{t} \mid x_{t}\right] \equiv \mu_{Y \mid X}=\beta_{0}^{*} x_{t}+E\left[u_{t} \mid x_{t}\right]$

The last term is not equal to zero, because $x_{t}$ must be correlated with $u_{t}$ due to

$u_{t}=\varepsilon_{t}-\beta_{0}^{*} \varepsilon_{x t}$

And the two equations from the conditional distribution above. The expectation for $\mathrm{u}_{\mathrm{t}}$ given $\mathrm{x}_{\mathrm{t}}$ can be written as

$E\left[u_{t} \mid x_{t}\right]=-\beta_{0}^{*} E\left[\varepsilon_{x t} \mid x_{t}\right]$ since $E\left[\varepsilon_{t} \mid x_{t}\right]=0$ by assumption from the DGP.

Given the assumption of normality there is a regression function:

$E\left[\varepsilon_{x t} \mid x_{t}\right]=\delta x_{t}$ where $\delta=\frac{E\left[\varepsilon_{x t} x_{t}\right]}{\operatorname{Var}\left[x_{t}\right]}=\frac{\sigma_{\varepsilon x t}^{2}}{\operatorname{Var}\left[x_{t}\right]}$

The numerator in the last term is the variance of $\varepsilon_{\mathrm{xt}}$. The stationarity condition implies the variance of $\mathrm{x}$ is defined.

$\operatorname{Var}\left[x_{t}\right]=\frac{\sigma_{\varepsilon x t}^{2}}{1-\pi_{22}^{2}}$

Therefore the regression coefficient is just $\delta=\left(1-\pi_{22}^{2}\right)$.

The conditional expectation for $y_{t}$ when the DGP is characterized by rational expectations becomes

$$
\mu_{Y \mid X}=\beta_{0}^{*} x_{t}-\beta_{0}^{*}\left(1-\pi_{22}^{2}\right) x_{t}=\beta_{0}^{*} \pi_{22}^{2} x_{t}
$$

When regressing $\mathrm{y}_{\mathrm{t}}$ on $\mathrm{x}_{\mathrm{t}}$ by OLS the estimated coefficient $\widehat{\beta_{0}}$ is always consistent. However, in this case we see that the coefficient in this example is not a single parameter, but $\beta_{0}^{*} \pi_{22}^{2}$. Thus we obtain

$\operatorname{plim}\left(\widehat{\beta_{0}}\right)=\beta_{0}^{*} \pi_{22}^{2}<\beta_{0}^{*}$, because $-1<\pi_{22}<1$.

The essence of the Lucas critique is that any change in the formation of expectation, represented here by $\pi_{22}$ is predicted to lead to a change in the plim $\left(\widehat{\beta_{0}}\right) \cdot \beta_{0}^{*}$ is often referred to as a deep structural parameter. 
This implies that the estimator for $\beta_{0}^{*}$ will yield the wrong conclusions about how a policy change in $\mathrm{x}$ affects $\mathrm{y}_{\mathrm{t}^{*}}$

This implies that the initial OLS parameter $\beta_{0}$ is not invariant to changes in expectations, $\pi_{22}$. Therefore $x_{t}$ is not super-exogenous when the DGP is characterized by rational expectations in the Gaussian VAR above. However, this is not true, $\beta_{0}^{*}$ is invariant to changes in $\mathrm{x}_{\mathrm{t}}$ under the assumption of the conditional distribution for $\mathrm{y}_{\mathrm{t}}$ conditional on $\mathrm{x}_{\mathrm{t}}$ as written in the two equation system.

As mentioned above, the important point is that the Lucas critique is a possibility theorem; it is not a truism. The lack of invariance in the parameters of a conditional model can arise from multiple sources. Pitfalls like omitted variables and misspecified dynamics can lead to the lack of invariance even when instrumental variables/generalized method of moments (IV/GMM) estimation techniques are employed. The critical point is the exact set of assumptions. Consider a rational expectations model for planned consumption.

\section{Empirical testing for the Lucas-critique}

Engle and Hendry (1993) and Engle, Hendry and Richard (1983) developed tests for invariance and super exogeneity. Their approach checks whether the predicted invariance occurs in the conditional model following a significant structural break in the marginal part of the model.

In the conditional plus marginal model considered above, if there is a structural break in the marginal model for $\mathrm{x}_{\mathrm{t}}$, then it is likely that one (or more) parameters in the conditional model for $\mathrm{y}_{\mathrm{t}}$ will change around the break. But this does not follow logically. A lack of change or invariance in the parameters for the specific break being tested could be as a result of a true structural break. Recursive tests for stability of the conditional and marginal models and parameters should have been conducted previously.

Formal testing can be performed by examining the stability of the marginal model. Structural breaks (impulses, shifts and/or trends) can be estimated using Autometrics. Impulse and step dummies are introduced into the conditional model to test for super exogeneity. The null hypothesis of invariance is that these do not add explanatory power. An F-test or Wald test is used. If the null hypothesis is rejected, the Lucas critique is "confirmed." But, failure to reject the null does not imply that it is true. Expectations are still important except in this case, where the impact is not that strong. The specification of rational expectations in the model is too focused. It does not reveal or capture how expectations are formed and transmitted through the model.

Favero and Hendry (1992), Ericsson and Irons $(1994,1995)$ provide reviews of the literature on testing for the Lucas critique. Rudebusch (2005), among others, also shows the empirical unimportance of the Lucas critique to monetary policy. Moreover, Ericsson and Irons $(1994,1995)$ conclude that virtually no evidence exists that empirically substantiates the Lucas critique. They also empirically refute the critique using a super exogeneity test. 


\begin{tabular}{|c|c|c|}
\hline \# & Mnemonic & Description and unit \\
\hline 1 & BCAP\$ & Capital account of the balance of payments, million US\$, nominal \\
\hline 2 & BSER & Services balance, LCU, million Saudi riyal (SAR), nominal \\
\hline 3 & BSER \$ & Services balance, million US\$, nominal \\
\hline 4 & BVI & Visible trade balance, LCU, million SAR, nominal \\
\hline 5 & $\mathrm{BVI} \$$ & Visible trade balance, million US\$, nominal \\
\hline 6 & BVI\$_Z_MERCH & Merchandise trade balance, million US\$, nominal \\
\hline 7 & C_RATIO & Value added tax collection efficiency ratio \\
\hline 8 & CAPi & $\begin{array}{l}\text { Capital stock, real, LCU, } 2010 \text { prices, i stands for the following } 13 \text { sectors: agr=agriculture, con= } \\
\text { construction, dis=distribution, fibu= financial and business services, fibuoth=other fibu, gov= } \\
\text { government, manno=non-oil manufacturing, noil=non-oil, oil=oil, oilref=oil refinery, oths=other } \\
\text { services, tracom=transportation and communication, } u=u t i l i t y\end{array}$ \\
\hline 9 & CCOIL_IND & Consumption of crude oil in industry sector, million SAR \\
\hline 10 & CDIS_IND & Consumption of diesel in industry sector, million SAR \\
\hline 11 & CDIS_TRA & Consumption of diesel in transport sector, million SAR \\
\hline 12 & CELE_AGR & Consumption of electricity in agriculture sector, million SAR \\
\hline 13 & CELE_COMM & Consumption of electricity in commercial sector, million SAR \\
\hline 14 & CELE_GOV & Consumption of electricity in public service sector, million SAR \\
\hline 15 & CELE_IND & Consumption of electricity in industry sector, million SAR \\
\hline 16 & CELE_RES & Consumption of electricity in residential sector, million SAR \\
\hline 17 & CEN_TOT & Consumption of energy in total economy, million SAR \\
\hline 18 & CEN_TOT_CPA & Total consumption of energy in commercial and public service sector, million SAR \\
\hline 19 & CEN_TOT_IND & Total consumption of energy in industry sector, million SAR \\
\hline 20 & CEN_TOT_RES & Total consumption of energy in residential sector, million SAR \\
\hline 21 & CEN_TOT_TRA & Total consumption of energy in transport sector, million SAR \\
\hline 22 & CGAS_TRA & Consumption of gas in transport sector, million SAR \\
\hline 23 & CHFO_IND & Consumption of heavy fuel oil in industry sector, million SAR \\
\hline 24 & CKER_RES & Consumption of kerosene in residential sector, million SAR \\
\hline 25 & CKER_TRA & Consumption of kerosene in transport sector, million SAR \\
\hline 26 & CLPG_RES & Consumption of LPG in residential sector, million SAR \\
\hline 27 & CNGA_IND & Consumption of natural gas in industry sector, million SAR \\
\hline 28 & CONS & Consumption, private, real, LCU, million SAR, 2010 prices (rebased from 1999) \\
\hline 29 & CONS_Z & Consumption, private, LCU, million SAR, nominal \\
\hline 30 & COTH_IND & Consumption of other in industry sector, million SAR \\
\hline 31 & CPI & Consumer price index, Index $2010=100$ \\
\hline 32 & CPI_WLD & Consumer price index, world, $2010=100$ \\
\hline 33 & CPI_USA & United States - Consumer price index, Index, $2010=100$ (rebased from 1982/84=10) \\
\hline 34 & CPli & $\begin{array}{l}\text { Consumer price index, Index } 2010=100 \text {, i stands for the following } 12 \text { sectors: art=recreation and } \\
\text { culture, cloth=clothing, comm=commercial, edu=education, food=food and beverages, heal=health, } \\
\text { hh=household items, htl=hotels and restaurants, misc=other, tobc=tobacco, tra=transportation, } u= \\
\text { utility }\end{array}$ \\
\hline 35 & CROSS_DEPS & Total cross-border deposits with foreign banks, at end-period, million US\$, nominal \\
\hline 36 & CROSS_DEPS_FB & Total cross-border deposits with foreign banks by non-banks, at end-period, million US\$, nominal \\
\hline 37 & CROSS_LOANS & Cross-border loans from foreign located banks, at end-period, million US\$, nominal \\
\hline 38 & CROSS_LOANS_FB & Cross-border loans from foreign located banks to non-banks, at end-period, million US\$, nominal \\
\hline 39 & DBij & $\begin{array}{l}\text { Blip dummy variable, positive unity value in year i and negative unity value in year } \mathrm{j} \text {, zero value } \\
\text { otherwise }\end{array}$ \\
\hline 40 & DCOIL_IND & Demand for crude oil in industry, Mtoe \\
\hline
\end{tabular}




\begin{tabular}{|c|c|c|}
\hline \# & Mnemonic & Description and unit \\
\hline 41 & DCOIL_U & Demand for crude oil in utilities, Mtoe \\
\hline 42 & DD & Demand deposits, nominal, million SAR \\
\hline 43 & DDIS_IND & Demand for gas/diesel oil excl. biofuels in industry, Mtoe \\
\hline 44 & DDIS_TRA & Demand for gas/diesel oil excl. biofuels in transport, Mtoe \\
\hline 45 & DDIS_U & Demand for gas/diesel oil excl. biofuels in utilities, Mtoe \\
\hline 46 & DEBTINT & Interest payments on external debt, million US\$, nominal \\
\hline 47 & DEBTS & Debt service ratio, paid, million US\$, nominal \\
\hline 48 & DEBTS_P_X & Debt service ratio, percentage of exports, million US\$, nominal \\
\hline 49 & DELE_AGR & Demand for electricity in agricultural sector, Mtoe \\
\hline 50 & DELE_COM & Demand for electricity in commercial services, Mtoe \\
\hline 51 & DELE_GOV & Demand for electricity in public services, Mtoe \\
\hline 52 & DELE_IND & Demand for electricity in industrial sector, Mtoe \\
\hline 53 & DELE_RES & Demand for electricity in residential sector, Mtoe \\
\hline
\end{tabular}

54 DEN_i

Demand for energy, i stands for the following 19 sectors: agr=agriculture, con=construction, dis=distribution, gov=government, comm=commercial, man=manufacturing, manno= non-oil manufacturing, $\min =$ mining, minoth=other mining, $\mathrm{mq}=$ mining and quarrying, noil=non-oil, oil=oil, oilmin=oil mining, oilref=oil refinery, oths=other services, ser=service, tracom=transportation and communication, $u=u t i l i t y$, de_oth_tra=other energy demand in transportation

\begin{tabular}{ll}
\hline 55 & DEN_TOT \\
\hline 56 & DEN_TOT_CPA \\
\hline 57 & DEN_TOT_IND \\
\hline 58 & DEN_TOT_RES \\
\hline 69 & DEN_TOT_TRA \\
\hline 61 & DGAS_TRA \\
\hline 62 & DHFO_IND \\
\hline 63 & DI_Z \\
\hline 64 & DKER_RES \\
\hline 65 & DKER_TRA \\
\hline 66 & DNGA_RES \\
\hline 67 & DNGA_U \\
\hline
\end{tabular}

Total energy demand, Mtoe

Total energy demand in commercial, public and agricultural sectors, Mtoe Total energy demand in industry, Mtoe

Total energy demand in residential sector, Mtoe

Total energy demand in transport sector, Mtoe

Demand for motor gasoline excl. biofuels in transport, Mtoe

Demand for HFO in industry, Mtoe

Private disposable income, million SAR

Demand for kerosene type jet fuel excl. biofuels in residential sector, Mtoe

Demand for kerosene type jet fuel excl. biofuels in transportation sector, Mtoe

Demand for liquefied petroleum gases in residential sector, Mtoe

Demand for natural gas in industry, Mtoe

Demand for natural gas in utilities, Mtoe

Refined oil, total demand, Mtoe. i i stands for the following 45 countries: Argentina, Australia, Austria, Belgium, Bulgaria, Brazil, Canada, Switzerland, Chile, China, Czech Republic, Germany, Denmark, Spain, Finland, France, United Kingdom, GRC=Greece, HKG=Hong Kong China, HRV=Croatia,

68 DOILREF_i HUN=Hungary, IDN=Indonesia, IND=India, IRL=Ireland, ITA=Italy, JPN=Japan, KOR=South Korea, MEX=Mexico, MYS=Malaysia, NLD=Netherlands, NOR=Norway, PHL=Philippines, POL=Poland, PRT=Portugal, ROM=Romania, RUS=Russia, SGP=Singapore, SVC=Slovak Republic, SWE $=$ Sweden, TAI=Taiwan, THA=Thailand, TUR=Turkey, UAM=UAE, USA=USA, ZAF=South Africa

\begin{tabular}{lll}
\hline 69 & DOILREF_T & Refined oil demand, total, Mtoe \\
\hline 70 & DOMD & Domestic demand, real, LCU, million SAR, 2010 prices \\
\hline 71 & DOMD_Z & Domestic demand, LCU, million SAR, nominal \\
\hline 72 & DOTH_IND & Demand for other refined oil products in industry, Mtoe \\
\hline 73 & Dpi & Pulse dummy variable, unity value in year i and zero value otherwise \\
\hline 75 & DQM & Other quasi-money deposits, nominal, million SAR \\
\hline 76 & DSHi & Shift dummy variable, unity value from year i onwards \\
\hline
\end{tabular}




\begin{tabular}{|c|c|c|}
\hline \# & Mnemonic & Description and unit \\
\hline 77 & ECT_i & Stands for the error correction term for the equation titled $\mathrm{i}$ \\
\hline 78 & ERREAL & Real earnings (relative to CPI), SAR per employee SAR, nominal \\
\hline 79 & ET & Total employment, person thousands \\
\hline 80 & ETi & $\begin{array}{l}\text { Employment in sector i, thousands. i stands for the following } 18 \text { sectors: agr=agriculture, } \\
\text { con=construction, dis=distribution, fibu=financial and business services, gov=government, } \\
\text { man=manufacturing, manno=non-oil manufacturing, min=mining, minoth=other mining, } \\
\text { noil=non-oil, oil=oil, oilmin=oil mining, oilref=oil refinery, mano=oil and oil refining, oths=other } \\
\text { services, ser=service, tracom=transportation and communication, u=utility }\end{array}$ \\
\hline 81 & ETP & Total employment, private, person thousands \\
\hline 82 & ETPNS & Employment, private, expatriate, person thousands \\
\hline 83 & ETPS & Employment, private, Saudi, person thousands \\
\hline 84 & ETS & Total employment Saudi, person thousands \\
\hline 85 & EXPL & Expat levies, million SAR \\
\hline
\end{tabular}

$86 \quad$ FDi

Final Demand in sector i, million 2010 SAR. i stands for the following 20 sectors: agr=agriculture con=construction, dis=distribution, fibu=financial and business services, gov=government, mining, mq=mining and quarrying, noil=non-oil, oil=oil, oilmin=oil mining, oilref=oil refinery, oths=other services, ser=service, tracom=transportation and communication, $u=u t i l i t y$, chpet=petro-chemicals

\begin{tabular}{ll}
\hline 87 & FDI\$ \\
\hline 88 & FDI\$IN \\
\hline 89 & FDI\$OUT \\
\hline 90 & FISIM \\
\hline 91 & FISIM_Z \\
\hline 92 & GAE_Z \\
\hline
\end{tabular}

93 GAP_i

Total foreign direct investment, million US\$

Foreign direct investment inflow, million US\$, nominal

Foreign direct investment outflow, million US\$, nominal

GDP, financial intermediaries, real, million SAR, 2010 prices

GDP, financial intermediaries, million SAR, nominal

Government administrative expenses, million SAR

GAP by economic activity, i stands for the following 11 sectors: agr=agriculture,

con=construction, dis=distribution, fibu=financial and business services, gov=government,

manno=non-oil manufacturing, noil=non-oil, oilref=oil refinery, oths=other services, tracom=transportation and communication, $\mathrm{u}=$ utility

\begin{tabular}{|c|c|c|}
\hline 94 & GB & Government balance, LCU, million SAR, nominal \\
\hline 95 & GBNOIL & Non-oil government financial balance, million SAR, nominal \\
\hline 96 & GC & Consumption, government, real, LCU, million SAR, 2010 prices \\
\hline 97 & GC_Z & Consumption, government, LCU, million SAR, nominal \\
\hline 98 & GCGPE & Personal sector transfers from central government, LCU, million SAR, nominal \\
\hline 99 & GDP & GDP, real, LCU, million SAR, 2010 prices \\
\hline 100 & GDP\$_WLD & World - GDP, constant prices and exchange rate, million US\$, 2010 prices, seasonally adjusted \\
\hline 101 & GDP\$_Z & GDP, million US\$, nominal \\
\hline 102 & GDP_Z & GDP, LCU, million SAR, nominal \\
\hline 103 & GEXP & Government expenditure, total, LCU, million SAR, nominal \\
\hline 104 & GI_Z & Investment, government, million SAR, nominal \\
\hline 105 & GMO_Z & Government maintenance and operation, million SAR \\
\hline 106 & GNDI_Z & Gross national disposable income, million SAR \\
\hline 107 & GREV & Government revenue, total, LCU, million SAR, nominal \\
\hline 108 & GREV_EN & Government revenue, energy, million SAR, nominal \\
\hline 109 & GREVNOIL & Government revenue, non-oil, million SAR, nominal \\
\hline 110 & GREVOIL & Government revenue, oil, million SAR, nominal \\
\hline 111 & GREVOTH & Government revenue, miscellaneous, million SAR, nominal \\
\hline 112 & GREVOTH_DUMMY & Dummy variable for other government revenues \\
\hline 113 & GREVOTHEXT & Existing non-oil government revenue, million SAR \\
\hline
\end{tabular}




\begin{tabular}{ll}
$\#$ & Mnemonic \\
\hline 114 & GREVNOIL
\end{tabular}

GVAi

\begin{tabular}{ll}
\hline 116 & GWS_Z \\
\hline 117 & GWSA_Z \\
\hline 118 & HUVF \\
\hline
\end{tabular}

ID

\section{Description and unit}

Non-oil revenue initiatives plus $85 \%$ energy sales, million SAR

Gross value added in sector i, real, LCU, million SAR, 2010 prices. i stands for the following 23 sectors: agr=agriculture, con=construction, dis=distribution, fibu= financial and business services, fibuoth=other fibu, gov=government, ind=industry, indno=non-oil industry,

man=manufacturing, manno=non-oil manufacturing, min=mining, minoth=other mining, $\mathrm{mq}=$ mining and quarrying, nit=import taxes, noil=non-oil, oil=oil, oilmin=oil mining, oilref=oil refinery, oths=other services, real=imputed rents, ser=service, tracom=transportation and communication, $\mathrm{u}=$ utility. _z indicates nominal values

Government expenditure, wages and salaries, million SAR, nominal

Government wages, salaries and allowances, million SAR

Haj and Umrah visa fees, million SAR

Intermediate Demand for sector i, million 2010 SAR. i stands for the following 22 sectors: agr=agriculture, con=construction, dis=distribution, fibu=financial and business services, gov=government, ind=industry, man=manufacturing, manno=non-oil manufacturing, $\min =$ mining, minoth=other mining, $\mathrm{mq}=$ mining and quarrying, noil=non-oil, oil=oil, oilmin=oil mining, oilref=oil refinery, oths=other services, ser=service, tracom=transportation and communication, $u=u t i l i t y$, chpet=petro-chemicals, fibuoth=other financial and business services, man=manufacturing

\begin{tabular}{lll}
\hline 120 & IF & Investment, total fixed investment, real, LCU, million SAR, 2010 prices \\
\hline 121 & IF_Z & Investment, total fixed investment, LCU, million SAR, nominal \\
\hline 122 & ILT_REV & Idle land tax revenue, million SAR \\
\hline & INVi & $\begin{array}{l}\text { i stands for the following nine sectors: agr=agriculture, con=non-residential building, gov= } \\
\text { government, ind=industry, noil=non-oil sector, oil=oil sector, oilref=refined oil, tot=total economy, }\end{array}$
\end{tabular}
tracom=transportation

\begin{tabular}{lll}
\hline 124 & IP & Industrial production index, Index $2010=100$ \\
\hline 125 & IS & Investment stock building, million 2010 SAR \\
\hline 126 & IS_Z & Stock building, LCU, million SAR, nominal \\
\hline 127 & LGT_REV & Luxury goods tax revenue, million SAR
\end{tabular}

128 LIABP Bank claims on private sector, million SAR, nominal

129 LIAB_BIS_LOC Locational liabilities to foreign banks, at end-period, million US\$, nominal

130 LOANS_FROM_FOR Loans from foreign controlled and located banks (maturity less than one year), million US\$, nominal

131 LS Labor supply, person thousands

132 LTDEBT External debt, long-term, million US\$, nominal

$133 \mathrm{M} \quad$ Imports, goods \& services, real, LCU, million SAR, 2010

134 M0 Money supply, M0, currency outside banks, LCU, million SAR, nominal

135 M1 Money supply, M1, LCU, million SAR, nominal

136 M2 Money supply, M2, LCU, million SAR, nominal

137 M3 Money supply, M3, LCU, million SAR, nominal

138 M_Z Imports, goods \& services, LCU, million SAR, nominal

$139 \quad$ MG Import of goods, real, 2010 prices

\begin{tabular}{|c|c|c|}
\hline 140 & MG\$_Z & Imports, goods, million US\$, nominal \\
\hline 141 & MG_Z & Imports, goods, LCU, million SAR, nominal \\
\hline 142 & MOILREF & Imports of oil refined goods, Mtoe \\
\hline 143 & MS & Imports, services, real, LCU, million SAR, 2010 prices \\
\hline 144 & MS\$_Z & Imports, services, million US\$, nominal \\
\hline 145 & NATSAV & National savings, LCU, million SAR, nominal \\
\hline 146 & NATSAV_P_IF & Gross national savings as \% of gross domestic investment \\
\hline 147 & NFDI\$ & Non-FDI net capital flow, million US\$, nominal \\
\hline 148 & OILMBD & Oil production, barrels per day million, real \\
\hline 149 & OILUSE & Oil, domestic use, barrels per day million \\
\hline
\end{tabular}




\begin{tabular}{|c|c|}
\hline$\#$ & Mnemonic \\
\hline 150 & ONOR \\
\hline 151 & OTHCAP\$_Z \\
\hline 152 & OVF \\
\hline 153 & PART \\
\hline 154 & $\mathrm{PC}$ \\
\hline 155 & PCOIL_IND \\
\hline 156 & PDIS_IND \\
\hline 157 & PDIS_TRA \\
\hline 158 & PE_i \\
\hline 159 & PELE_AGR \\
\hline 160 & PELE_COMM \\
\hline 161 & PELE_GOV \\
\hline 162 & PELE_IND \\
\hline 163 & PELE_RES \\
\hline 164 & PGAS_TRA \\
\hline 165 & PGC \\
\hline 166 & PGDP \\
\hline 167 & PGDP_USA \\
\hline
\end{tabular}

Description and unit

Other non-oil revenues, million SAR

Other capital flows (net), million US\$, nominal

Other visa fees, million SAR

Labor force participation rate: Saudi Arabia

Consumption, private deflator, Index $2010=100$

Price (SAR/toe) Arab light SAR/toe

Price of industrial diesel (SAR/toe)

Price of transport diesel (SAR/toe)

Price of energy in sector $\mathrm{i}$, weighted average, SAR/toe. i stands for the following eight sectors: con=construction, fibu=financial and business services, gov=government, oths=other services, manno=non-oil manufacturing, oilref=oil refining, tracom=transport and communication, $\mathrm{u}=u$ utility Price of electricity for agriculture sector (SAR/toe)

Price of electricity for commercial sector (SAR/toe)

Price of electricity for government sector (SAR/toe)

Price of electricity for industrial sector (SAR/toe)

Price of electricity for residential sector (SAR/toe)

Weighted average nominal gasoline price (SR/toe)

Consumption, government deflator, Index 2010=100

GDP deflator, Index 2010=100

United States - GDP deflator, Index , 2009=100

GDP deflator, in sector i, Index $2010=100$. i stands for the following 24 sectors: agr=agriculture, con=construction, dis=distribution, fibu=financial and business services, fibuoth=other fibu, fisim=GDP deflator, Imputed financial services, gov=government, ind=industry, indno=non-oil

$168 \quad$ PGDPi industry, man=manufacturing, manno=non-oil manufacturing, min=mining, minoth=other mining, $\mathrm{mq}=$ mining and quarrying, nit=import taxes, noil=non-oil, oil=oil, oilmin=oil mining, oilref=oil refinery, oths=other services, real= imputed rents, ser=service, tracom=transportation and communication, $\mathrm{u}=$ utility

\begin{tabular}{|c|c|c|}
\hline 169 & PHFO_IND & Price of heavy fuel oil (SAR/toe) \\
\hline 170 & PKER_RES & Kerosene price (SAR/toe) \\
\hline 171 & PKER_TRA & Price of jet fuel (SAR/toe) \\
\hline 172 & PLPG_RES & Price (SAR/toe) effective LPG price for year (SAR/toe) \\
\hline 173 & PMG & Import deflator, goods, Index $2010=100$ \\
\hline 174 & PNGA_IND & Natural gas price (SAR/toe) \\
\hline 175 & POP & Population total, person thousands \\
\hline 176 & POPS & Population, Saudis, person thousands \\
\hline 177 & POPSF & Population, total Saudi females, person thousands \\
\hline 178 & POPSM & Population, total Saudi males, person thousands \\
\hline 179 & POPNS & Population, non-Saudis, person thousand \\
\hline 180 & POPNSF & Population, total non-Saudi females, person thousands \\
\hline 181 & POPNSM & Population, total non-Saudi males, person thousands \\
\hline 182 & POPi & $\begin{array}{l}\text { Population, person thousands. i takes the following } 12 \text { age groups: } 0-14,15-19,20-24,25-29,30 \text { - } \\
34,35-39,40-44,45-49,50-54,55-59,60-64,65 \text {-above }\end{array}$ \\
\hline 183 & POPFi & $\begin{array}{l}\text { Population, female, person thousands. i takes the following } 12 \text { age groups: } 0-14,15-19,20-24 \text {, } \\
25-29,30-34,35-39,40-44,45-49,50-54,55-59,60-64,65 \text {-above }\end{array}$ \\
\hline 184 & POPMi & $\begin{array}{l}\text { Population, male, person thousands. i takes the following } 12 \text { age groups: } 0-14,15-19,20-24,25- \\
29,30-34,35-39,40-44,45-49,50-54,55-59,60-64,65 \text {-above }\end{array}$ \\
\hline 185 & POPW & Working-age population, person thousands \\
\hline 186 & PORT\$ & Net portfolio investment flows (net of fc bonds), million US\$, nominal \\
\hline 187 & PORT\$IN & Inward portfolio investment (net of fc bonds), million US\$, nominal \\
\hline 188 & PORT\$OUT & Outward portfolio investment, million US\$, nominal \\
\hline
\end{tabular}




\# Mnemonic Description and unit

189 POT

Potential output by economic activity, i stands for the following 11 sectors: agr=agriculture con=construction, dis=distribution, fibu=financial and business services, gov=government, manno=non-oil manufacturing, noil=non-oil, oilref=oil refinery, oths=other services, tracom =transportation and communication, $\mathrm{u}=$ utility

\begin{tabular}{|c|c|c|}
\hline 190 & POTH_IND & Price of other refined oil products used in industry, weighted average, SAR/toe \\
\hline 191 & PPI & Prices, producer index - total, Index $2010=100$ \\
\hline 192 & PSCAPE & Public capital expenditures, million SAR, nominal \\
\hline 193 & PSCE & Public sector current expenditures, million SAR, nominal \\
\hline 194 & $\mathrm{PX}$ & Export deflator, total, Index $2010=100$ \\
\hline 195 & QOILREF & Refined oil, supply, Mtoe million \\
\hline 196 & $\mathrm{RCB}$ & Interest rate, central bank policy, \%, nominal three months \\
\hline 197 & RCBEOP & Interest rate, central bank policy, end of period, $\%$, nominal three months \\
\hline 198 & RDEBT & Effective interest rate on external debt, \%, nominal \\
\hline 199 & RES\$ & Reserves, foreign exchange, million US\$, nominal \\
\hline 200 & RES\$GOLD & Reserves, gold, million US\$, nominal \\
\hline 201 & RES\$INCGOLD & Reserves, foreign exchange, including gold, million US\$, nominal \\
\hline 202 & RES\$M & Reserves, months of import cover, months \\
\hline 203 & RES\$XGOLD & Reserves, foreign exchange, excluding gold, million US\$, nominal \\
\hline 204 & RES\$XGOLD_BIS & International reserves excluding gold, at end-period, million US\$, nominal \\
\hline 205 & RLEND & Interest rate, lending, \%, nominal \\
\hline 206 & RLG & Interest rate, 10-year government bonds, \%, nominal \\
\hline 207 & RLGEOP & Interest rate, long-term, end of period, \%, nominal \\
\hline 208 & RRLEND & Real interest rate, lending, \% \\
\hline 209 & REER & Real effective exchange rate, units of MTP currency basket for a unit of SAR, $2010=100$ \\
\hline 210 & RRXD & Real exchange rate, US\$ price of per SAR, Index $2010=100$ \\
\hline 211 & $\mathrm{RSH}$ & Interest rate, short-term, \%, nominal \\
\hline 212 & NEER & Effective exchange rate, units of MTP currency basket for a unit of SAR, $2010=100$ \\
\hline 213 & $\mathrm{RXD}$ & EOP exchange rate, SAR/US\$ nominal, nominal \\
\hline 214 & SDR_HOLD & SDR holdings, at end-period, million US\$, nominal \\
\hline 215 & STDEBT & External debt, short-term, million US\$, nominal \\
\hline
\end{tabular}

Total demand for sector i, million 2010 SAR. i stands for the following 22 sectors: agr=agriculture, con=construction, dis=distribution, fibu=financial and business services, gov=government, ind=industry, man=manufacturing, manno=non-oil manufacturing, $\min =$ mining, minoth=other mining, $\mathrm{mq}=$ mining and quarrying, noil=non-oil, oil=oil, oilmin=oil mining, oilref=oil refinery, oths=other services, ser=service, tracom=transportation and communication, $u=u t i l i t y$, chpet=petro-chemicals, fibuoth=other financial and business services, man=manufacturing

\begin{tabular}{ll}
\hline 217 & TDEBT\$ \\
\hline 218 & TF_REV \\
\hline 219 & TFE \\
\hline 220 & U
\end{tabular}

External debt, total, million US\$, nominal

Traffic fines, million SAR

Total final expenditure, real, LCU, million SAR, 2010 prices

Unemployment, person thousands

Unit Labor Cost in sector i. i stands for the following 12 sectors: con=construction,

$221 \quad$ ULC

dis=distribution, fibuoth=other financial and business services, gov=government, manno=on-oil manufacturing, noil=non-oil, oil=oil, oilref=oil refinery, oths=other services, ser=service, tracom= transport and communication, u=utility

\begin{tabular}{lll}
\hline 222 & UR & Unemployment rate \\
\hline 223 & UR_C & Cyclical component of unemployment rate \\
\hline 224 & UR_N & Non-accelerating inflation rate of unemployment \\
\hline 225 & VAT_RATE & Rate of VAT, \% \\
\hline 226 & VAT_REV & VAT revenues, million SAR \\
\hline 227 & VAT_REV_DUMMY & Dummy variable for VAT \\
\hline
\end{tabular}




\section{Appendix B. KGEMM Variables}

\begin{tabular}{|c|c|c|}
\hline \# & Mnemonic & Description and unit \\
\hline 228 & WEALTH & Wealth, private sector, in 2010 SAR, million \\
\hline 229 & Wi & $\begin{array}{l}\text { Wage, SAR. i stands for the following } 15 \text { sectors: agr=agriculture, con=construction, dis=distribution, } \\
\text { man=manufacturing, manno=non-oil manufacturing, min=mining, minoth=other mining, noil=non-oil, } \\
\text { oil=oil, oilmin=oil mining, oilref=oil refinery, oths=other services, ser=service, tracom=transportation } \\
\text { and communication, u=utility }\end{array}$ \\
\hline 230 & W_CEIC & Wage, annual average, thousand SAR \\
\hline 231 & WPC_WLD & World - World commodity index price, non-fuel, Index, 2005=100 \\
\hline 232 & WPO_AL & World crude oil spot price: Arab Light, US\$ per barrel, nominal \\
\hline 233 & WTOUR & Saudi Arabia tourism demand indicator, Index $2010=100$ \\
\hline 234 & WTREF & World trade index, refined oil, Index $2010=100$ \\
\hline 235 & $\mathrm{X}$ & Exports, goods \& services, real, LCU, million SAR, 2010 prices \\
\hline 236 & $X \$ Z Z$ & Exports, goods \& services, million US\$, nominal \\
\hline 237 & X_Z & Exports, goods \& services, LCU, million SAR, nominal \\
\hline 238 & XCOM & Exports, communication services, SAR Millions, $2010=100$ \\
\hline 239 & XFI_Z & Exports, freight and insurance, million SAR, nominal \\
\hline 240 & XFIN & Exports, financial services, million SAR, $2010=100$ \\
\hline 241 & $X G$ & Real exports of goods, $2010=100$, million SAR \\
\hline 242 & XG\$_Z & Exports of goods, million US\$, nominal \\
\hline 243 & XGNOIL & Real exports of non-oil goods, $2010=100$, LCU millions \\
\hline 244 & XGNOIL\$_Z & Exports of goods, non-oil, million US\$, nominal \\
\hline 245 & XGNOIL_Z & Exports of goods, non-oil, LCU, million SAR, nominal \\
\hline 246 & XGOIL & Real exports goods, oil, $2010=100$, LCU millions \\
\hline 247 & XGOIL\$_Z & Exports of goods, oil, million US\$, nominal \\
\hline 248 & XGOIL_Z & Exports, oil, LCU, million SAR, nominal \\
\hline 249 & XGOV_Z & Exports, government, SAR, nominal \\
\hline 250 & XOILREF & Refined oil, exports, Mtoe \\
\hline 251 & XS & Exports, services, real, LCU, million SAR, 2010 prices \\
\hline 252 & $X S \$ Z Z$ & Exports of services, million US\$, nominal \\
\hline 253 & XS_Z & Exports, services, LCU, million SAR, nominal \\
\hline 254 & XSII_Z & Exports, investment income, million LCU, nominal \\
\hline 255 & XSNOIL_Z & Exports, non-oil services, million LCU, nominal \\
\hline 256 & XSOTH_Z & Exports, other services, million LCU, nominal \\
\hline 257 & XTRAN\$_Z & Exports, transportation, million US\$, nominal \\
\hline 258 & XTRAN_Z & Exports, transportation, million SAR, nominal \\
\hline 259 & XTRAV_Z & Exports, travel, million SAR, nominal \\
\hline
\end{tabular}

Note: For simplicity, we do not report discrepancy terms and add factors here.

The third version of KGEMM has 310 endogenous variables. It also has 278 exogenous variables, and many of them are rest of the world variables and dummy variables. 


\section{Appendix C. KGEMM In-Sample Simulations Results}

Figure C1. The Real block indicators: GDP, GVANOIL and IFNOILP.
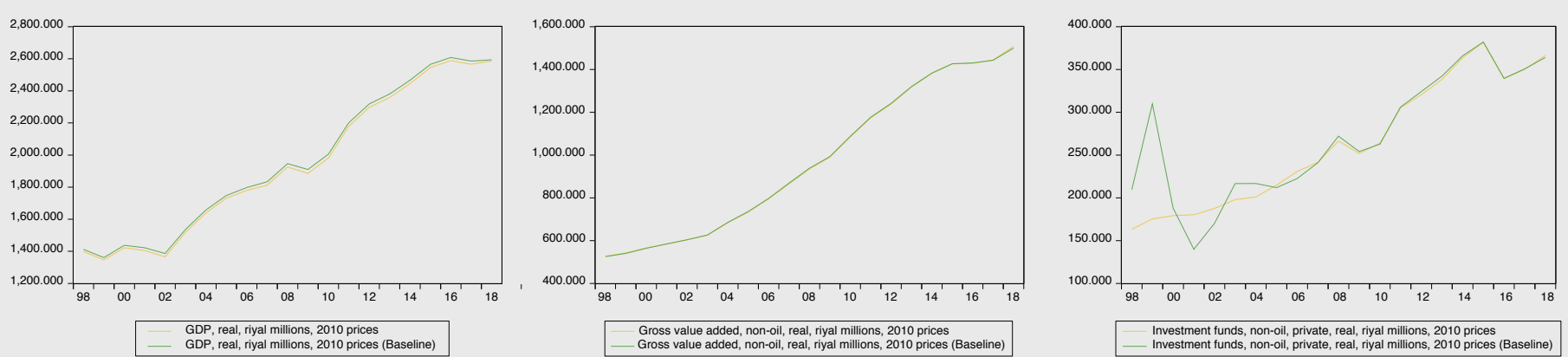

Source: EViews

Figure C2. The Fiscal block indicators: GEXP, GREV and GREVEN.
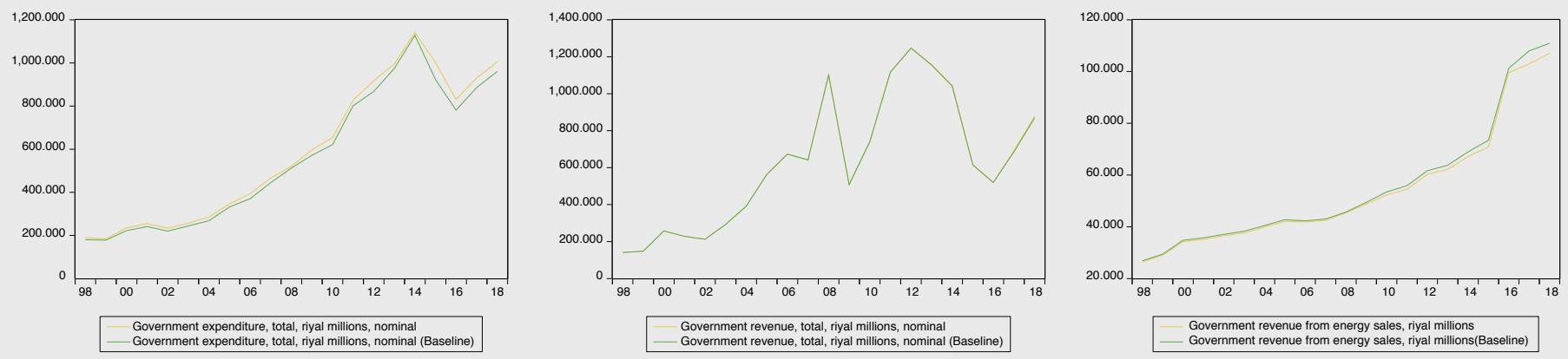

Source: EViews

Figure C3. The Prices block indicators: CPI inflation, CPIFOOD inflation and CPIU inflation.

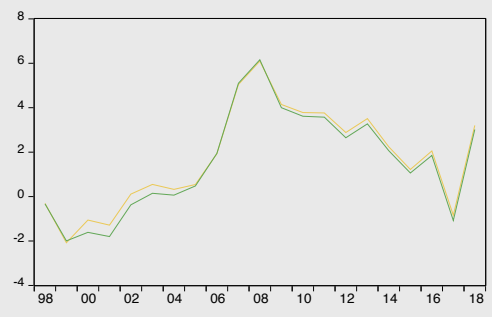

Year \% change consumer price index, Index $100=2010$

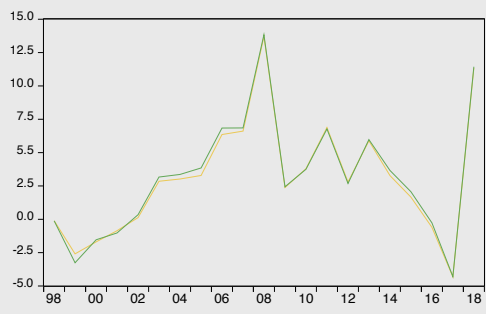

Year \% change consumer price index, food \& beverages, Index $100=2010$

Source: EViews

Figure C4. The Labor market block indicators: ET, ETNOIL and ETMANNO.
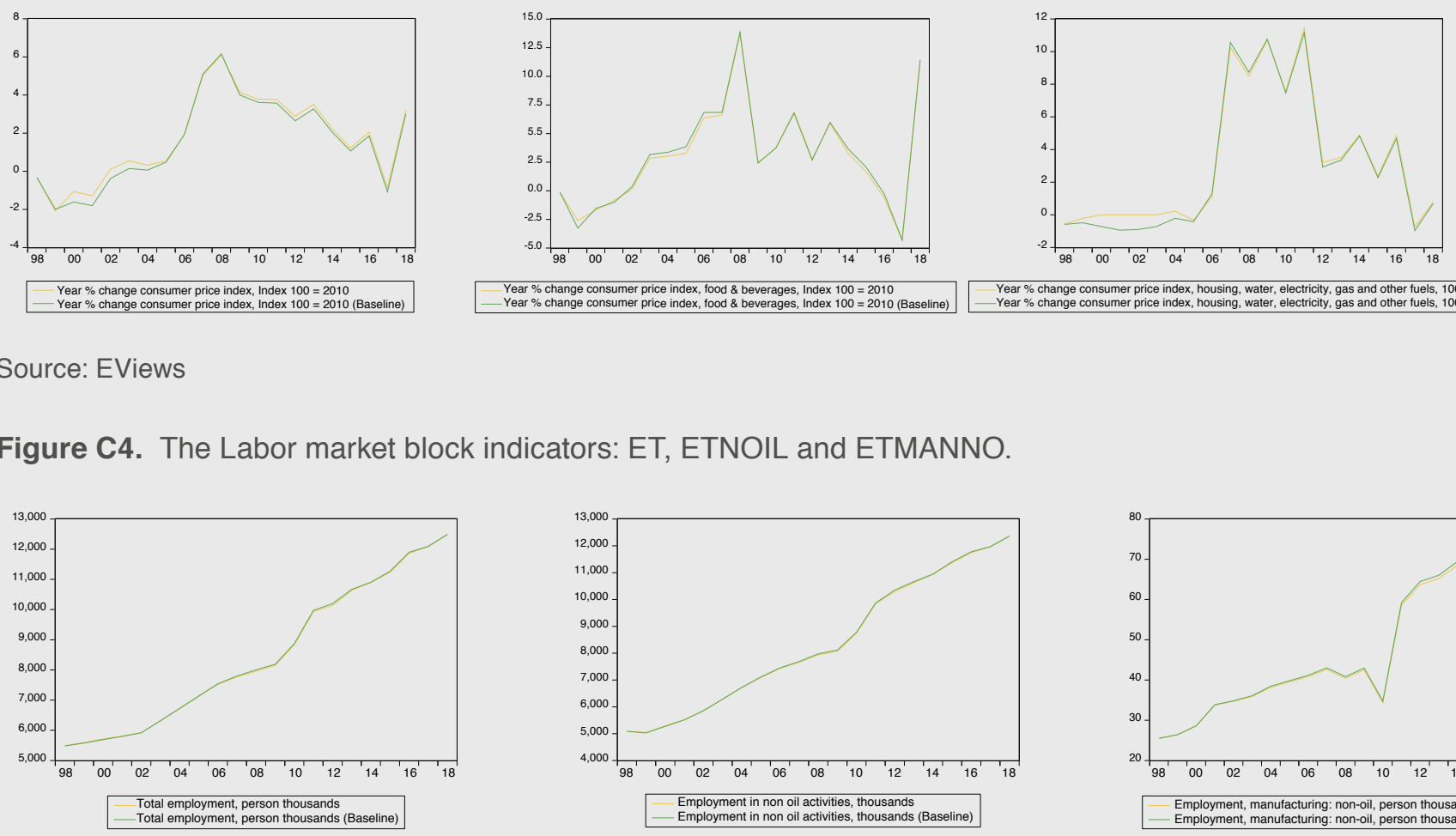
Year \% change consumer price index, housing, water, electriity,yas and other fuels, $100=2010$
Year \% change consumer price index, housing, water, electricity, gas and other fuels, $100=2010$ (Baseline) 
Figure C5. The Monetary block indicators: M2 growth, M3 growth, REER growth.

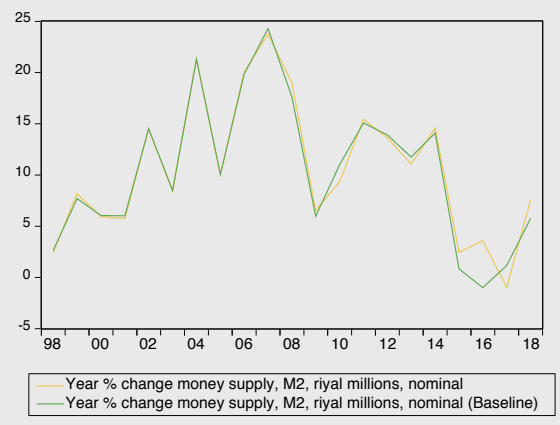

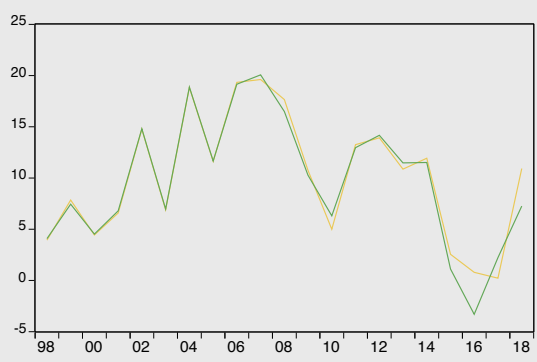

Year \% change money supply, M3, riyal millions, nominal Year \% change money supply, M3, riyal millions, nominal (Baseline)

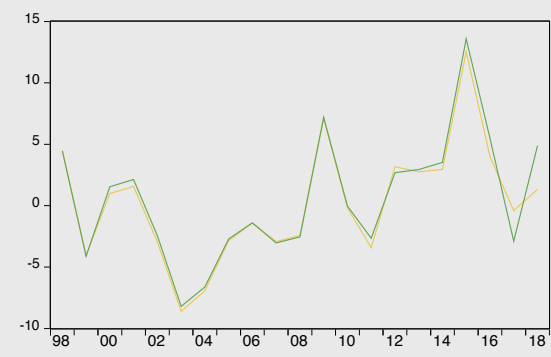

Year \% change real effective exchange rate, SAR/USD, 2010 Year \% change real effective exchange rate, SAR/USD, 2010 (Baseline)

Source: EViews

Figure C6. External and Energy blocks indicators: XGNOIL, M and DEN_TOT.
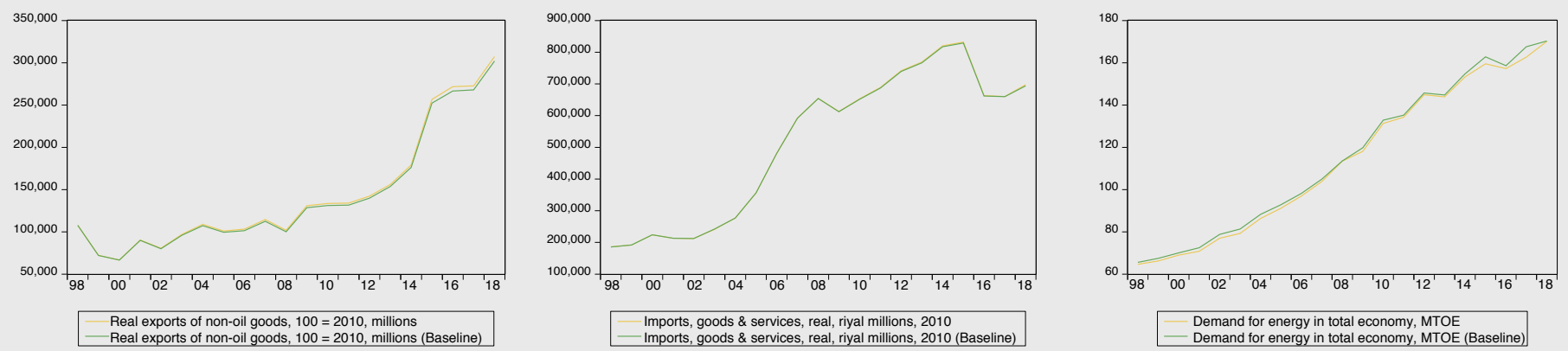

Source: EViews 
Notes

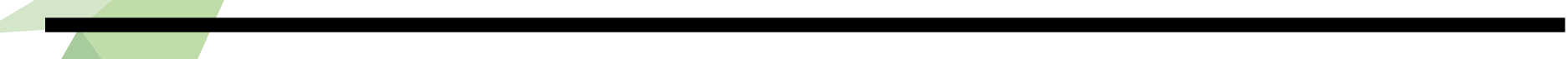




\section{Notes}

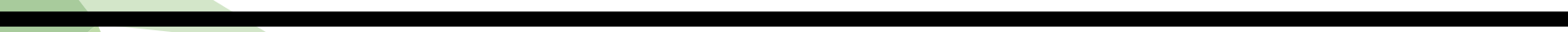


Notes

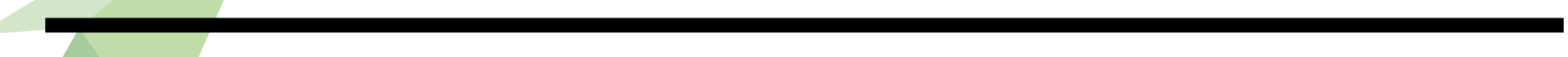




\section{About the Authors}

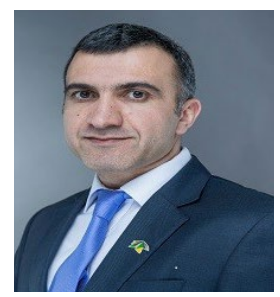

\section{Fakhri J. Hasanov}

Fakhri is a research fellow leading the KAPSARC Global Energy Macroeconometric Model (KGEMM) project. His research interests and experience span econometric modeling and forecasting, building and applying macroeconometric models for policy purposes, energy economics with a particular focus on natural resource-rich countries. He holds a Ph.D. in Economics.

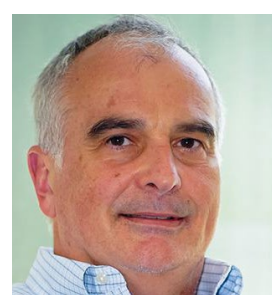

\section{Frederick L. Joutz}

Fred is a visiting fellow at KAPSARC working on the KGEMM project and a full professor of Economics at George Washington University. The primary focus of his research has been in the areas of economic modeling and forecasting. He holds a Ph.D. in Economics.

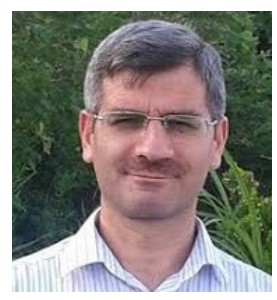

\section{Jeyhun I. Mikayilov}

Jeyhun is a research fellow at KAPSARC working on the KGEMM project. His primary research interests include, but are not limited to, applied time series econometrics, the economics of energy and environment, and sustainable development. He holds a Ph.D. in Applied Mathematics.

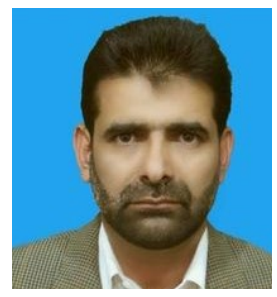

\section{Muhammad Javid}

Muhammad is a visiting fellow at KAPSARC working on the KGEMM project and a research economist in the Macroeconomic and Growth Division of the Pakistan Institute of Development Economics. Muhammad's primary research interests include, but are not limited to ,applied time series econometrics, the economics of energy and environment, and sustainable development. He holds a Ph.D. in Economics. 


\section{About the Project}

The objective of the KAPSARC Global Energy Macroeconometric Model (KGEMM) project is to develop a domestic policy analysis tool that examines the impacts of domestic policy measures and global economic and energy shocks on the Kingdom of Saudi Arabia. Commonly available models are typically more focused on the global economy (and the major contributors to global GDP), using an oversimplified representation of major oil and gas exporting economies, including Saudi Arabia, to capture energy flows into the global system.

The project develops and enhances the model described above with the following purposes:

To provide a better representation of the Saudi economy by taking into account the stylized facts of the Saudi economy.

To offer KAPSARC's research team and its stakeholders a macroeconometric model that is capable of, and flexible and customizable in, evaluating the effects of different policy options (for energy price reforms and fiscal policy changes among others) on the Kingdom's economy. The model is also capable of analyzing the current status and future paths of macroeconomic and energy indicators. 
INAPSARC

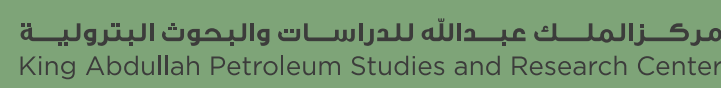

www.kapsarc.org 